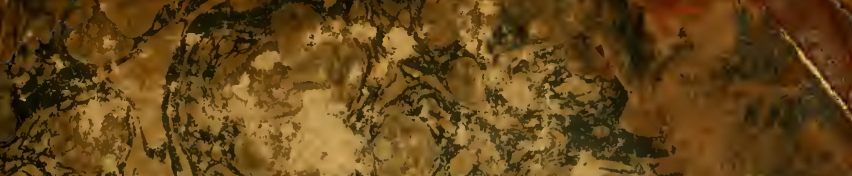

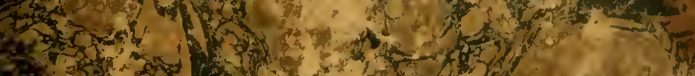

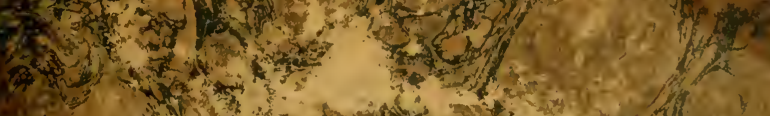

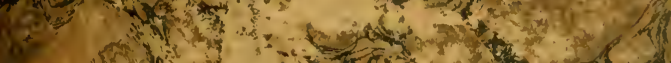

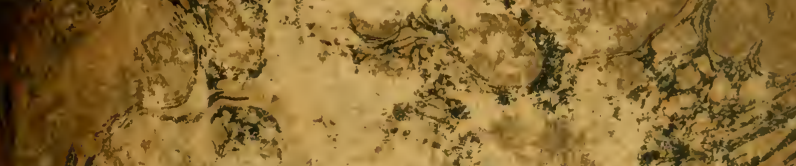

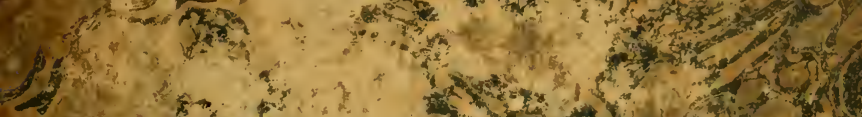

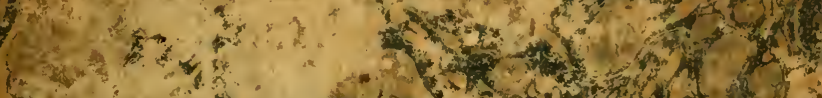

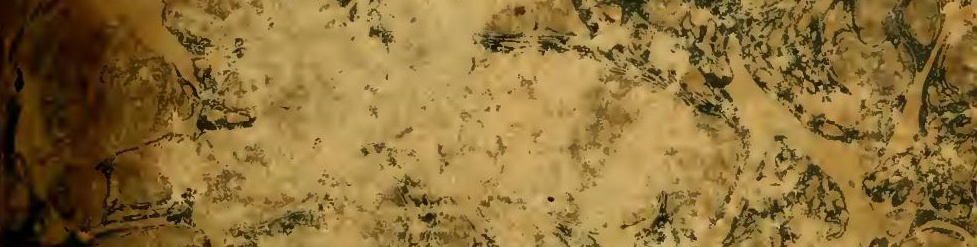

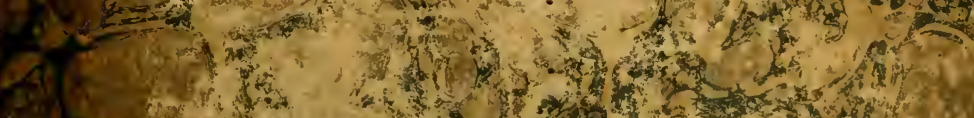

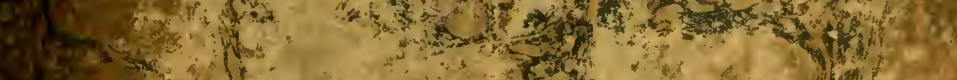

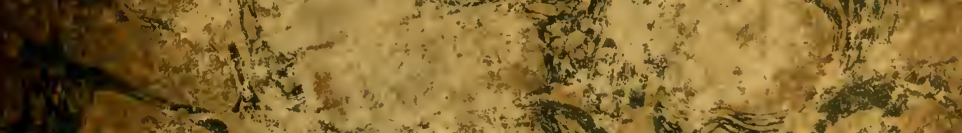

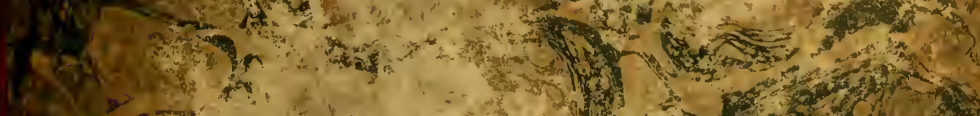

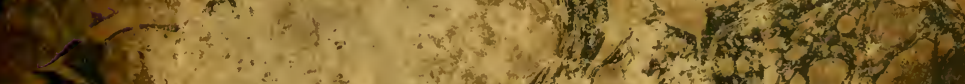

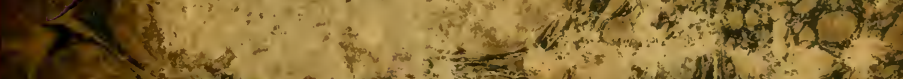

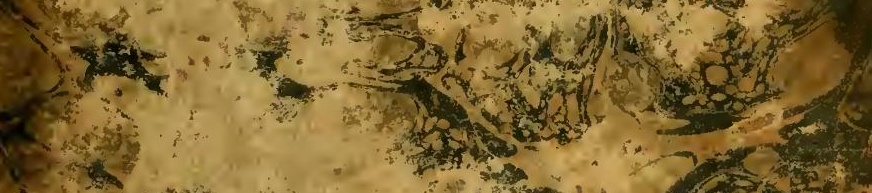

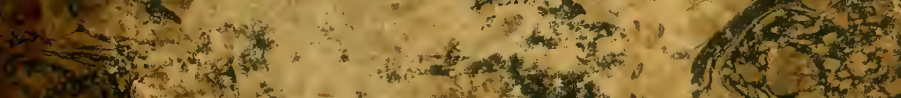

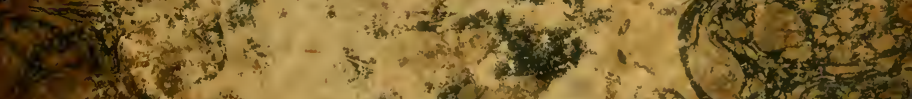

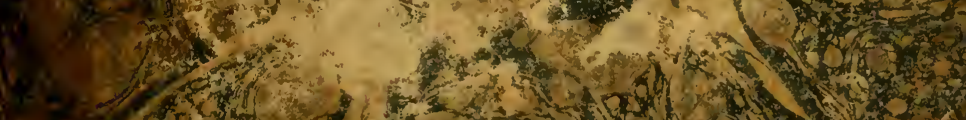

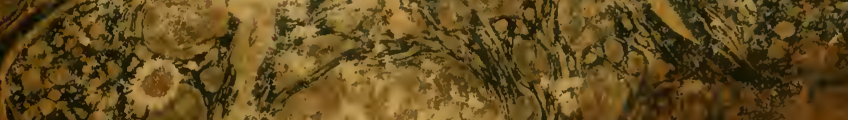

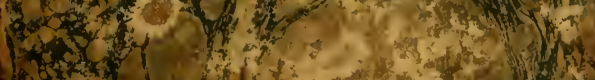

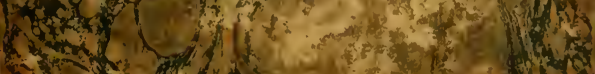

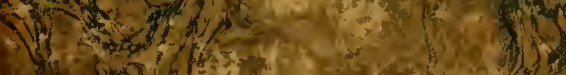

3260 if

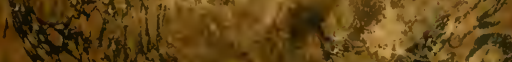

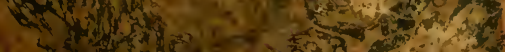




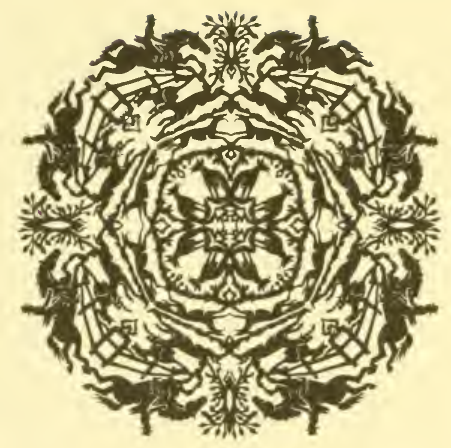

JOHN A.SEAVERNS 





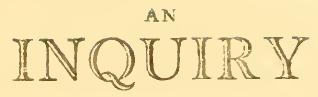

INTO THE

\section{STRUCTURE \& ANIMAL CEONOMY}

OF

\section{TIHIE HIORSE:}

COMPREHENDING

THE DISEASES TO WHICH HIS LIMBS \& FEET ARE SUBJECT,

WITH PROPER

\section{DIRECTIONS FOR SHOEING;}

AND POINTING OUT

A Method for ascertaining his Age until his Trelfth Year.

$$
\longrightarrow
$$

TO WHICH IS ADDED,

An Attempt to explain the Laws of his Progressive Motion, ON

MECHANIGAL AND ANATOMICAL PRIVCIPLES.

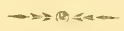

The Whole illu?trated by SEVENTEEN COPPER PLATES.

SECOND EDITION, REVISED AND CORRECTED.

By RICHARD LAWRENCE, VETERINARY SURGEON, BIRMINGHAM.

CONTINUO PECORIS GENEROSI PULLUS IN ARVI3

ALTIUS INGREDITUR, ET MOLLIA CRURA REPONIT:

PRIMUS ET IRE VIAM, ET FLUVIOS TENTARE MINACES

AUDET, ET IGNOTO SESE COMMITTERE PONTI:

NEC VANOS HORRET STREPITUS,

VIRGIL. GEORG. LIB. 3.

$$
\text { BIRMINGHAM, }
$$

PRINTED FOR THE AUTHOR, AND SOLD BY KNOTT AND LLOYD;

SOLD ALSO BY G. AND W, NICOL, AND L. B, SEELEY, LONDON.

Printed at the Office of the Executors of T. A. Pearfot. 



\section{LORD HEATHFTELD.}

MY LORD,

\section{GRATITUDE for the repeated faims}

I have received at your Lordslip's hands, would alone sufficiently induce me thuts pulblickly to acknowledge them; but when I consider how grealy the Veterinary Art is indebted to your generous patronage, I feel an additional incentive to dedicute to your Lordship these forst fruts of my literary labours.

The annals of the Veterinary College testify, that your Lordship has ever stood foremost in exer- 


\section{( vi )}

tions for its interest and prosperity, by taking that institution under your Protcction, and endeavouring to rescue an useful animal from the baneful effects of ignorance and prejudice. That your Lordship may live to see the object of your wishes completely fulfilled, is the ardent prayer of

Your Lordship's

Most devoted and most obliged

Humble Servant, RICHARD LAWRENCE. 


\section{PREFACE,}

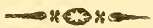

$\mathrm{N}$ EXT in dignity to that branch of the medicat art which is applicable to the human species, me may, with propriety, class that which has for its object the diseases of the horse.

IT therefore appears extraordinary, that, until a recent period, neither humanity nor interest should have prompted mankind to investigate, on scientific principles, the Veterinary Art, which must certainly be of the first importance in a country which abcunds with the finest horses in the world.
A 4
THE 
THE necessity of long study in anatomy, ' pathology, and the composition of drugs, to qualify a practitioner in medicine, is universally acknowledged*, and as the horse exists by similar laws, and is subject to many of the diseases incident to mankind, it cannot require much penetration to discover that studies of the same nature must be absolutely requisite to constitute a good farrier. But if conclusions were to be drawn from the basis on which the reterinary system has hitherto rested, it would seem that the science of farriery has been considered as a natural gift, and not in the least dependant on the tedious process of medical inquiry and

* Cicero, in his orations, makes the following just observation: "Mredico diligenti, priusquam conetur ægro adhibere medicinam non solum morbus ejus cui medere rolet, sed etiam consuetudo valentis, et natura corporis cognoscenda est," 
investigation; for every blacksmith, groom, and stable boy, not only conceives himself, but is often believed by his employer to be fully competent to the important task of curing diseases, of the nature of which he is totally ignorant.

SURELY nothing can be more absurd than to imagine that a groom, by having fed and cleaned a horse for a few years, must consequently become acquainted with his diseases and their causes; it would be equally plausible to assert, that because he knows by ocular experience, that the sun rises in the morning and sets at night, he must be an astronomer. The majority of the affuent, to avoid the trouble of reflection, suffer themselves to be influenced in matters of this nature by men, whose opinions 
on any other subject they would treat with the utmost contempt.

Few things can be more affecting to a contemplative and humane mind, than the sufferings of a mute and patient animal, the estimable contributor to our pleasures and comforts, when afflicted with some violent disease in which nature exerts her utmost efforts to relieve herself; but how must this scene of distress be heightened, could the proprictor be convinced, that the very men he applies to for assistance only aggravate the evil by their ignorance.

THE most learned and experienced physicians confess the insufficiency of their art, and consequently their attention is directed to the means of rendering it less fallible. To men of 
this description, the infinite varicties which the same disease presents in different habits, will sufficiently demonstrate the difficulties attending their practice; but the empyric, whose confidence ever keeps pace with his want of skill, boldly prescribes the same treatment under every difference of age, sex, and constitution.

Consonant to this was the practice of farriery, until the establishment of the Veterinary College took place.

THE treatises written on the subject before that period, were found to be so fallacious in the description of diseases, as well as in the proportions of drugs prescribed, that it was judged necessary to begin de novo. Horses were procured 
for the purposes of dissection, and of making experiments with regard to the quantity of different medicines which might be given with safety, as well as to their effects.

The professor and pupils were liberally seconded in their endeavours by the following gentlemen, whose names are sufficient testimonials of their abilities, viz. Sir GEo. BAKER, Mr. Cline, Mr. Abernethy, Dr. Geo. ForDyce, Mr. J. Hunter, Dr. Baillie, Mr. Cruikshanks, and Mr. Home; the latter five gencrously granted to the pupils of the college the liberty of gratuitous attendance at several courses of their respective lectures. To this source I shall always be proud to acknowledge myself "much indebted, and shall cver hold it in grateful remembrance. 
With respect to the plan of the present work, it will be perceived that I have not entered very extensively into a description of internal diseases, from a conviction that such a treatise would be attended with more danger than utility.

THE internal diseases of horses, except some few which are well marked, are so obscure as even to baffle the skill of an experienced practitioner in his endeavours to ascertain then.

IIENCE it cannot be expected that proprietors of horses, from the casual and confined observation furnished by their own stables, can acquire the faculty of discrimination in this respect, and the mischief arising from an improper administration of medicine, must be sufficienty 
ficiently obvious both from condid reflection and fatal experience. To confirm more strongly this remark, I am in possession of many proofs within the circle of my own employers, where horses have fallen a sacrifice, particularly in attempts to destroy worms, and yet we see exhibited at the window of every druggist's shop, a list of horse medicines prepared from the most approved recipes; nor does the evil terminate here, since regularly educated veterinarians, bartering their better judgment for temporary interest, carry on the traffic in the form of medicine chests, with pamphlets containing directions for making use of their contents. This is certainly a cheap mode of conveying knowledge, and, if well founded, must do away at once the necessity of a veterinary college, and all its relative studics. 
BUT farther to obviate any disappointment which might accrue to my readers, in not meeting in the following pages with what has been generally termed a compleat system of farriery, I have only to add, that I have directed my endeavours to point out the means of preventing diseases, and thereby to save the animal the pain and danger of undergoing medical discipline from the hands of those who are unqualified for that purpose; and I wish it to be understood, that my motive for introducing the foregoing observations originated purely from the conviction, that this branch of medicine, as well as all others, would, in every point of view, be more beneficial to the public, and to practitioners themselves, if it was divested of those little artifices which have too long disgraced it.

FOR 
For this reason I have treated principally ' on the structure and diseases of the limbs, shoeing, management of the stable, \&c. than which, I conceive, nothing can be more important. How far I have succeeded, I must submit to the candour of the public to determine. I shall at least possess the satisfaction of having endearoured to promote the science, by promulgating that theory which I have found to be true in practice.

THE source of peculiar properties in the structure and motion of the animal is, in general, but little understood. This brànch I have attempted to elucidate upon mechanical and anatomical principles; and the explanatory plates being designed by myself, will, I trust, 
be more accurate than they would have been from the hands of a second person.

To the Professor at the Veterinary College, and my Fellow Pupils, the privilege of criticism more immediately belongs; but I feel much confidence in the expectation of their candour and impartiality, more especially when I declare, that it will always give me pleasure to acknowledge any improvements which their industry and abilities may hereafter produce. 



\section{CONTEENTS.}

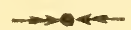

CHAPTER I.

Page

ON the cxternal Conformation of the Horse _ I

CHAPTER II.

On the Eye

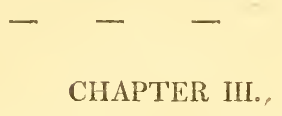

On Shoeing, and the Diseases of the Foot

$-43$

CHAPTER IV.

On the Grease

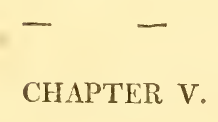

On Lameness

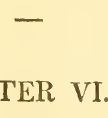

On Wounds

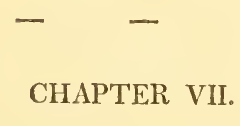

On Respiration, natural and diseased

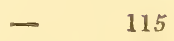

$$
2
$$

CHAPTER 


\section{CHAPTER VIII.}

On the Structure and (Economy of the Stable

CHAPTER IX.

On the Age of the IIorse
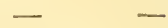

CHAPTER X.

On the Education of the Horse

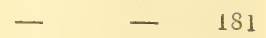

CHAPTER XI.

On Progression

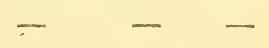

$-193$ 


\section{IN NDX.}

Page

IAR. Form of, bad consequences of clipping the?

hair from the inside of it $\quad$ \} 8

EYE. Its healthy and diseased state - 31

Hawe, or membrana nictitans, its use 38

Lachrymal duct, obstruction of $\quad-\quad 41$

FOOT. Its form and component parts _ $\quad 26$

Treatment of it in shoeing - - 47

Pumied or convex sole _ _ _ $\quad 52$

Contracted hoof - $\quad-\quad 55$

Corns - $\quad-\quad$ - 59

Diseased frog or running thrush - 61

Quittor - $\quad-\quad-\quad-\quad 66$

GREASE. Description of and method of cure - 71

HORSE. Proportion considered - $\quad 6$

Fore quarters, confurmation of - 10

Body, proportion of - $\quad-\quad-17$

Hind quarters, conformation of - 20

Age, 
Age, method of ascertaining it

Nethods employed by dealers to make an old horse inpear younger -

Ditto to make a horse which is four years? old appear to be fire $\quad$ - $\} 178$ Education

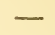

Blood, characteristic of 188

LAMENESS
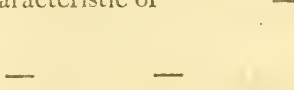

Splent

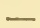

Ring-bone

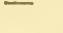

Stiff joint or anchylosis

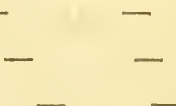

Bone spavin

-

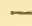

Strain of the sheath of the tendon - 92

Rupture of the suspensor ligaments 93

Windgalls — $\quad-\quad$ - $\quad 94$

Thorough pins _ $\quad$ - $\quad 95$

Blood spavin $\quad-\quad$ - $\quad 96$

Bog sparin - $\quad$ - $\quad$ ibid.

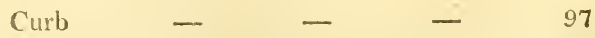

Coffin joint, lameness of - $\quad 98$

Muscular lanieness _ $\quad$ - 100

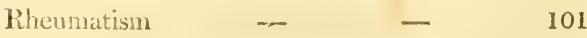

$\begin{array}{llll}\text { Spasm } & - & 0 & 102\end{array}$

Stringhalt - $\quad-\quad$ - ibid. PROGRESSION 


\begin{tabular}{|c|c|c|c|c|}
\hline & & & & Page \\
\hline PROGRESSION & - & - & - & 193 \\
\hline Walk & - & - & - & 194 \\
\hline Trot & - & - & 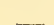 & 200 \\
\hline
\end{tabular}

Forging, or striking the fore feet with the hind feet, method of preventing it $\quad 202$

Trotting widely with the hind legs, the reason of it - $\quad$ \} $\quad 205$

Canter and gallop _ $\quad$ - $\quad 208$

Danger of stopping suddenly in the gallop 214 Passage _ - $\quad$ - $\quad$ ibid. Advantage of teaching this pace $\quad-\quad 216$

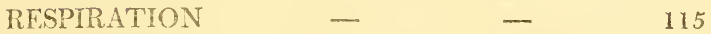

Peguliar form of the throat of the horse $\quad 116$

Peculiar form of the nostrils _ $\quad 118$

$\begin{array}{llllll}\text { Broken wind } & - & - & & & 121\end{array}$

$\begin{array}{llll}\text { Roarer described } & - & - & 126\end{array}$

Crib-biter - $\quad$ - $\quad$ - 129

STABLE. Structure and orconomy of - 135

Ventilation - $\quad-\quad \ldots \quad 138$

Light - $\quad-\quad$ - $\quad 143$

Narrow stalls, inconvenience of _ $\quad 145$

Gromnd surface of the stall, erroneous con- $\} 146$

Organs 
xxiv

INDEX.

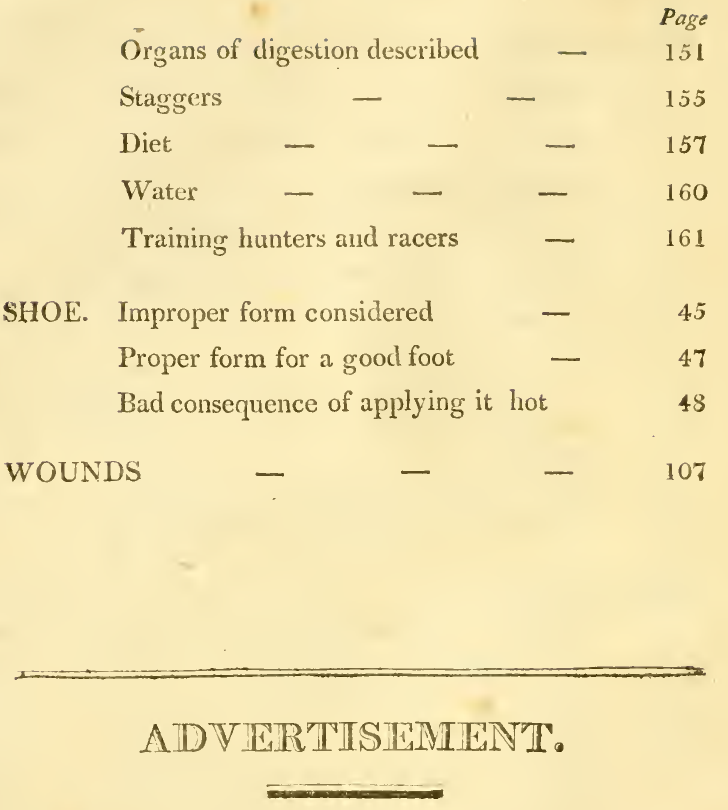

THE Reader is requested to observe, that THIS TREATISE has no connevion whatever with one pubtished' by John LAwrence. 


\section{AN INQUIRY}

INTO THE STRUCTURE AND ANIMAL GCONOMY

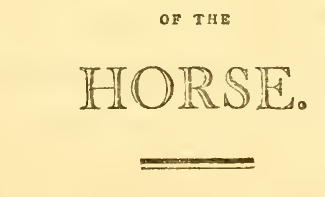

\section{CIAPTER I.}

On the external Conformation.

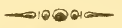

\section{ConsidereD in his relative situation in the} class of quadrupeds, the horse appears not to be so immediately conducive to the necessary comforts of man, as those animals which furnish food or raiment; but when his utility in agriculture, and in the transport of merchandise, as well as the share he contributes to our case and pleasure, are viewed collectively, the horse has an undoubted claim to precedence, and consequently to an ample share of attention. 
The horșe possesses speed, strength, and beauty, conjunctively in a degree far superior to all other animals. He is also more docile, and more easily applied to the service of man, whether for luxurious or laborious uses. For the purposes of parade he is peculiarly adapted, by a beautiful proportion and an innate pride and grandeur of deportment, particularly manifest in the manege, where, by the spirit and elegance of his movements, he appears to participate with his rider in the ostentatious pleasure. When employed in the field or the race, he visibly demonstrates the ardour of emulation, and finally merits our gratitude, by the patience and perseverance with which he endures the lower offices of labour and hardships of fatigue.

AN animal possessing such estimable qualities, must certainly have claims on our attention sufficient to call forth an inquiry into his structure and animal oconomy, on more scientific principles than has hitherto been accomplished. 
ON THE EXTERNAL CONFORMATION. 3

In the exposition of the external structure, which I have attempted in the following sheets, I certainly do not lay claim to originality in the undertaking, since certain French veterinary writers, particularly Bourgelat, have treated on the subject, and the late Mr. St. Bel, who was the first professor at the veterinary college, had it in contemplation to publish a work of the same nature, but did not live to complete his intentions. With regard to myself, the profession of portrait painter of horses, which I have pursued in conjunction with the veterinary practice, has directed my attention particularly to this branch of the science; and the accuracy of observation which the eye acquires by making draughts from living objects, has probably enabled me to make more minute researches than might have been effected by others who possessed not the same advantages. The principles upon which I have founded the present system, I can with truth affirm to be the result of experience. 
The data have been taken from the majority of objects in the same class, as no particular laws have yet been discovered which are unexceptionable in explaining the operations of nature, her productions being frequently in direct contradiction to our metaphysical reasoning.

As no accurate judgment in the proportions of architecture can be formed without possessing some knowledge of its rudiments, so can no experience in the proportions of a horse be acquired without some general acquaintance with his external anatomy.

Habitual observation may, in some degree, impart the faculty of discriminating in this respect; but it can never produce a true fundamental knowledge of the advantages or disadvantages arising from certain peculiarities of structure

HENCE 
ON THE EXTERNAL CONFORMATION. $\mathbf{5}$

HENCE we find every man adapts his ideas of perfection to the peculiar conformation of his own horse.

FOR instance, the proprietor of a long legged horse will tell you, that he is thereby better enabled to clear his leaps; while, on the other hand, another, who has a short legged hoise, assures you, that no other can get so well through a heavy road; a third, who possesses a long backed horse, declares that they must have length somewhere; and, finally, the dealer in horses, who keèps fifty in his stables, sums up the business on a broad scale, and answers all your objections by asserting that they will go in all forms.

IT would be thoroughly incompatible with the object of the present work, to suffer it to be biassed by such vague opinions, generated rather by partial comparison, than by actual experiment. 
THEY who have no knowledge of mechanical powers, will, perhaps, ridicule the idea of reducing the animal to any such principle. Anatomical dissection, however, presents a machine of the truest mechanism, capable of locomotion by means of muscles acting upon bones in various directions.

This being the fact, it will not be difficult to discover in what way the power of those muscles may be increased or diminished, not entirely by their own susceptibility of stimulus, but simply by their position when in a state of inaction. To explain this theory, will be the object of the present chapter.

THE body and legs of the horse, exclusively of the head and tail, may be said to form nearly a square, as represented in plate I.

THIS square is divided horizontally into two parts, nearly equal, by the body and legs, as represented by the line $\mathrm{A} A$. 
IT is again perpendicularly divided into three parts, as expressed by the lines B C.

THE first of these lines B, descends perpendicularly from the withers to the ground, and gives the proportion of the fore quarters.

THE second line $\mathbf{C}$ divides the body from the hinder quarters, and shews their proportion. These three divisions are nearly equal, except that the center division is rather the widest.

THE necessity for this general proportion will be explained hereafter.

THE head should be small, and the countenance animated; the forehead straight and broad, the eye prominent, the ears erect, the nostrils open and thin, the mouth lean and deep, the posterior part of the lower jaw should be open and capacious, which contributes much to the 
$S$ ON THE EXTERNAL CONFORMATION.

the freedom of bending the head inwards, and is also considered to facilitate respiration.

THE form of the ear is admirably adapted for the purpose of collecting sound; and it is worthy of remark, that a horse seldom sleeps without pointing one car forwards and the other backwards, to enable him to receive notice of the approach of objects in either direction.

THE horse's sense of hearing is very acute, and it is a fact pretty well known by sportsmen, that he can hear the cry of the hounds at a greater distance than his rider. Hence it will scarcely be necessary to point out the absurdity of cropping; yet there exists another bad custom, nearly as injurious as the former, viz. trimming the hair close out of the ears. The utility of hair in that part consists in moderating sound, excluding cold air, rain and flics, and other extrancous substances, which might otherwise 
ON THE EXTERNAL CONFORMATION. 9 wise drop into the ear*. The method of trimming the ears is by singeing the hair with a candle, and as the ear itself is frequently injured and rendered sore by this process, the horse in consequence becomes shy of any thing approaching his head.

THE form of the mouth and lips clearly indicates that the animal was intended to be guided by the bit, as there are no teeth in that part to prevent the action of it against the bars of the mouth, Lean lips are most sensible of impression, and are therefore to be preferred.

* The ears of all animals are defended in some peculiar manner. The mole which lives under ground, and whose ear is constantly exposed to the ingress of earthy particles, has the fuculty of closing that orifice by means of a sphincter muscle.

The hunuan ear also secretes a fiuid, which, being waxy and cohesive, arrests the progress of insects and dust, and prevents their entrance. 
As deformity is constituted by a want of harmony in the component parts, it will not be difficult to perceive, that a long head and a short neck, or a short head and a long neck, cannot be esteemed handsome.

THE neck should proceed in a line from the top of the head, forming a regular progressive curve to the withers. The trachea or windpipe should be large in diameter, and somewhat detached from the fleshy part of the neck. The size of its diameter has a considerable influence in respiration. Large windpipes are peculiar to blood horses, whence, probably, they are better winded than all others. The chief beauty of the forehand depends on the union of the neck with the shoulders. The neck should issue high, and nearly in a line with the withers, and its lower part should enter the chest high, and above the point of the shoulders: the opposite conformation to this produces what is termed an ewe neck, which can never be esteemed handsome.

THE 
THE shoulders constitute the center of motion in the fore part of the body, and the extent and elasticity of that motion will depend chiefly on the position of the shoulder blades. The connexion of the shoulder blades with the body is established by muscles only, independently of any joint whatever. It is by the alternate contraction and extension of these different muscles that motion is produced, and it is by their united elasticity that the shock is broken when in action.

THis would not have been the case, had the shoulder terminated in a fixed joint. The truth of this remark may be ascertained by riding alternately on the withers and the croupe, and comparing the difference of their respective motions.

As it is the office of the hinder quarters to propel the body forwards, it is necessary that they should be closely united with the body by 
means of joints. But, on the other hand, as the fore quarters are chiefly cmployed in sustaining the equilibrium of the machine, the concussion which must have been produced if they had been united to the body by joints, would have been considerably greater than what is produced by their being attached by muscles only. In describing the action of the shoulder, it will be necessary to consider its position when in a state of immobility.

THe scapula or blade bone is placed obliquely from the chest to the withers, and the center of its action is fixed in the middle of it. In its action, it describes as large a portion of a circle as the extension of its muscles will admit. If this portion of a circle, for instance, be ten degrees; and two different scapulie possess the same degree of extension, the one situated obliquely (vide plate 2, fig. 1) the other perpendicularly (fig. 2) it must nccessarily follow, that, acting on their respective centers, the one which 
ON THE EXTERNAL CONFORMATION. 13 is oblique must elevate its lower extremity higher than that which is perpendicular, and consequently will increase the projection of every part of the fore limb. Hence it appears, that an oblique position of the shoulder is most favourable for progression.

ThE shoulder may want liberty either by being too fleshy or too lean. In the first instance it is overloaded, and in the last, it possesses not muscle sufficient to enable it to perform its functions with strength and celerity.

The muscles of the chest contribute greatly to the motion of the lower part of the shoulder. Hence a strong and moderately full chest, is to be preferred to one that is narrow and meagre. It will probably be urged, that horses are sometimes possessed of great speed, whose forehands in no wise agree with this description; but such horses are generally endowed with particular powers in their hinder quarters. The fore quarters 


\section{ON THE EXTERNAL CONFORMATION.}

quarters are merely passive, and extend themselves to receive the weight of the body, and if they arc sufficiently strong for that purpose, the animal may certainly move with considerable velocity; but thence it is not to be inferred, that a greater velocity might not be produced if both the fore and hinder quarters were alike perfect in their conformation.

The fore legs will next come under consideration, on the good structure of which the safety and ease of the pace of the animal will chiefly depend.

A horse, whose legs are twisted, or improperly placed too far under his body, may possess great speed; but that his action must be imperfect, the following reasons will sufficiently demonstrate :

If the foot turns either inwards or outwards, it cannot alight flat on the ground, in which 
ON THE EXTERNAL CONFORMATION. $\quad 15$ case the position can never be firm and steady, because the pressure will be partial on either the inward or outward quarter of the foot. If the leg is not perfectly straight from the shoulder to the foot (vide plate $3, f i g .1$ ) its action cannot be true, nor the center of gravity so readily found, as by one that is even and uniform in all its parts (fig. 2). If the elbow inclines inwards close to the ribs ( $f g .1, \mathrm{~A} \mathrm{~A}$ ) the leg must be thrown sideways when in action, which will remove the foot too far from the center of gravity, and produce a lateral rolling motion very unpleasant to the rider. Again, if the legs incline too much under the body, they will be overloaded, and the freedom of their action will be reduced in proportion as they are oppressed.

THE fore legs, to be perfect, should, in a front view, be widest at the chest, gradually approaching each other downwards towards the foot, and descending in a perpendicular direction to the ground, as exemplified in plate 3, fig. 2. 
Tine upper part of the fore leg next the shoulder, should be broad and muscular.

THE power of elevating the knee, and throwing the leg forwards, depends much on the size of the muscles in this part.

THE knee in a front view should be broad, flat, and square; the lower part of the limb, between the knee and the fetlock, should be short, flat, and wide in a lateral view. The tendons should be distinct, firm, and detached from the bone. The fetlock should correspond in proportion with the rest of the leg, neither too upright nor too sloping. If it is too long, its ability of sustaining the weight of the body will be diminished; and if it is too short, it will be liable to knuckle over. Short pasterns are generally attended with contracted feet, the weight of the body not being thrown so much on the heel as is the case with long pasterns. 
THE general proportion of the limb is constituted by two equal divisions, viz. from the elbow to the knee, and from the knee to the ground.

ThE length of the fore leg should correspond with that of the hind leg, that is to say, the elbow D, should describe a horizontal line with the stifle $\mathrm{E}$, plate 1 , otherwise the harmony of motion is lost, as is the case in a carriage, where the fore wheels are of a smaller diameter than the hinder wheels, on which account they are obliged to perform three revolutions to two of the latter.

\section{THE BODY}

Contains the principal viscera and organs of life. The common appellation of this part, amongst horsemen, is the carcase; thus a horse is said to be long or short in the carcase. A horse which is short in the carcase, is usually 
15 ON THE EXTERNAL CONFORMATION.

ribbed lome, as it is termed, that is to say, there exists but a small space between the last rib and the hip bone. This conformation is justly esteemed excellent. A horse thus formed is generally short in the back and wide in his loins, and better adapted to carry weight and bear fatigue than a horse of a different form.

Horses of this description, however, are commonly supposed to be deficient in speed, from the idea that they have not sufficient length. But when it is considered that the carcase has no motion of itself, but is entirely acted upon by the quarters and extremities, it is manifest that the length should exist in these parts, and not in the body. In proof of this, two horses may be found exactly of the same length from the point of the shoulder, at the chest, to the point of the buttock, and yet one horse shall be long in the carcasc, and the other short. Vide plate 5, fig. 1 and 2. 
ON THE EXTERNAL CONFORMATION. 19

THE difference consists in the one having longer quarters than the other, and this is undoubtedly the form to be preferred.

The fore part of the carcase contains the heart and lungs, and thould therefore be sufficiently capacious to admit of a free action in those viscera. Horses with flat ribs experience a greater pressure from the atmosphere in their breathing, than those do which have their ribs more arched, consequently they are not so well adapted for respiration. The posterior part of the carcase contains the stomach and intestines, and is generally round and capacious in horses of a strong constitution. The back should sink in a small degree behind the withers, and proceed in a straight line to the end of the loins, and thence fall gradually to the tail. A hollow back renders the motion of the animal easier to the rider, but certainly cannot be so strong as one that is straight. A roach or hog back constantly throws the saddle forwards on the shoulders.

C 2

THE 
20 ON THE EXTERNAL CONFORMATION.

THE loins should be wide, and the hips low. The distance of the point of the buttock from the hip should be considerable. The lower part of the buttocks, in a posterior point of view, should be wider than the hips (vide pl. 4, fig. 2, l, A A). The tail should issue from the croupe in a regular progressive curve, and not appear as if it was stuck into the rump.

THE hinder quarters may properly be considered as the main spring of the whole machine. This is clearly demonstrated by the superior size of the muscles, and the angular position of the thigh bones.

Ir has generally becn the custom to attributc the source of motion principally to the fore quarters, under the idea, that if the fore quarters could more well and with speed, the hinder quarters must naturally follow. The fal- 
lacy of this doctrine may be easily exposed. In the action of a self-moring body, the posterior part generally constitutes the fixed point from whence the motion takes its origin. Thus, if the horse lean forwards, the center of gravity ceases to be supported, and he is obliged to advance one of his fore legs in order to recover the equilibrium. Again, if the chief source of motion exist in the fore quarters, whence does it arise that many good forc-quartered horses are bad leapers? The reason is obvious: from weakness in their hinder quarters; for the principal strength of a horse lies in the muscles of his thighs. Therefore a horse may rise well at a leap, and clear it with his fore legs, but cannot bring his hinder legs over, unless the muscles of his thighs are sufficiently powerful.

IT may be urged, that leaping differs from galloping; but galloping is, in reality, constituted by reiterated leaps on a plain surface.

$$
\text { C } 3
$$


22 ON THE EXTERNAL CONFORMATION.

Hence the necessity of a good conformation in the hinder quarters*.

THE hinder quarters commence from the center of the back, and continue to the tail, including the hinder legs.

WheN viewed in a lateral direction, the distance from the hip bone to the point of the rump should be very considerable. Vide pl. 1 , l. I K.

The stifé (E) should fall perpendicularly in a direct line under the hip (I). By this means the length of the thigh bone (from $\mathrm{L}$ to E) is increased, and its position rendered more

* A strong instance in favour of this doctrine may be adduced in the celebrated horse Eclipse, who was unquestionably the most speedy horse of his day.

His fore quarters were very ill formed, and his shoulder low; but his hinder quarters were particularly strong and muscular. 
ON THE EXTERNAL CONFORMATION. 23 oblique and angular. The leg from the hough to the ground should be perpendicular, and exactly under the hip joint. Vide L L.

THE thigh above the hough should be broad and muscular (M M); the hough wide, flat, and lean. The width of the hough mechanically increases its powers, by removing the acting muscle to a greater distance from the joint, thereby lengthening the lever. The utility of the above conformation in the hinder quarters, consists in furnishing a greater length to the haunch and thigh bones, without adding to the volume of the part wherein they are contained, and without removing the foot too far from the center of gravity. The hinder quarters, when viewed from behind, should appear wider from stifle to stifle (A A, pl. 4, fig. 2) than from hip to hip (B B). Herein may be traced a strong characteristic of the blood horse. 
24 ON THE EXTERNAL CONFORMATION.

THE hips of the blood horse are lower and narrower, proportionably than those of the cart horse; on this account he is supposed to be weaker than the latter; but this be not the fact. For if the croupe of a blood horse be measured from hip to hip, the space will be found (proportionably) to be as large as that of a horse with wider and higher hips (vide pl. 4, fig. 1) because the surface is more circular, which, if extended flat, would occupy as wide a space. Hence it is evident that the blood horse, in this instance, possesses as large a proportion of muscle, although it be concentrated into a circular form.

THE leg should be perpendicular from the hough to the ground, as exemplified in fig. 2, l. $\mathrm{c}$ c, and the houghs not too close to each other, which is vulgarly termed cat or cowhoughed. Vide fig. 1. l. A A, same plate.

Horses of this description have, in general, the reputation of speed; but not altogether with justice. 
justice. In this position of the leg, a greater portion of weight must be thrown on the hough than if it were upright. Moreover, it is clear, that a moving part must be impeded in its action in proportion as it is oppressed, and this oppression is sufficiently manifest by the production of thorough pins, curbs, spavins, and weakness in the fetlock joint, commonly called knuckling over ; injuries to which horses of this mould are peculiarly subject.

THE foregoing remarks upon the external conformation, apply only to the mechanical advantages to be derived from a peculiar construction of the component parts. The force of the muscles not being directly proportioned to their bulk, but being in a compound ratio of their size and density or elasticity, the latter not being visible, the force can only be ascertained by experiment, that is, by a trial of the animal. 
¿6 ON THE EXTERNAL CONFORMATION.

Having thus considered the external conformation of the animal, the next object of inquiry will be the structure and œconomy of the foot, than which nothing can be more important. For be the fabric ever so beautiful, yet if the foundation be not good, it liolds its perfection by a frail tenure, which the progress of time at length totally annihilates.

\section{THE FOOT}

Consists of three principal parts, viz. the wall or crust, the sole, and the frog.

THE wall or crust is the part which iscues immediately from the coronet, and grows downwards to the ground.

IT is composed of a firm horny substance, which becomes harder the nearer it approaches 
ON THE EXTERNAL CONFORMATION. 27 the toe. It consists of two sets of fibres, circular and perpendicular.

THE circular fibres surround the whole, and by their contractile power, prevent the sides of the hoof from bursting asunder. The degree of density in these fibres, will depend on the texture of the skin from whence they originate, and, on this account, the hoof's of blood horses are commonly much harder and more compact than those of cart horses, whose skin is of a more spongy nature.

THE sole forms the bottom of the foot, and is closely connected with the wall, which connexion may be distinguished at a small distance from its edges. The sole is naturally concave, and if the wall be firm, and possess sufficient contraction, it will have the property of an arch.

THE frog is a substance projecting above the surface of the sole, and occupies the posterior 
terior part of the hoof. Its form is wedge-like, with its point terminating in the center of the sole, and is admirably adapted to give stability to the foot by its resistance to slipping. It is softer than the rest of the hoof, and serves as an elastic cushion for the terminating point of the flexor tendon of the foot.

THE hecls constitute the posterior part of the hoof, and are composed of the reduplication of the wall, forming a ridge to the side of the frog. This part is called the bar or binder of the foot, and tends considerably to keep the heels apart from each other.

THE foot of a colt, antecedently to being shod, describes nearly a circle, of which the lieels constitute the widest part (vide plate 6 , fig. 2). The hoof contains the lesscr pastern bone, the coffin bone, and the navicular bone. The coffin bone occupies the largest part of the cavity of the hoof as closely as the kernel of a 
nut within the shell. It is connected with the hoof by laminæ, which arise both from the inward surface of the hoof, and the surface of the bone (vide fig. 4). These lamine maintain their connexion with each other by the attraction of cohesion; they also contain innumerable ramifications of blood vessels and nerves. The composition of this part is singularly beautiful; for if the coffin bone and hoof were not separate from each other, the growth of the hoof downwards could not have been carried on independently of the parts contained within it; thus we find the connexion exists by the attraction of these laminæ to each other, and which are folded together like a fan, in order to occupy less space, and yet, if expanded, would furnish a surface twenty times the circumference of the foot.

Within the coronet, at the sides of the hoof, are placed two cartilages, in the shape ot a half moon. These cartilages cover the larger 
30 ON THE EXTERNAL CONFORMATION.

branches of the arteries, and furnish a defence against injuries, such as treads and overreaches. They also prevent the coronet from pressing on the blood vessels and nerves which surround that part.

THE foot is subject to many defects, which will be considered under the article of shoeing. 


\title{
CIIAPTER II.
}

\author{
On the EIE.
}

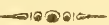

\section{THE great utility of sight to animals which enjoy the faculty of loco-motion, must render an inquiry into the diseases of that organ pecu- liarly interesting.}

INFLAMMATORY attacks on the eye of the horse, eventually producing blindness, are so general as almost to sanction a belief, that he is naturally more subject to this infirmity than any other animal. Such a supposition, however, would tend more to arraign the wisdom of Providence, than to throw any light on the subject. A difference in the perfection of the eye, as well as of other parts of the body, certainly prevails amongst different horses; but not to such a degree as to occasion blindness, provided 
the animal remained in a state of nature. Unnatural confinement in hot and dark stables, the constant costiveness produced by dry food, and more especially a general derangement of the system brought on by violent and excessive excrtions, are undoubtedly the primary causes of diseased eyes. The necessity of speedily counteracting inflammation in the eye, must be sufliciently manifest, when the reader is informed, that a total and irrecoverable privation of sight frequently takes place in twenty-four hours.

THE local situation of the eye is so familiar to every one, that it is scarcely necessary to describe it. It is placed sideways in the head of the horse, as well as in all other animals who preserve themselves from danger by flight*.

* This position of the eye is common to hares, birds, and several other animals. $\Lambda_{\mathrm{n}}$ instance has occurred of a hare, when closely pursued by a dog, having her eyes so attentively fixed on the object bebind her, as to run against a tree, and to be stunned by the concussion. 
This position of the eye enables him, in some degree, to see behind him, and to kick against an adversary with greater certainty. The anatomy of the horse's eye varies, in some instances, from the human eye, although the functions are precisely the same. The pupil of the human eye is circular in its form, that of the horse oblong. By this formation, the horse's eye takes in objects horizontally to a much greater extent than the human.

THE muscles which move the horse's eye, are seven in number; in the human eye there are but six. The seventh seems to be adapted for the purpose of retracting the eye within the orbit, to shield it from injury, and also to suspend it in the action of grazing. It differs also from the human eye by being furnished with a membrane, situated at the anterior corner (vide pl. 7, l. c). This membrane is common to most quadrupeds*, as well as to birds. The

* The monkey is an exception to this rule. 
anatomical name for this membrane is Membrana Nictitans; but, perhaps, it will be more readily understood under the appellation of Hawes. Farriers are so universally ignorant of the use of this membrane, that they consider it as a disease, and under that idea remove it by excision. The pernicious consequences of this practice will be explained hereafter.

THESE are the principal points in which the eye of the horse differs from that of the human being: a more minute and technical explanation would be, perhaps, both uninteresting and unintelligible to the majority of my readers.

THE external surface of the eye, in its healthy statc, is thoroughly transparent.

THE center of it, which is denominated the pupil, is generally of a dark indefinite colour. The pupil has the property of contracting or dilating itself, in proportion to the strength of light 
light which enters the eye. Vide plate 7 ; letter A represents the eye in an obscure light. Let$\operatorname{ter} \mathrm{B}$, in a strong light. The non-enjoyment of this faculty is a certain indication of blindness. To examine a horse's eyes properly, he should be placed under a stable door, with his head facing the light. In this situation the pupils of both eyes should be exactly of the same dimensions. As he advances more into the light, the pupils should contract; but if either of them does not contract, the horse is certainly blind of that eye.

THE disease which occasions this species of blindness is termed, in pathology, the Gutta serena, and arises from a palsy in the optic nerve. It is so little perceptible, that ferv but anatomists can detect it.

ANOTHER cause preventing the impression of light on the optic nerve, is more perceptible, but equally incurable, viz. an opacity in the D 2 surface 
surface of the chrystalline lens through which the rays of light pass to the retina.

THE crystalline lens is a pellucid transparent convex body, situated immediately behind the pupil*. It frequently becomes opaque, in consequence of general inflammation in the globe of the eye. In this state the surface of the lens, which presents itself in the cavity of the pupil, assumes a greyish aspect, and in the confirmed state it becomes perfectly white.

AT the commencement of this disease, small grey specks, about the size of a pin's head, are sometimes perceived in the pupil, so small as not to interrupt the entrance of light; but the presence of these specks is a certain indication that the eyes have been attacked at some former

* The crystalliue lens is more or less convex in different animals. In fish it is perfectly spherical, as the aqueous medium which surrounds them, renders a greater refraction of the rays necessary to vision. 
period (vide $p l .7, l . \mathrm{D}$ ). The appearance of the eye in an inflamed state, whether from external injury or from a bad habit of body, is nearly the same. The surface becomes clou$\mathrm{dy}$ and opaque, and frequently a yellowish red, and sometimes green fluid is seen floating in the anterior chamber of the eye. The opacity of the outward surface is produced by the coagulable lymph being forced between the laminæe of the transparent cornea, but is generally mistaken for a film covering the outward part of the eye; hence the pernicious custom of blowing powdered glass, and other irritating applications into the eye, is resorted to with a view of eroding it.

THE blood ressels of the tunica conjunctiva, or white of the eye, are turgid during inflammation. In this state the light is painful, and, in order to prevent its entrance, the eye-lids are generally closed. When the eye-lids are opened

D 3 
by the hand to examine the state of the eye, the membrana nictitans or hawe is brought, by the animal, considerably over the surface of the eye, to supply momentarily the office of the eye-lids, in preventing the access of light. Vide plate $7, l$.c.

THIs temporary appearance of the hawe the farrier mistakes for a disease, and generally removes it by cutting it away. The hemorrhage and superficial irritation produced by these means, sometimes relieve the eye; but the subsequent effects is an exposure to inflammation, created by the presence of any extraneous substance, such as dust, hay-seeds, \&c. which, from the loss of the hawe, the animal is disabled from wiping away.

INFLAMMATION in the eyes is often produced by plethora, from want of sufficient exercise. In this case topical applications alone are not to be depended upon. Evacuations to 
a very considerable degree are absolutely necessary.

Two or three quarts of blood may be taken, and the bowels may be kept in a laxative state by mild purges, such as four drachms of aloes given at a dose, night and morning, until they operate; the horse to be fed with bran mashes, and the same precautions attended to as are generally observed in physicking.

THE best lotion which can be applied, is a mixture of one-fourth vinegar to three-fourths of water, to be used with a clean spunge and light hand very frequently. A rowel under the jaw, or blisters applied to the cheeks, will be found highly useful, together with regular exercise, just sufficient to produce a moisture on the skin. Draught horses of every description are probably more subject to inflamed eyes, arising from the pressure of the collar preventing a free circulation of blood in the head.

D 4

YOUNG 
YouNG animals are more disposed to local inflammation than old ones, from the blood vessels not having acquired the habit of sufficiently resisting the increased force of the circulation; hence horses are more subject to diseased eyes before their sixth year than afterwards.

THE mode of treatment here recommended will, in general, remove the inflammation, but will not prevent its return, except proper attention is paid to the management of the animal. It is certain that this disease arises most frequently amongst horses which are highly fed, and not sufficiently exercised, and, in proof of this fact, many instances occur where horses have recovered perfect sight and retained it, in consequence of regular labour in a mail coach or post chaisc.

'THERE is another description of imperfect eyes, commonly called Moon Eyes or Buck Eyes. This term originated probably from some peculiar 
peculiar influence which the moon was supposed to have upon them, as the inflammatory attacks are generally periodical. In this disease the eye is usually smaller than the common size, and its outward appearance is cloudy and of a greyish colour. The animal also is much addicted to starting at objects, particularly at shadows and reflections from water. The same rules, with regard to regimen and exercise, will be found useful in this complaint.

EXTERNAL inflammation of the eye-lids, with a flowing of the tears down the cheek, is frequently occasioned by an obstruction in the lachrymal duct, which opens into the cavity of the nostril. In this case water should be syringed up the duct, or some strong snuff may be blown into the nostrils to produce sneezing. 
$x^{2}+x^{2}$

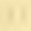
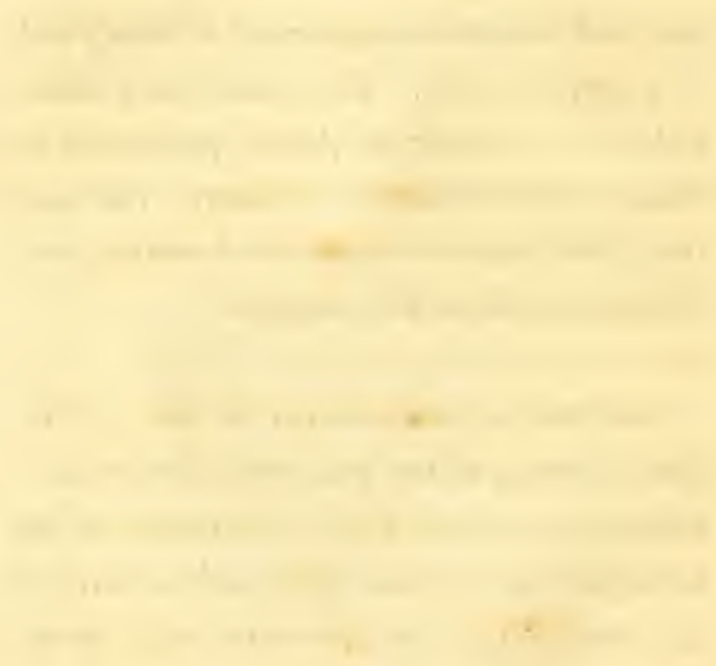

r

\section{.}




\section{CHAPTER III.}

ON SHOEING.

\section{$-1000-$}

IF the surface of the earth had remained in its natural verdant state, the necessity of an artificial defence for the horse's foot would not have existed. But since it has been found more convenient to the general interest of the community to construct roads of hard materials, shoeing the animal has become an unavoidable evil.

From the first moment a colt is shod, the contest between nature and the blacksmith may be said to take place.

THE foot of a colt, as already described, is concave in the sole, it will therefore be obvious, that the most prominent parts of the sole must 
come more immediately into contact with the ground.

The parts which are most prominent are the wall, the binders, and the frog. These parts, therefore, constitute the chief support of the foot.

WIEN the horse is shod, the inward surface of the shoe becomes the support of the foot instead of the ground; hence it will not be irrational to conclude, that the nearer this support resembles the surface of the earth, the better it will be adapted to the foot.

THE quarters and heels are naturally capable of an elastic expansion when the hoof is not shod. This elasticity contributes to facilitate the circulation of the blood through the foot, to furnish a spring to the action of the leg, and to lessen concussion. It has been before observed, that the foot possessed three points of support, 
support, viz. the wall, binders, and frog. But the common method of shoeing completely frustrates this design, for the shoe being made concave and thick at the heels, the points of contact are thereby reduced from three in number unto one, that is to say, the wall of the hoof only. This concavity of the shoe next to the sole, counteracts the elastic expansion of the quarters and heels, by constantly pressing them towards each other. The thickness of the heels also elevates the frog above the ground, and prevents the pressure which its texture and use require. Nature, faithful to her laws, resists injury with her utmost efforts, but, unfortunately is unable to counteract the continued application of an injudiciously constructed shoe.

HENCE the mischief arising from bad shoeing is slow in its progress, but fatally certain in its effects. For if the alteration of the form of the hoof, and the consequent lameness, were produced 
produced instantaneously, conviction would immediately follow, and even the most uninformed would detect the erroneous system. The practice of shoeing, therefore, should be adapted solely as a defence to a part which is already perfect, and which stands in need of no alteration whatever from its original form.

THE greatest merit which a blacksmith generally assumes, is built upon his dexterity in shoeing a bad foot, where much caution and precision is required in driving the nails so as to keep the shoe fast without injuring the animal. But if he would bestow cren one half of this cleverness in attentively considering the primitive shape of the foot and its component parts, his abilities and his time would be employed to a much better purpose. It would be fruitless, however, to expect reformation from men who are so firmly bigotted to their old maxims, that neither precept nor example can make the smallest impression upon them. 
THE plan to be pursued in shoeing a perfect foot will be as follows:

To pare the wall just sufficient to make it level; to pare the sole as much as will be necessary to remove the dead surface which endeavours to detach itself by scaling off, spontaneously; the frog to be cleared of its ragged edges; the heels not to be scooped out, nor notched in any way whatever. The shoe for a sound foot to be about three quarters of an inch broad in the web, and of an equal thickness from toe to heel; the surface next the hoof to be half flat and half bevilled, except at the heels, which should be entirely flat, so as to press on the bars as well as on the heels.

ThE nails should be eight in number, four on each side, and inserted principally near the front of the hoof so as to leave the heels as much at liberty as possible. 
IN order to save trouble, it is a common practice with blacksmiths to apply the shoe hot, and burn down the hoof until it corresponds with the surface of the shoe. This method should never be tolerated on any pretence whatever, for it dries up the natural fluid of the hoof, destroys the pores, and renders the crust, to a considerable extent, perfectly insensible, and also causes it to be so brittle, as to be incapable of holding the nails in their respective situations. It has been before observed, that the shoe should be half flat and half bevilled. By being half flat, it will embrace a small portion of the sole as well as the wall, and although it is generally asserted, that the sole will not endure pressure from the shoe without injury, yet daily experience will sufficiently prove the contrary.

If the whole weight of the animal be sustained by the wall of the foot only, the pressure 
will be partial, the concussion more considerable, and the sole will gradually sink and become flat, and even convex or pumied.

THE shoe should never be made of a smaller diameter than the foot, particularly at the quarters. This plan, however, is generally pursued from the apprehension of the horse's cutting his fetlock joints from the feet being too broad. But a horse seldom cuts whilst his feet are sound and free from pain, except from a natural malposition of his legs.

$\mathrm{HE}$ is more liable to cut when his tread becomes wavering and unsteady by being cramped and pinched from bad shoeing. The foot should not be rasped too much below the clenches of the nails, as it is thereby partially weakened, and loses its straight direction from the coronet to the ground. 
THE nails should be as small as possible, and in a wedge-like form at the head, by which means they will retain their hold with greater effect.

THE foregoing rules are pointed out for the purpose of shoeing a perfect foot, which has not been injured either by accident or disease ; and if they are strictly adhered to, will generally ensure a continuance of that perfection. But this method, however excellent in principle and confirmed by experience, may be easily brought into disrepute by an injudicious application.

THIS misfortune frequently occurs from the unqualified opposition of blacksmiths in general, who, to use the words of Tacitus, will ever be found " Consilii quamvis egregii, quod ipse non afferret inimicus." 
Their low cunning is sufficiently fruitful to point out to them, that the sudden reduction of a horse's heels which have been accustomed to thick concave shoes, will be productive of considerable pain and temporary lameness, and will thereby furnish them with an epportunity of asserting the justice of their predictions respecting the fallacy of the new mode of shoeing. Hence, if a horse with high and contracted heels, is sent to a blacksmith with orders to have them reduced moderately at every time of shoeing, he seldom lets slip the opportunity of bringing on the consequences beforementioned, by executing the orders to an extreme.

Nor is this the only instance wherein he has it in his porrer to pervert the present system of shoeing. For if a flat narrow shoe is recommended as the best adapted for a good foot, the same party will apply it to a pumied or convex sole, knowing at the same time that a foot of that description cannot possibly bear it.

E. 2 
In this case the proprietor of the animal, who, probably, is not sufficiently versed in the art of shoeing to detect such iniquitous schemes, discovers that his horse is lamed, and, unfortunately for his future interest, possesses a still higher opinion of his blacksmith's abilities, and

- thenceforth condemns the veterinary college and its doctrines in toto. But notwithstanding all their objections to the new system of shoeing, the defenders of the old mode cannot disprove this deplorable fact, that there is scarcely one horse in a thousand, at six years of age, that is perfectly sound in his feet.

\section{PUMIED OR CONVEX SOLE.}

THis alteration of the original form of the sole is sometimes produced by inflammation in the foot, and frequently by bad shoeing only. When it is the result of inflammation, the horse is said to be foundered, and the coffin bones to 
be sunk. This disease seldom admits of a cure. But when the convexity of the sole has arisen from bad shoeing, the only method by which permanent relief can be obtained, will be by running at grass, without shoes, for six months at least. As the complaint is brought on, in a great degree, by partial pressure on the wall of the lioof by hollow-webbed shoes, nothing can be so conducive to the restoration of the primitive form of the foot, as a general pressure on the sole and frog, by which means the wall of the hoof will be less impeded in its growth, and will be thence enabled to recover its original strength and texture.

THis is to be effected by no other means than by remaining at grass, barefoot, for a considerable length of time.

As the front of the foot loses, in this disease, its natural straight direction, and becomes curred as it approaches the ground, it is necessary E. 3

that 
that the toe should be kept as short as possible, in order to counteract this tendency. The heels, frog, and binders, however, should be left untouched.

Turs plan will considerably improve the shape of a pumied foot; but a complete reestablishment of the original concavity of the sole is not to be expected. The shoe which is proper for a pumied foot varies, in some degree, from that which is adapted to a perfect foot. Its internal surface must correspond, in some measure, with the convexity of the sole; but not more than is absolutely necessary to admit a picker between them. The heels of the shoe to be kept as flat as possible, with a view to bring the frog into contact with the ground; the nails to be inserted principally round the toe. By bevilling the shoe from the outward edge of the web to the inward edge, a flat surface will be presented to the ground, which will certainly be more firm and steady than one that 
is convex. The caution against applying a hot shoe, is particularly necessary to be attended to in the present case.

\section{CONTRACTED HOOF}

Consists of a contraction of the heels of the hoof, and is. most indubitably, the offspring of bad shoeing (vide plate 6 , fig. 1). Other circumstances, however, may concur in producing it, such as a natural disposition to heat in the foot, increased by standing in the stable, or running thrushes, or it may be brought on by the horse's not pressing on the foot, in consequence of lameness in any other part of the leg.

WHEN the contraction exists to a great degree, a perfect cure is not to be obtained. Hence the necessity of counteracting it on its first appearance. Contraction in the hoof canE 4 not 
not take place suddenly, as the internal parts of the foot will resist it for a certain length of time; but the continued pressure of the quarters will ultimately produce an absorption in the coffin bone, which is obliged, in this manner, to adapt itself to the diminished capacity of the hoof. Feet which are disposed to contract, generally possess great strength and thickness in the wall or crust, and this contractile power must be greatly increased by the common practice of notching the heels, paring the frog and sole to an extreme, and shoeing with convex shoes with thick heels, thereby preventing the frog from touching the ground. In this case the frog, for want of pressure, will be diseased and wasted in substance, and the animal will become unsafe in his progression whenever he happens to tread on a stone, or any other projecting substance. Corns also commonly attend fcet of this description, from the heels being bound both by the strength of the walls and the bad construction of the shoc. In the 
worst state of a contracted hoof, the sole is sometimes so pressed upon laterally by the quarters, as to be forced upwards against the fleshy sole in such a manner as to cause great pain. This is denominated by the French, an encastelated hoof. It is easily distinguished by a preternatural concavity in the sole.

A cure is often attempted by scoring the hoof perpendicularly from the coronet to the ground, rasping the quarters to the quick, and applying a screw shoe.

But attempts of this kind to produce a sudden alteration in the dimensions of the hoof, will be found totally useless, if not injurious. The disease is brought on gradually; the remedy, therefore, must be gradual, as the texture of the hoof is too firm and tenacious to yield hastily to artificial impressions. If the horse is worth the trouble and expence, the most pro- 
bable means of effecting a cure will be either to turn him out barefoot, or to oblige him to stand without shoes on the bare stones during the day, and to litter him down at night as usual.

THE pavement of the stall, howerer, should be perfectly level, by which means the heels will be pressed upon properly, and will progressively expand. The quarters may be moderately rasped, and the heels to be pared as low as possible. This process to be repeated once monthly at least.

WET rags may be tied loosely over the coronet, to be wetted frequently in the course of the day. This plan, however, must be persisted in for a considerable length of time to produce the desired effect. But it happens sometimes, unfortunately, that the internal parts of the hoof, such as the bones, cartilages, and ligaments, are disorganized beyond recovery. In this case an expansion 
expansion of the hoof will be productive of little benefit, from the impossibility of restoring to these parts their natural functions and elasticity.

IT is a practice with most farriers to draw the sole with a view to effect a cure; but, independently of the barbarity of this operation, it will ever be found useless, and will rather have a tendency to increase the disease, by removing one of the principal sources of resistance to the contraction of the walls of the foot. Yet we see on the shop door of every village blacksmith, horses soles nailed up in regular order-trophies of his ignorance and his cruelty.

\section{CORNS,}

This troublesome disease also takes its origin from bad shoeing.

A corn 
A corn is generally produced by a partial pressure of the shoe, from its sitting too hollow, or by the shoe being too short, and indenting itself into the heel.

Tre blood being forced into the horny fibres of the hoof, gives it sometimes a red, and somctimes a black appearance.

THE concomitant inflammation is frequently so great, as to cause internal suppuration of the laminated surface of the hoof, even up to the coronet. In this case the corn should be properly laid open with a drawing knife, to procure a fiee egress for the matter downwards, and a bar shoe should be applicd, in order to remore the pressure from the hed unto the frog. As soon as the injured part is healed, the best and most radical mode of cure will be to harden its surface by an equal pressure, which will be best effected by the horse's remaining some weeks without shocs.

DISEASED 


\section{DISEASED FROG, \\ Commonly called a Runnixg Thrustr.}

Turs disease attacks the frog of the foot, extending from its center up to the cleft of the heels, and if neglected, terminates sometimes in a canker.

IT is often improperly attributed to a bad habit of body, and, on this account, it has been supposed to be dangerous to attempt its removal. A running thrush, however, is more frequently produced by bad shoeing, than by any other cause, as we daily find that horses of all habits ot body are subject to it. In cases where the discharge from the frog has been of long standing, it is possible that the system may experience some temporary inconvenience by the sudden privation of an outlet to which it has been for some time accustomed, but hence we are not to suppose that an evacuation, which is not natural, should be essential to the health of an ani- 
mal, except it is brouglit on as a critical termination of some other disease.

QUADRUPEDS are not subject to periodical discharges, such as menstruation or hæmorroidal fluxes, and in this instance they are more perfect in their oconomy than the human being. The frog, in its healthy state, is a firm elastic substance, somewhat softer than the rest of the hoof. The form of it clearly points out its use, viz. to give stability to the foot, to serve as a basis for the flexor tendon of the leg, and to furnish elasticity to the posterior part of the hoof.

But the common method of shoeing would lead to a supposition, that not one of these properties belonged to the part in question, and hence the intention of nature is frustrated in every instance. The frog being, by thick heeled shoes, deprived of pressure against the ground, becomes soft, from the accumulation of 
the natural fluid which it secretes, in this part, in great abundance, from the fatty substance which lies immediately under the aponeurosis of the flexor tendon. This accunulation of fluid, at length, makes its escape through the fissure of the frog and heels, and acquires, by exposure to the atmosphere, a fetid smell, and an acrimonious quality sufficient to crode the adjacent parts. In this state the frog becomes so sore and irritable, as not to endure pressure without a very painful sensation. But the mischief does not terminate here. The frog naturally constitutes a point of resistance to the heels, and in conjunction with the bars of the hoof, prevents them from approaching each other; but when it is thus destroyed by disease, it no longer performs that office, and the hecls consequently contract and produce an incurable lameness. Hence, the necessity of counteracting this disease in its infancy, must be suf-, ficiently evident. 
THE discharge may be stopped by astringent applications; but no permanent cure can be obtained without such a method of shoeing as will bring the frog into contact with the ground, and thus, by pressure, increase its surface and harden its substance.

OrL of turpentine, or blue vitriol dissolved in vinegar, may be applied daily to the part.

THE heels of the hoof to be pared as low as possible, and the heels of the shoe to be made very thin.

CoLts at grass are sometimes subject to diseased frogs; but this occurs only in cases where the walls of the hoof are exceedingly strong, thereby preventing the heels from being sufficiently worn down so as to bring the frog into contact with the earth. Soft and wet pastures also contribute to the same bad tendency.

Here 
Here likewise the heels ought to be pared down very frequently.

If the disease has existed so long as to liave insinuated itself between the horny and fleshy soles of the foot, it is then termed a canker, and must be treated in the following manner: First, it will be necessary, with a drawing knife, to remove all that part of the horny sole which the discharge has detached from the fleshy sole, or, in other words, all that part which is hollow underneath. The diseased surface being thus exposed, is to be dressed with a caustic, such as butter of antimony, or nitrous acid and water, equal parts, and some dry tow or powdered lime to absorb the discharge. When this plan has been pursued, the cure will aferwards depend upon the application of pressure to the part affected. The sole being, in fact, a plexus of blood vessels, granulations arise much more rapidly there than in any other situation, hence they are better checked in their exuberance by 
pressure than by caustic, which always puts nature to the expence of regenerating the surface.

\section{QUITTOR, \\ Or UlCER in the Coronet of the Hoof.}

Wounds on the coronet, between hair and hoof, occasioned either by treads or overreaches, may be easily cured by washing the part thoroughly clean, and applying some tow steeped in spirits of wine, and a moderate degree of pressure, so as to bring the divided parts as near as possible to each other. By these means they generally heal by the first intention.

But if they are neglected in their origin, or are improperly treated by the use of caustic or violent dressings, they become fistulous ulcers, ultimately rendering carious the cartilages and bones of the foot. In this state they are called quittors.

A quittor 
A quittor may also arise from the foot being pricked in shoeing, and the matter forcing itself through the coronet.

WHEN the ulcer has arrived at this state, the original cause will be immaterial, the treatment must be uniform in this particular, viz. to get to the bottom of the sinus. The number, depth, and direction of the sinuses may generally be ascertained by the probe.

If there is only one sinus, the orifice may be enlarged with the knife, and some butter of antimony may be introduced, at the same time dressing the surface with common digestives; but if there are more sinuses, and in a tortuous direction, it will be necessary to lay the whole open, and to cut away all the diseased part, after which it becomes a simple wound. This operation should be performed by a skilful hand, as there is danger of injuring both the capsular F 2 ligament 
ligament of the coffin joint, and the principal artery running to the foot.

A quittor frequently leaves a deformity in the growth of the hoof, which is denominated a false quarter. This arises from the regenerated substance in the coronet producing an unequal shape afterwards. In this case it will be necessary, in shoeing, to avoid driving any nails near the part, if possible. 


\title{
CHAPTER IV.
}

\author{
The GREASE.
}

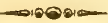

IN treating of the diseases of the legs, it will be proper to begin with those which are external.

THE grease is so common a complaint, as to require little or no description of its appearance. It has hitherto been usually ascribed to a gross and foul habit of body, and the customary measures of blecding, purging, and rowelling have been, and continue to be adopted for the attainment of a cure.

In this disease, as well as in all others, it will be necessary first to ascertain the predisposing cause, on sound principles, before we can proceed to the administration of medicine. 
The necessity of this basis is seldom or never considered, and foulness, humours, \&c. are assigned indiscriminately to horses of all ages, habits, and constitutions, and cæetcris paribus, the same mode of treatment is uniformly persisted in.

EXPERIENCE has proved that this mode of treatment is not always attended with success, and it remains to enquire into the causes of its failure. The original cause of the grease is debility in the system. Other circumstances, however, concur in its production, which will be noticed in their proper places. Debility may arise from directly opposite causes, viz. repletion and exhaustion.

Tre healthy state of all animals is constituted by a due and regular circulation of the blood, and an uniform maintenance of the natural evacuations of the body. 
Whatever disturbs any of these functions will produce debility. In a full plethoric habit, the vessels which are appropriated for the circulation of the blood become oppressed by being overloaded, and are thus rendered incapable of performing their office. Hence debility takes place, and the legs, which, by their situation, are most remote from the center of circulation, and through which the blood has to return in opposition to its own gravity, become swelled for want of the accustomed absorption. On the other hand, when the horse is lean and emaciated, either from want of a sufficient quantity of nutritive food, or from excessive labour, the circulation of the blood will be languid from a deficiency of stimulus, and debility will naturally ensue.

IN addition to either of the above-mentioned causes, the following may be given as collateral promoters of the disease, viz. the season of the year, unnatural confinement in the stable, the 
acclivity of the parement of the stall, cutting the hair off the heels, and want of proper exercise and cleaning.

In the winter season, at which period the grease is most prevalent, the insensible perspiration of tine body is not so regular, nor so profuse as in the summer; but nature generally provides against this decrease, by increasing the discharge of urine, and the expiration of vapour from the lungs; and this mode of expulsion would be fully sufficient for the purposes of the animal œconomy, if the horse remained in a state of nature. But it is far different with him in a domesticated state, in which he is alternately exposed to a warm and cold atmosphere, as he is within or without the stable. The secretion and evacuation of urine is disturbed in its process, by forcing him to proceed in his labour at the moment when the fulness of the bladder stimulates him to discharge its contents; and although the perspiration may be increased 
to an excessive degree by exercise, and which might be supposed to compensate for deficiencies in other respects, yet it will be found, that the result of excessive labour and perspiration will be a proportionate debility, whereas the insensible perspiration is a tranquil and imperceptible evacuation, carried on without putting nature to any expence of corporeal powers. The bad effects arising from the foregoing causes, are considerably aggravated by confinement to one situation, probably during eighteen hours out of the twenty-four. The pavement of the stall being on an ascent, will throw three-fourths of the weight of the body on the hind legs, and will also distress them by the toe being placed upon higher ground than the heel, whereby the ligaments and membranes are kept constantly distended. Under these unfavourable circumstances the legs swell, a rupture of the skin eventually takes place, and a serous discharge ensues, which, by exposure to the atmosphere, acquires a fetid and acrimonious quality. As the 
the disease advances, the part affected becomes extremely sore and irritable, so as to give excessive pain to the animal when be moves the limb; at the same time the excoriation spreads, destroys the roots of the hair, and creates a chancrous or pustulous induration of the skin, understood in farriery by the appellation of grapes.

WHEN the disorder has arrived at this state, the horse is generally supposed to be foul and full of bad humours. Bleeding, purges, and diuretics are made use of, during the action of which the fluids are absorbed and evacuated, and the legs are relieved. This temporary absorption, however, serves but to palliate the complaint, for its subsequent effects will be an increase of the original debility, and with it an increase of the disease.

THIs objection to purges, it will be necessary to inform the reader, includes only those of the strong drastic kind. 
As the horse is generally costive in the stable, mild aperients will undoubtedly prove serviceable; but drastic purges generally increase the costiveness after their effects have subsided. If the horse has proper exercise, diuretics will, in general, remove the complaint.

BuT antecedent to pointing out the mode of cure, it will be expedient to enquire into the consequences of the practice of cutting the hair off the heels.

So arbitrary is custom, that it frequently occurs that practices are persisted in, which, by a proper investigation, would be found to be most directly contrary to truth. Under this head we may class the foregoing. The common opinion upon this subject is, that the hair harbours dirt, and prevents the legs from being properly cleaned. Under this position, its removal certainly would appear necessary. But when it can be proved that this hair does not harbour 
harbour dirt, but, on the contrary, prevents its access to the limb, it will be no difficult task to shew its utility.

Nature has cloathed the animal with hair for the obvious purpose of defending the skin from the contact of the atmosphere. Other membraneous parts, such as the nostrils and the eyes, are shiclded, with the same intention, by peculiar secreted fuids, which in a state of health constantly cover their surfaces. The inward surface of the nostrils is kept moist, in order to preserve the sense of smelling; and the outward surface of the eye is kept moist, in order to preserve its transparency.

Вотн of these faculties would be destroyed by the contact of atmospheric air, which, by drying the surface of the nostril, would render it incapable of smelling; and which also, by drying the surface of the cye, would corrugate it, and render it opaque by the multiplicity of refractions 
refractions which would arise from its irregularity.

As the body is thus defended with hair, it accordingly follows that those parts which would if they were naked, be most exposed to water and dirt, are furnished with a greater portion of this covering. Hence the hair on the lower part of the leg is considerably longer than elsewhere. This is sufficiently manifest in horses which are bred in cold marshy soils, such as Holland, Flanders, and many parts of England.

If a leg of this description, with the hair on it in its natural state, is examined after passing through the dirtiest roads for several hours, when the hair is divided by the hand to inspect the skin, it will be found that the external part only is wet, whilst the internal part, together with the skin, will have remained perfectly dry and free from dirt. In this state it will be only necessary to wash the dirt off the hair on the 
outside, and leave it to dry by its own evaporation. On the other hand, if the hair has been cut off close to the heels, both water and dirt will have access to them, and when the pastern bends during progression, a very considerable friction is produced, which must consequently irritate the surface of the skin. When the animal returns from his daily labour, the legs are washed with cold water, and except they are well rubbed with straw or the hand (a benefit which seldom falls to the lot of ordinary horses) they are suffered to become dry in a natural way; but whilst this evaporation is going on, the legs are extremely cold for two or three hours, and the skin being deprived of its own fluid, which it sccretes in order to preserve its pliancy, becomes corrugated and inflamed, and swelling of the cellular membrane ensues, with all its bad consequences.

IN objection to this doctrine it will probably be argued, that blood horses are not thus furnish- 
ed with long hair on their legs. But it must be considered, that the blood horse is not originally the produce of this country. The climate in which he is generated is much warmer, and the surface of the soil is generally sandy and frec from moisture. In this country, however, his legs are well protected by the closeness of the hair, for his skin, which is finer and more compact in its texture than that of the cart horse, produces three hairs in the same space as would be occupied by two only in the latter. Independent of this property, his natural habit is more vigorous, and less subject to those diseases which attend habits of the indolent and phlegmatic kind.

THE necessity of a covering to the skin of animals which are much exposed to the cold elements, may, in an analogous point of vicw, be carried still farther, viz. to water-fowl and fish. 
THE body of the first is completely enveloped in feathers, which, being oily on their surfaces, repel water for a great length of time. The legs are defended by a scaly coat. When the fowl is inclined to wash his feathers, he rubs off the oil with his beak whilst in the water; but as soon as his feathers are dry, he oils them again by rubbing his beak against his rump, which secretes a greasy fluid, and afterwards applies it to every part of his body.

Fish, which are constantly exposed to water, throw out on the surface of their bodies a mucus, which prevents the contact of that element.

In slight attacks of the grease, a cure may generally be effected by employing such medicines internally as will increase the urinary and perspiratory discharges, and by attending to cleanliness and moderate excrcise. 
THE following ball may be given every other night for four or five nights :

Emetic Tartar, - -2 draclıms

Venice Turpentine, - $\frac{x}{2}$ ounce

Liquorice Powder, - 1 ounce

Mixed together into one ball.

THE heels may be dressed at night, after being well washed with soft soap and warm water, with the following lotion:

$$
\begin{aligned}
& \text { Vinegar, - - - - half a pint } \\
& \text { Water, - - - half a pint } \\
& \text { White Vitriol, - - one ounce } \\
& \text { Mixed. }
\end{aligned}
$$

If the disease has been of long duration, and has become exceedingly virulent in its effects, purges must be administered, and a rowel introduced in some convenient part.

THE purging ball may consist of

$$
\begin{aligned}
& \text { Aloes (Barbadoes) - } 9 \text { drachms } \\
& \text { Ginger, - - - } 1 \text { drachm }
\end{aligned}
$$

to be given when the horse has been prepared

$$
\text { G for }
$$


for two days with bran rashes; warm water to drink during its operation, and also warm cloathing. The ball to be repeated in eight days.

As the ulcers in the heels are generally more inveterate in a case of this kind, the following detergent lotion will be necessary, viz.

$$
\begin{gathered}
\text { Nitrous Acid, - }-1 \text { ounce } \\
\text { Water, - - - } 1 \text { pint } \\
\text { Mixed, }
\end{gathered}
$$

to be applied every night. The following poultice ivill also prove beneficial :

Pordered Charcoal and Oatmeal, equal quantities, made into a poultice with cold beer grounds. 


\section{CHAPTER V.}

On LAMENESS.

-

\section{I}

AMENESS, which does not originate from any disease in the hoof, may be divided into three kinds, viz. of the muscles, of the tendons and ligaments, and of the bones. Lameness which has its seat in the bones, arises from adventitious and diseased ossifications in different parts of the extremities, and which are commonly distinguished by the following terms, viz.

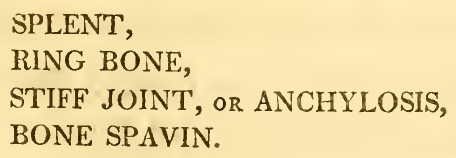

THE splent is one of the most common diseases incident to the fore legs. The proximate G 2 cause 
cause is inflammation in the bone, produced sometinies by concussions of the limb from quick riding upon hard roads; or by blows from the opposite leg during progression, which is called the speedy cut. It is a hard immoveable excrescence, situated on the shank bone, and most frequently on the inside of the leg. Vide plate 8 , fig. 2, letter A.

IT more generally attacks young horses, their bones not having acquired the firmness which belongs to a more advanced age. Splents are supposed not to occasion lameness, unless they arise under a tendon, or near a joint. Lameness, however, will ensue from their existence in any situation. The bone of the leg, in common with all other bones, is surrounded by a firm inelastic membrane, strongly adhering to its surface, and which is called Periosteum.

WHEN the bone is inflamed in any particular part, an increased secretion of bony matter is brought 
brought on in that part, and an enlargement of the bone consequently takes place. In this state, the bone (which, when free from disease, is perfectly insensible) becomes extremely irritable, and the pain which the animal experiences from the concussion of the limb when it alights on the ground, is sufficient to occasion lameness.

THIs sensibility of the bone will continue until the periosteum yields, and adapts itself to the increased substance which is contained within it.

IF the splent is generated under a ligament, or under a tendon, it increases the lameness; for, by displacing the ligament, or the tendon, from their natural situations, it more or less impedes their functions, until they adapt themselves to their new direction. Instances have occurred of an absorption of splents, without any external application; but cases of this kind 
are so rare, that it would not be prudent to trust to so precarious an event. The best mode of treatment consists in repeated blisters applied to the part, and cold water and bandage between the periods of their operation.

\section{THE RING BONE}

Is an ossified enlargement of the lesser pastern bone at a small distance from the coronet of the hoof, sometimes producing a stiff joint. Vide pl. 3, fig. 3, letter c.

THE cartilages of the foot are also sometimes ossified. This last disease occupies nearly the same situation as the ring bone, but is totally different from it. In the ring bone, the joint of the lesser pastern is affected. In the ossificd cartilages, the lameness arises from their having lost their elasticity. 
BLISTERING will suffice for both cases in an incipient state; but if they are of long standing, or very rapid in their progress, firing will be absolutely necessary.

\section{STIFF JOINT, or ANCHYLOSIS,}

Is most commonly the consequence of wounds through the capsular ligament of the joint. When the capsular ligament is perforated by any accidental injury, the synovia or fluid, which is secreted for the purpose of lubricating the heads of the bones in their action with each other, escapes outwards. Great irritation and inflammation attend this state of the wound, probably from the action of the atmospheric air which enters it. If the capsular ligament is not speedily healed, or its divided edges brought into contact with each other, so as to prevent the synovia from continuing to Aow through the orifice, the membranes begin

$$
\text { (6) } 4
$$


to thicken, and bony matter is thrown out from the heads of the bones, which unites them into one solid mass, and the use of the joint is irre. coverably lost.

WounDs of this description require a very different treatment from all others; for relaxants and emollients tend but to increase their bad properties.

As ligaments are not so vascular as nuscles, they are consequently much slower in forming granulations, or, in other words, they do not possess so completely the powers of regeneration. Hence, as soon as it is ascertained that the ligament is perforated, the injured part should be stimulated by an active caustic, such as butter of antimony, or else by the application of the actual cautery to the edges of the wound. The external surface may be dressed with common digestive ointment, and the whole defended as much as possible from the air. 


\section{BONE SPAVIN}

TAKES place on the upper end of the bone of the hind leg, adjoining the lower and inside part of the hough, where it forms a round bony excrescence. Vide plate 8, fig. $6, l$. F.

THE hough is more frequently the seat of lameness, than any other part of the hind leg; and young horses, whose houghs stand obliquely, which is conmonly termed cow-houghed (Vide pl. 4, fig. 1) are particularly subject to this complaint. It is produced generally by some partial exertion in the hough bringing on inflammation and a deposition of bony matter.

The lower part of the joint of the hough is composed of several small bones, which, though they are exactly fitted to each other, and occupy one common cavity, yct possess a distinct separate motion independent of each other.

The 
The utility of this conformation consists in furnishing greater clasticity to the joint than it wo:lld have possessed had this part been composed of one solid mass. When the inflammatory attack commences in this part, osseous matter is thrown out, and an union of these small bones ensues, forming together a hard substance, perceptible not only to the touch, but to the eye. When an union of these bones has taken place, their original individual motion and elasticity will be lost, and the result will be an incurable lameness. The farourable crisis for the removal of this complaint is on its first attack, before the exostosis is formed, for a horse will frequently be lame for a considcrable time before the spavin makes its appearance. But an unaccountable propensity which grooms and farriers have to fix upon either the whirlbone or the stifle, as the scat of lamencss in the hind extremities, induces them to apply the remedy to those parts; and during the time which is wasted in this injudicious process, a 
spavin is formed beyond the possibility of being eradicated. A cure is often attempted by the application of caustics, and even by the mallet and chissel; but as neither of these methods will separate the small bones which have been united into one mass, and thereby restore their former functions, they consequently will be found useless. Frequent blisters should be resorted to on the first attack, and if these do not succeed, the part should be fired without loss of time.

LAMENESS in the ligamentary and tendinous parts consists of

STRAINS of the SHEATH of the TENDONS, RUPTURE of the SUSPENSOR LIGAMENTS of the LEG,

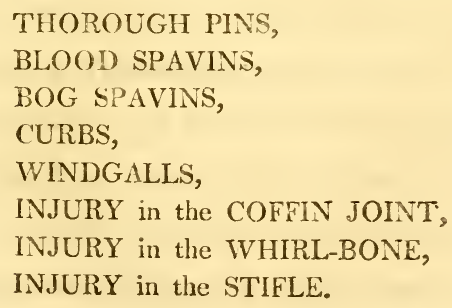




\section{STRAIN of the SHEATH of the TENDONS.}

THIs will probably be better understood by the common term of strain in the back sinews, which generally shews itself on the back part of the leg above the fetlock. Vide plate 8, $f \mathrm{~g}$. 1, l. B.

IT may be brought on by sudden and violent exertion, or by a blow from the toe of the hind foot, which accident often occurs in hunting over heavy land, in which case the fore leg is prevented from extricating itself in time to avoid the toe of the hind leg.

THE injury very rarely exists in the tendon itself, but is more commonly confined to the sheath which surrounds it. Camphorated spirits of wine well rubbed on the part affected, and a moderately tight bandage dipt in cold water, will effect a cure, if applied immediately. 
Bur if the complaint has been of long duration, so as to have become callous, repeated blisters will be necessary.

\section{RUPTURE of the SUSPENSOR LIGAMENTS of the LEG.}

THIs may happen to either the fore or hind leg. It is generally and improperly supposed to constitute a rupture of the tendon or back sinews. When the suspensor ligaments are ruptured, the fetlock joint is incapable of preserving its natural oblique position, on which account it becomes so horizontal as nearly to touch the ground. But as the flexor muscles still possess the power of bending the leg (which they could not do if the tendons were ruptured) it is manifest that the ligaments, whose office it is to maintain the proper position and connexion of the shank and pastern bones, are alone the parts affected. A perfect recovery is seldom obtained, 
obtained, from the impracticability of confining the limb in a manner that would be most favourable to a re-union of the divided parts. A shoe with a high heel, and a bandage round the leg, are the most likely means of promoting a cure. The re-union of the ligament, however, does not restore the original position of the leg, the horse, therefore, decreases much in value.

\section{WINDGALLS}

Present themselves in the form of small puffy swellings above the fetlock joint, and are common to both fore and hind legs. Vide $p l$. 8, fig. 2, l. D.

THEY are constituted by the relaxation of the bursa mucosa, and are produced by hard labour, and, probably in a great measure, by the horse being obliged to stand up hill in the stall of the stable.

BLISTERING, 
BListering, rest, and a level pavement, are the best remedies*.

\section{THOROUGH PIN}

Is a disease of the same nature as the wind. gall. Its situation is in the hough, and may be distinguished by a small round swelling, which yields to the pressure of the finger. Vide $p l .8$, fig. 5, l. I. It is brought on by the same causes as the windgall, and requires the same treatment.

* I have had opportunities of ascertaining the good effects of a level pavement in restoring a horse's legs, in the stables of a Nobleman in Warwickshire, who does me the honour to employ me.

A horse which his Lordship purchased, had all his legs considerably affected with windgalls, which totally disappeared in six months, without the assistance of any external application whatever. 


\section{BLOOD SPAVIN.}

THE disease so called is simply a relaxation of the vein running orer the front of the hough. Vide $p l .8$, fig. $6, l$. G.

IT very rarely occurs, and never produces lameness; but it is commonly mistaken for another complaint, denominated the

\section{BOG SPAVIN,}

Wнгсн consists of an inflammation and distension of the bursa mucosa, or the part surrounding the ligament of the hough. This enlargement occasions a protrusion of the vein which lies immediately upon it, and hence the disease has been crroneously supposed to occupy the vein.

REPEATED blisters are here also necessary. 


\section{THE CURB}

Is manifested by a swelling on the back part of the hough. Vide pl. 8, fig. 5, l. H. It is occasioned by a strain in the annular ligament or sheath of the tendons, the office of which is to keep the tendons in their proper situations.

THIs complaint prevails most among young horses, particularly those which are cowhoughed.

BListers must be employed also in this case.

\section{LAMENESS in the STIFLE}

Seldom occurs, except from external injury, in which case it makes itself apparent by the swelling of the surrounding parts. Cam- 
phorated spirits of wine may be applied once daily until a cure is effected.

\section{LAMENESS in the WHIRL-BONE,}

Or the Articulation of the Thigh Bone with the Pelvis.

In this case the ligaments of the joint are probably principally affected. The whole part, however, is surrounded by such massy and powerful muscles, as to be protected, in a considerable degree, from injury. When the animal is lame in this situation, he drags the leg after him on the toe. Camphorated spirits of wine will be found useful in a recent case; in an old injury, recourse must be had to blisters.

\section{LAMENESS in the COFFIN JOINT.}

Although the seat of this lameness is within the hoof, yet as the ligaments of the joint 
joint are the parts affected, it was thought most proper to class it with ligamentary lameness. From its situation, it is the most dangerous lameness that can befal a horse, and it is very rarely overcome, except the remedy is applied on the commencement of the malady. It is usually to be discovered by the sensation of great heat round the coronet, by the horse not bringing his heel to the ground, and by his standing with his leg advanced before him as much as possible.

THE same propensity which farriers have to ascribe the lameness of the hinder quarters to the whirl-bone and the stifle, prevails also in this case; for except they can feel some enlargement or external mark of injury in the leg, they always fix upon the shoulder as the part. affected.

UNDER that persuasion they apply the res medy to the shoulder, during which time the

disease 
disease becomes incurable; for although the ligaments of the coffin joint might recover by rest, yet the means which the animal himself employs for that purpose, namely, by standing with the lame leg advanced before him, brings on a contraction of the hoof, which, in its consequences, is equally as detrimental as the first complaint. Blisters should be applied to the coronet on the first appcarance of lameness, and repeated as occasion may require.

\section{MUSCULAR LAMENESS}

INCLUDES all disorganization of the muscles of the extremities, whether from external injury, immoderate exertion, or loss of tone from the influence of cold, producing rheumatism or spasm.

THE shoulder is sometimes impeded in its action by muscular lameness, which may arise 
from a blow, or from violent extension of the leg in passing orer a slippery surface. It is distinguished from lameness in any other part by the horse dragging his toe, and describing a circular motion outwards with the leg, which motion is occasioned by the want of action in the pectoral and adductor muscles, on which account the abductor muscles act alone without resistance from the adductors, and draw the leg outwards when the animal is put into motion. Camphorated spirits of wine may be rubbed on the side of the chest and under the arm of the lame leg, daily until a cure is effected.

\section{RHEUMATISM.}

As it is difficult, perhaps impossible, to ascertain the existence of this complaint, it will be unnecessary to treat upon it.

\section{H 3}




\section{SPASM}

Is rarely a partial affection, but generally attacks the whole frame, producing universal rigidity and loss of motion in the muscles. This being connected with internal causes, the cure will depend principally on the administration of sudorifics, viz. emetic tartar, two drachms every night, until the symptoms are removed.

\section{STRINGHALT}

Is caused probably by a convulsive action of the flexor muscles of the hind leg, whereby the leg is raised higher, and bended more in the hough and stifle than is necessary. An attempt to explain its origin would, perhaps, tend neither to its elucidation nor to its removal. 


\section{RECAPITULATION.}

In concluding this chapter it will be proper to state, that a peculiar conformation of the limbs renders a horse more subject to lameness of one kind than another. Thus horses with short pasterns, and whose fore legs incline much under the body, are most liable to bony excrescences, such as splents, ring bones, and ossified cartilages of the foot, all of which, in a great measure, arise from concussion, for a horse whose legs stand far under him, will put them down during progression in a perpendicular direction, whence the concussion will be greater than when the leg is advanced before the body, and alights in an oblique direction. Contracted heels also are generally the fruits of this conformation. Horses with long pasterns are more liable to ligamentary lameness than others; but as the great length of the pastern

$\mathrm{H} 4$ gives 
gives more pliancy and elasticity, they are consequently less exposed to those diseases of the bones which arise from concussion, such as splents, ring bones, \&c.

Horses which are cow-houghed are particularly subject to spavins, curbs, and thorough pins, owing to the malpusition of their legs.

ThE tendency to lameness of every description is greatly aggravated by the acclivity of the stall of the stable, and by working the animal at too early an age. In the mode of treatment recommended in the foregoing cases, it will perhaps be remarked, that the formula do not possess much variety; but in cases where an immediate effect is required, it is certainly best to employ those remedies, the efficacy of which has been established by experience, than to waste time in fruitless experiments with less active 
active materials. Therefore, as lameness arising from disease in the bones, whether it occupies the coronet of the foot, or the hough of the hind leg, may be reduced to the same principles, it follows that the same prescription will be adapted for the attainment of a cure in either case.

FARMERS and breeders of horses ride them from three years of age, until their legs and feet, from premature exertion, are so much injured as to render their soundness doubtful, and this state often comes on before they are six years old. Under these circumstances they are offered for sale, and generally warranted perfectly sound. But although such horses do not manifest lameness in any particular leg, by a want of harmony in their motion, yet their injured state may be detected by their stepping short with their fore legs, and pressing principally on the toe; and upon examining their 
legs when standing still, if the pasterns (particularly long ones) appear perpendicular, and not oblique in their direction, or if the fetlock joint knuckles over, or in other words, bends forwards, little doubt may be entertained of their being unsound. 


\section{CHAPTER VI.}

On WOUNDS.

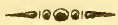

\section{$\mathrm{T}$}

HERE is no part of the modern practice of farriery in which the animal is more injudiciously treated, than in that which relates to wounds, and this appears the more extraordinary, when it is considered that this branch of the diseases of the horse is much more ostensible than those which are internal, and consequently less liable to uncertainty and misconception. But it is here, as it is in every other case where the practitioner acts without possessing the rudiments of his art; for although he has the same remedies within his reach, yet he will rarely succeed in his application of them. Wounds which are incident to horses, are generally unconnected with any specific disease, except in the cases of farcy and glanders, and upon this ground 
ground the mode of treatment must be plain and simple. It appears to have been a primordial provision of nature, to have endowed animals with the faculty of reparation of such parts of their bodies as hare been injured and disorganized by accidental violence. This faculty is more perfect in brutes than in man, and exists in a different degree of perfection in different classes, in some, even to the power of complete regeneration of an amputated part, as in the lizard, the crab, and the polypus. In the practice of surgery, the catalogue of salves, ointments, \&c. has been, of late years, very judiciously curtailed. Practitioners have discovered, that the common pretence of assisting nature, has but too often proved the means of counteracting her endeavours. It is much to be lamented, that the same improvement has not extended to the reterinary art. In all recent injuries, the first process which nature employs is an increased action in the part affected. For, as an injured part is rendered weaker, either by 
a loss of tone or a loss of substance, it is evident that a re-establishment of its original organization cannot be effected without very considerable efforts in the system. Hence inflammation almost always succeeds injury, in proportion, either with the extent of the mischief, or its situation, or the greater or less irritability of the patient. In trifling accidents, the degree of inflammation is so small as to require no attention; but in wounds of greater magnitude, or of parts most essential to life, the inflammation will be more serious, and will demand greater skill in the treatment. As, therefore, inflammation, to a certain degree, is the natural basis of restoration, it remains to point out the proper mode of regulating it, so as to prevent the bad effects either of its excess, or of its want of sufficient activity. In the first of these cases, mortification will be the consequence; in the last, callosity and schirrus, or permanent disorganization. Wounds may be divided into two classes, namely, simple and compound. 
THE simple wound consists of a division of muscular parts, either by laceration or a sharp cutting instrument. The compound wound consists of an affection of more than one part at the same time, viz. muscle, tendon, ligament, and bone. In the simple wound, the first step should be to ascertain the depth of it, and also to discover whether any extraneous substance is lodged within it.

THIs is particularly necessary in cases where horses have been staked in leaping over hedges. If there is no extraneous body within it, and the muscular parts alone are injured, or if any pieces of the stake are discovered, and carefully extracted, nothing more will be required than to bring the divided surfaces of the wound as close together as possible, and to defend it from the air: nature will perform the rest very speedily. If, however, the patient is very fat and plethoric, and has not lost much blood from the wound, bleeding will be necessary. 
THrs is called union by the first intention, that is, without the necessity of matter being formed for that purpose. Here, therefore, it appears that nothing more is necessary than to regulate the inflammation. But the common practice in this case is to keep the surfaces of the wound apart from each other, by introducing a substance between them, such as a candle, or a tent of tow dipped in some strong stimulating mixture; and this is done with a view to the production of good matter. The mischief arising from such treatment must be obvious to every rational mind, for the first process of nature, in this instance, will be an endeavour to get rid of the substance which is thus officiously interposed between the surfaces, and in this attempt the inflammation is carried to an excessive degree, very frequently to mortification. But even if the animal escapes this unfortunate crisis, nature becomes weary in making fruitless efforts, and the surfaces of the wound change their nature, and become callous and inactive, producing a 
diseased abscess incapable of cicatrization. In this state of the wound it is necessary to destroy the callous surface, either by the knife or by caustic, in which processes the animal is put to great pain, and nature generally employs treble the time in performing by this artificial and misapplied treatment, that which she could have effected with case and expedition, if left to her own uninterrupted operations.

\section{THE COMPOUND WOUND}

Requires, in some respects, a different treatment from that of the simple wound. For as the different parts which may be affected by the same injury (for instance, muscle and bone) possess a different action in themselves, it is necessary to assimilate them as much as possible to each other. Thus, when the bone is injured at the bottom of a wound, and inevitably exposed to the air, a certain process called exfoliation, must 
must be carried on before it can be restored to health. This exfoliation is simply the operation whereby the living bone throws off the dead surface; but as bone is much more tedious in its efforts of restoration than muscle, it follows that the muscular parts will unite and heal long before the bone has completed its process. In this case, that part of the bone which is detached becomes an extraneous body, producing new inflammation and a fresh abscess.

THis, therefore, demonstrates the necessity of allowing a sufficient length of time for the bone to exfoliate, by preventing the muscular parts from uniting over it, and in this case (and this only) tents are to be employed.

These may be dipped in common digestive ointment, and the surface of the wound should be kept clean and defended from the air. In matters of this kind, which require skill and experience, the proprietor of a horse would pro- 
bably find it most to his interest to call in professional assistance. As this branch of the veterinary art would require a much more extensive detail than the object of the present work could embrace, and as it would also afford but little information to that class of my readers for whom it was principally intended, it will perhaps be sufficient to have pointed out the common errors attending it, and thereby to shew the necessity of a more rational mode of practice. 


\section{CHAPTER VII. \\ On RESPIRATION.}

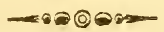

\section{$\mathbf{R}_{\text {ESpiration consists in the inhalation and }}$}

exhalation of atmospheric air into the lungs of man and quadrupeds, or analagous viscera of other animals; part of the air is there absorbed, and another part is exhaled, but is altered in its properties, only part returning in the state of atmospheric air, and the remainder in the state of fixed or carbonic acid air, and of phlogisticated or azotic air, accompanied with a considerable quantity of moisture. It is not necessary here to explain the uses of respiration in the animal œconomy, that having been already done by several eminent physiologists, but to shew the peculiarities of the organs destined to that function in the horse. 
THE posterior part of the mouth or throat of the horse is so constructed as aimost entirely to prevent the return of air through its cavity, or, in other words, precludes expiration. 'Thus, although he can receive air through his mouth, he returns it only through his nose. Hence the horse always manifests great uneasiness when he is held by the nostrils, as under those circumstances he naturally dreads suffocation.

From the posterior part of the roof of the mouth a membrane descends, the extreme edge of which lies on the surface of the tonguc. This membrane is called Velum palati, and one of its uses is to prevent the food and water from returning through the nose in their passage to the stomach. This membrane, in the human being, terminates in a descending point, termed the Uvula; but in the horse it preserves one regular form, on which account the animal has no usula, the whole of the velum reaching down to the root of the tongue, and resting upon it. 
it. Immediately behind the velum palati is situated a cartilaginous substance of a triangular pointed shape, having its base attached to the root of the tongue in the horse, which is denominated the Epiglottis. Its office is to cover the orifice of the trachea or windpipe in the action of deglutition. The epiglottis is constantly elevated by its own elasticity, and never covers the trachea, except at the moment when it is pressed downwarks by the food passing over it.

WHEN it is elevated, it turns back with its upper surface immediately against and behind the velum palati, with which it enters into close contact in such a manner, that it forms a valve, preventing the return of air, or any substance whatever, through the mouth (Vide plate 9, letters $\mathrm{C}$ and $\mathrm{E}$ ). Thus it may always be observed, that the horse, even during the most violent exertions, never opens his mouth for the purpose of breathing, but performs it solely through his nose, 
nose, on which account his nostrils are wider in proportion than in other animals, which, when urged by exercise, or otherwise when requiring more air, open their mouths for its freer admission.

Tне horse has a peculiarity in the formation of his nostrils which descrves notice, each nostril being divided by a septum, on one side of which is the canal which communicates with the throat and lungs, on the other side of the septum is a canal or sac, which may be called the false nostril, which reaches upwards about four or five inches, and is imperforate (Vide plate 9, letter $\mathrm{H})$; but for about two inches of that depth the septum is slit up, and the edges of the slit are fringed with short hairs; the particular use of this conformation has not yet been pointed out, and remains a problem for the physiologists. When the horse inspires, this part is filled with air, which remains stationary until the act of expiration, at which time it 
passes back again in conjunction with that which is retumed from the lings. The inflation of this cavity gives to the animal that animated appearance observable upon various occasions.

IN other respects, the organs of respiration differ but little from those of the human being, except that the diaphragm is much more muscular, and situated more obliquely, by which means the stomach lies below it, although the body is in an horizontal position. This inclination of the diaphragm renders the resistance of the stomach and intestines less powerful than if it were placed in a more perpendicular direction. When the lungs collapse, this diaphragm is slackened, but in the act of inspiration it is tightened so as to force back the contents of the abdomen, by which means the capacity of the chest is enlarged. This is performed partly by its own muscular contraction, and partly by the expansion of the ribs, whereby the lateral I 4 points 
points from whence the diaphragm takes its origin are removed farther from each other.

THis being the natural process of respiration, it will not be difficult to conceive how much it must be impeded when the saddle is girthed extremely tight, or too far back towards the flank; but this inconvenience does not end with the removal of the saddle, for the horse is constantly girthed with a tight surcingle whilst he is in the stable, with a view to keep up his belly. In either of these situations, respiration is carried on principally by the action of the diaphragm, as the intercostal muscles cannot perform their office.

OLd horses are so sensible of this inconvenience, that, during the act of girthing, they swell out their chests as much as possible, by which means the girths become slack when the chest returns to its former dimensions. 
THE horse is nore frequently attacked with inflammation of the lungs than any other quadruped. This may probably arise from the abuses and irregularities which he is obliged to submit to in his domesticated state, for by cloathing and the unnatural temperature of the stable, he is rendered much more susceptible of cold than he would be under other circumstances. When the attack is violent, the inflammation is frequently so great as to produce mortification in a few hours, and even if it is overcome by bleeding and medicine, it generally lays the foundation for a permanent cough or broken wind. This may be brought on by an effusion of water in the chest, or by lymph being thrown out into the cells of the lungs, and possibly by a paralysis of the diaphragm, or by the destruction of part of the lungs in consequence of the inflammation. In any of these cases respiration will be laborious, and the animal will become unfit for violent exertion. However, the most common appearance of the lungs in brokenwinded 
winded horses, is a general thickening of their substance, by which their elasticity is, in a great measure, destroyed, and their weight specifically increased, at the same time that their capacity for receiving air is diminished. During life, the lungs entirely fill the cavity of the chest, so as to leave no space between their outward surface and the inward surface of the ribs; thus they dilate and contract, following up by their own elasticity the action of the ribs and diaphragm. Hence it is probable, that adhesions of the lungs to the ribs are not so injurious to respiration as might be imagined.

If the chest is punctured in the dead subject, the external air rushes in, and the lungs collapse; but if the horse was broken-winded, the lungs do not collapse, which proves that they have lost their elasticity. This state of the lungs sufficiently accounts for the difficulty of respiration, for, as thcir faculty of dilatation is in a great measure destroyed, the ribs cannot expand 
pand without forming a vacuum in the chest, which the pressure of the external atmosphere prevents, and which may be readily perceived in the case of broken wind, for then the intercostal muscles are so strongly retracted, as to form a deep furrow between every rib, as well as a depression in the flanks. On this account, air is received into the lungs with great difficulty, but its expulsion is not so difficult, as the return of the ribs and diaphragm naturally force it out by their pressure. Thus, in broken-winded horses, inspiration is very slow, but expiration is sudden and rapid, as may be seen by the flanks returning with a jerk. If there is water in the chest, the horse never lies down, as the pressure which would take place in that situation, would produce suffocation instantly.

THE foregoing are the general symptoms attendant on broken wind : it remains to inquire into the less violent affections of the lungs. The most frequent of these are manifested by

$$
\text { coughs, }
$$


coughs, which may be divided into the inflammatory and chronic kinds. In the inflammatory cough there is generally some discharge from the lungs, but in the confirmed chronic cough there is seldom any discharge whaterer. As the horse does not expectorate through his mouth, the mucus of the lungs is coughed up into the nose, from whence it is afterwards discharged by the action of snorting or sneezing. Hence, if a horse snorts after he coughs, he is generally supposed to be (although the reason is not known) sound in those viscera. In the human subject, asthma is commonly divided into two kinds, the humoral and the spasmodic. Veterinary practice has not hitherto furnished any proofs, that the horse is subject to asthma of the spasmodic kind; and from what may be collected from the symptoms of broken wind, it is probable that the latter disease in horses is totally different from the asthma in the human being. For the attacks of asthma are usually periodical, whereas the effects of broken wind 
are constant, though not always equal, their violence being increased by excrcise, which naturally demands more frequent and more copious respiration, as well as by some other cause. Dissections of the dead subject afford little or no proof of the nature or existence of nervous complaints, hence it is not possible to ascertain whether a paralysis of the diaphragm may constitute one cause of broken wind. We must therefore recur to such causes as admit of ocular demonstration, and, of these, none are so distinct as the general thickening of the substance of the lungs, just mentioned.

WITH regard to water in the chest, it is frequently problematical, on examination of the dead subject, whether the extravasation took place before or after death.

ANother imperfection which may be included in the class of diseased respiration, is the sound which arises in breathing, with some

horses, 
horses, when their pace is accelerated. A horse of this description is termed a Roarer. From my own observation, I bave not been able to discover whether its source is in the lungs, the trachea, or the nose, though it is probable its seat is in the trachea or larynx. Dealers have a method of ascertaining the existence of the disease by striking the horse under the belly with a whip, and turning him suddenly round at the same time. If he groans during this process, they say it proves that he is a roarer. This is probably occasioned by the sudden contraction of the abdominal muscles forcing air from the lungs through the trachea with greater rapidity, in consequence of the pain he feels from the stroke of the whip, as well as from the bending of the ribs in the action of turning round in a small compass. This disease prevails to a different degree in different subjects; in its commencement it is generally manifested by a whistling noise, but in the confirmed state it is more sonorous, and resembles dcep groaning. 
In either case it has hitherto remained incurable.

The orifice of the trachea is frequently injured by the custom of pinching it with the hand, to discover, by the manner of coughing, whether or not a horse is sound in his wind. A case of this kind occurred during my residence at the veterinary college. A horse was brought to the infirmary which was afflicted with an excessive difficulty of breathing, accompanied with great noise from the nostrils, and a copious discharge of saliva from the mouth. As the horse eat and drank as usual, and in all other respects was in perfect health, it was suspected that the laborious respiration arose from some obstruction about the larynx, or at the entrance into the nasal cavities. In order to give immediate relief, Mr. St. Bel, who was at that time professor, performed the operation of bronchotomy, or, in other words, made an opening into the windpipe about four inches from 
from the lower jaw. Into this opening a leaden tube was introduced, which was kept in its situation by a ligature round the neck. The animal was instantly relieved, and respiration was carried on entirely through this hole in the trachea, - The tube was removed and cleaned every day, and the horse appeared perfectly easy in every respect for nearly thrce weeks, until the ligature happening to get loose in the night, the tube dropped out, and he was suffocated. On dissection, it appeared that the membrane lining the mouth of the windpipe was so thickened, as to have entirely filled up the cavity, and thereby prevented the air from passing and repassing freely.

As free respiration is the basis of health and vigour, so will the contrary produce general debility. Thus, the digestive powers of the stomach being weaker in horses that are broken winded, flatulency is produced, and the air which is gencrated in the intestines makes 
its escape backwards whenever the animal coughs. This circumstance probably gave birth to the ridiculous custom of making an artificial and supplementary anus, with a view of facilitating the egress of the wind, which was erroneously supposed to be the cause of the disease. Broken-winded horses are commonly much better at grass than in the stable. This arises from their being surrounded with a more salubrious atmosphere, and from the green food being more easy of digestion than hay and corn. On this account carrots are given to horses of this description with advantage.

Some horses acquire a habit of biting their manger, accompanied with a convulsive motion of the windpipe; in the language of the stable, they are distinguished by the name of Crib-biters.

During this action, it is supposed that they suck air into the stomach; but several 
reasons may be adduced to prore that this is not the fact.

Horses which are addicted to this habit, generally perform it whilst they are masticating their food.

During the convulsion there is a great loss of saliva, which escapes whilst the mouth is open and fixed upon the edge of the manger. As the saliva is a very essential agent in digestion, it will be reasonable to conclude that the loss of it must be prejudicial to the animal, inasmuch as the digestive powers of the stomach will be insufficient for their proper functions. From this cause, therefore, ensues the flatulence, or collection of wind in the stomach and intestines of horses of this description. Again, that the wind is not drawn into the stomach through the mouth and œsophagus, may be proved by the mechanism of the organs of respiration, which have been described. If the animal sucked 
sucked in air during the action of crib-biting, it must necessarily enter the lungs, as the orifice of the windpipe is always open, except at the moment of deglutition, and air cannot be sucked inwards without a cavity being formed for its reception, as is the case in inspiration. The only way in which air could enter the stomach would be by the action of swallowing; but air could not be swallowed whilst the mouth 'was open. This disease, therefore, seems to consist in a spasmodic affection of the œsophagus and trachea, excited by some sympathy with the muscles of the jaws. But from whatever cause the habit of crib-biting may arise, it is always deemed incurable.

IT is customary, however, to buckle a strap round the upper part of the neck, in order to prevent the movement of the windpipe. A horse subject to this complaint decreases much in va. lue, as he is generally lean and emaciated, and therefore incapable of performing much labour. 
He also wears out his teeth, whereby he is prevented from grazing properly.

IT is a prevailing opinion amongst grooms, that a horse's wind may be affected by giving him too much water, and under this impression they would (if possible) deprive him of it entirely.

IT certainly is not prudent to permit the animal to drink very copiously immediately before he is put into motion, as the increased dimensions of the stomach would confine his powers of respiration. But this furnishes no reason why he should not be allowed a sufficient quantity at proper periods. The food which he takes in the stable is perfectly dry, and very different from what he would eat in a state of nature, consequently he will require more fluids for the purposes of digestion. The grcat consumption of perspirable fluid which the horse experiences during exercise, also renders a proper 
per supply of water absolutely necessary. The imperfect digestion in horses that are thickwinded, produces fermentation and an unnatural heat in the stomach, on which account horses of this description are more eager for water, and that in proportion to the privation of it.

IT is customary to water them twice daily, viz. in the morning and in the evening; the quantity, a pailful at each time. But it would be much more beneficial to give them half a pailful at four times, instead of double that quantity at twice. 



\section{CHAPTER VIII.}

On the Structure and Eiconomy of the STABLE.

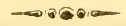

SINCE it has been found necessary to domesticate the horse, in order to appropriate him more immediately to our scrvice, it surely becomes not only incumbent on humanity, but essential to private interest, to employ such modes of treatment as are most likely to contribute to his health and comfort. With this view it should first be considered, that, in this state of subjugation, the animal experiences a total change in his natural habits, not only with regard to his lodging, but also to the quality of his food.

UNDER these circumstances, it will not be surprising that he should be exposed to many

K 4

diseases 
diseases to which, in a state of nature, he would not be subject.

THE extraordinary exertions which are frequently required of him, from cases either of necessity or amuscment, are such as he could not endure, if he were not prepared by daily exercise and the most nourishing diet. But the majority of the world use him as a machine, the powers of which they conceive to be inexhaustiole, and hence arise such shameful abuses of one of the best animals in the brute creation.

NothiNg can be a greater reproach to mankind than the appearance of a post-horse. This miserable and patient creature shews how far our feelings can be blunted by custom. The wretched animal is seldom reduced to the condition of a post-horse, until some bodily imperfection has rendered him unfit for the purposes of parade or amusement. In this situation he is consigned, by his merciless owner, for a pal- 
try consideration, to perform double labour, with the loss of half of his original ability, until at length nature, overcome by continued injuries, sinks under the burthen, and he is converted into food for his late associates the dogs.

THIs termination of misery is accelerated as much by improper management, as it is by ex cessive fatigue. But custom, the tyrant of ordinary minds, has sanctioned numerous rules in the œeconomy of the stable, which a moment's reflection would be sufficient to explode. Great obstacles to a thorough reformation in this respect, will always arise from the obstinacy and ignorance of those to whose care the animal is entrusted. It therefore behoves the proprietor to exert his authority, by enforcing obedience to such maxims as his own better judgment must naturally dictate, and this will be the best effected by visiting the stable at uncertain periods, whereby improper practices will be more liable to detection. 
IN describing the particulars most necessary to be attended to in this important branch of the present subject, it will be expedient to begin with the structure of the stable.

THE principal errors in this department consist, generally, in the want of ventilation, the deficiency of light, the narrowness of the stalls, and the declivity of their parement.

Ventilation is of the greatest importance, inasmuch as the health of the animal is most materially connected with it. The impossibility of excluding air from space (except by exhaustion) is a fortunate circumstance for the horse, as it frustrates, in some degree, the attempts which are constantly practised to prevent its entrance into the stable, even by stopping the key-hole of the door. This custom originates among grooms, from the motive of giving to the animal the same appearance in his coat in winter, as it generally puts on in summer. 
Such a perversion of the laws of nature is productive of certain bad consequences, which the following observations will tend to demonstrate.

For this purpose, it will be first requisite to describe the source from whence animal heat is produced, and maintained in a degree sufficient for the support of life. This source is atmospherical air, and the mode whereby it is applied to the vital organs of animal bodies is by respiration. A certain part of this air combines with the blood in the lungs, and by some chemical action not yet thoroughly understood, furnishes heat to the whole frame. But, as in this climate the heat of the animal is greater than that of the air by which he is surrounded, it follows, from the known laws of heated bodies, that there is a constant emission of heat from the horse, which is absorbed by and warms the cooler air with which he is in contact. Along with the heat, a quantity of moisture constantly escapes from the 
the pores of the skin, which, when the animal is at rest, and not kept too close, is insensible to our organs; but when he is put into violent motion, or kept too hot, it becomes sensible in the form of sweat, or of steams issuing from his skin.

THE sensible perspiration is greatly augmented whenever the air surrounding him is not changed sufficiently quickly to enable it to absorb the moisture as it is perspired*, therefore when the horse goes with the wind, he sweats more than when he goes against it, because, in the first instance, he is constantly surrounded by the vapour which fiies off from the surface of his body, whereas, in the latter case, the wind, meeting him, drives it behind him.

* Hence it is that, in hunting, the best scenting mornings are the most fatiguing to horses, for the same moisture of the air which suffers the scent to lie on the earth, prevents absorption of the sweat from the body of the horse. 
BEASTS of chace appear, either from instinct, or some other cause, to be sensible of this difference, for they almost invariably run with the wind, whereby they, in a great measure, carry their scent with them; they are also, by this means, better enabled to hear the cry of their pursuers. The alternate action of the production of heat by the combination of air with the blood in the lungs and arteries, and the throwing it out from the body by perspiration, is carried on without intermission during health.

From what has been said, it appears that the heat thus produced by the animal is expended upon heating the air which comes in contact with him; whence arises that species of warmth which is generally met with in a close or confined stable, and upon this ground very erroneous conclusions have been formed; for it is generally supposed that this artificial temperature increases the warmth of the animal, and measures are consequently adopted to support it, 
it, by excluding the external air as much as possible. Flannel applied to the skin prevents animal heat from evaporating so quickly as it does when the body is exposed without covering, and thus the surface of the body will be considerably warmer. Yet the warmth doesnot exist in the flannel, but in the body which it covers; for the temperatures of ice, and metals when cold, are not increased by being enveloped in flannel, although heated bodies thereby retain their heat much longer; but these ultimately become cold, unless the original generating cause of heat is continued to be applied. In the same manner, therefore, the heat which flies off from the body of the horse when in a close stable, certainly renders the atmosphere of the stable warmer than that which is without; but this heat will not continue to be generated in a proper degree, unless the lungs are plentifully supplied with fresh air, unpolluted by the breath and perspiration of the animal, and the fumes arising from his excrements. On this account, close 
close stables do not increase the internal heat of the horse, but rather have a tendency to diminish it, by rendering the circulation of the blood languid, for want of a sufficient quantity of the natural stimulus contained in that portion of the atmosphere called oxygen or vital air. The confined vapour also becomes condensed on the walls, racks, and mangers, producing a constant and unhealthy dampness. As the horse, when in the stall, is stationed to one spot, and consequently cannot warm himself by exercise, it therefore is not improper to clothe him moderately; but, at the same time, he should breathe fresh air ; for which purpose nothing is required but an outlet for the foul air, by which a proper circulation of that fluid will be maintained. This may be effected by carrying a tube of six inches diameter from the center of the ceiling through the roof. The next circumstance to be attended to, is the admission of a sufficient portion of light. It is the prevailing custom to have small windows to stables, and frequently 
frequently none whatever. The vigorous and full enjoyment of animal faculties, depends considerably on their being sufficiently exercised; hence the stimulus of light is necessary to strengthen the eye, and to render it capable of perfect vision. But when the animal is shut up in an obscure situation, probably during the greatest part of the day, it must necessarily follow that the function of sight will be proportionably impaired, which is manifest by his winking his eyelids, from being unable to bear a sudden increase of light on being led out of the stable. It is usual to lessen the darkness of stables by whitewashing the walls; but this intention would be better effected by enlarging the windows. The influence of light upon vegetable and animal bodies has been ascertained by experiment, and it appears that, when deprived of it, they are neither so perfect in their colours, nor so vigorous in their constitutions. Birds of the northern regions are not so brilliant in their plumage as those of the south. It is 
also a remarkable fact, that blind horses are seldom so fine and glossy in their coats as other horses. What analogy this last circumstance may bear with the foregoing, I shall not pretend to determine.

NARrow stalls are a source of great inconrenience and danger to the animal when he turns round in them. In the course of my practice, I have met with several cases of diseased spines or back bones from this cause only. Injuries of this nature are generally beyond relief, on which account they point out very forcibly the necessity of prevention.

WHEN the horse is required to turn round in a narrow stall, his own experience of his situation would teach him to move backwards out of it, but the groom prevents him from so doing, by standing close behind him, and urging him, either by a threatening tone of roice or the 
whip, to turn instantaneously in a space considerably shorter than his own body.

Alrhough by exerting the utmost flexibility of his frame, the animal may, perhaps, perform this motion daily without injury, he is nevertheless constantly exposed to an accident which may, in an instant, render him for the future totally unserviceable.

THE width of the stall, therefore, should be at least six feet, the length, nine fect. This will enable the horse to stretch out his limbs when he is lying down, which is a great relief to him when fatigued.

THE manner in which the stall is usually paved, is equally productive of bad effects. The surface is generally formed with a descent from the head of the stall backwards, with a view to 
let the urine run off from the litter*. Thus the horse stands constantly up hill, by which position he naturally becomes so much fatigued, that he may be said to have performed half his work before he is led out of the stable. For the ligaments of his joints, and the flexor muscles of his legs, are thereby perpetually extended. If the reader will stand for a few minutes with his toes higher than his heels, the pain he will feel in the calves of his legs will soon convince him of the truth of this remark. Hence, when the horse is not eating, he always endeavours to find his level, either by standing across the stall, or else as far back as his halter will permit, so that his hind legs may meet the ascent of the other side of the channel.

* This is done with a view to save straw, which in some situations is probably an object of importance; but with farmers it would be an advantage to have level pavements without drains, in which case the urine would be absorbed by the straw, and from the quantity of salts that it contains, would produce better manure, whereas upon the old construction of the pavement it is wasted. 
But the greatest mischiefs which arise from this mode of constructing the pavement, consist in obliging the horse to stand with his fore legs farther under him, and out of a perpendicular direction, by which position he not only acquires a bad habit of leaning formards, but also becomes. liable to a contraction in the licels of his feet, by the weight being thrown principally on the tocs. It moreover promotes an inclination to swelling in the hind legs, as well as being frequently the cause of his body slipping backwards in the stall when lie lies down, so that being at the utmost extent of his halter, he has not the power of rising again on his legs, for want of the free use of his head and neck.

TuE ground surfice of the stall, therefort, should be perfectly level, and paved with hard bricks. A conductor for the urine may be obtained by means of a drain passing from the center backwards under the parement. For this purpose the center of the stall should sink 
somewhat lower than the other parts of it, and the entrance to the drain should be covered with an iron grate, about six inches square.

I $\mathrm{T}$ will be advantageous to construct the manger in such a manner that it may be removed by sliding into the wall, so that when the horse has eaten his corn, he may have nothing to bite at when the groom is cleaning him, from which habit horses sometimes become crib-biters.

THE racks should be composed of cast-iron, as wooden rack staves frequently introduce splinters into the lips during the action of gathering the hay.

THE door of the stable should be at least seven feet in height, which will render the horse less liable to strike his head against the upper part of it in passing through it.

L 3 
As the foregoing are the principal points to be attended to in the structure of the stable, it will be proper, in the next place, to enquire into its aconomy, under which head may be included diet and cleaning. In the customary mode of regulating the diet of the horse, there are many cvident improprieties; but previous to an exposition of this subject, it will be necessary to treat of his organs of digestion.

Although he is a quadruped of the herbiferous tribe, he does not chew the cud, as such an operation would have been very inconvenient to him in performing the offices for which he was intended by nature. His stomach, therefore, is smaller than that of the ox. But to make up the deficiency in the quantity received at one time, he is obliged to eat more frequently; and although his digestion is not so perfect as it is in animals which ruminate, yet it is much more rapid, so that the 
the horse fills his stomach twice as often as the ox.

NATURE has for this purpose furnished his stomach with the faculty of secreting the gastric juice in very large quantities; she has also endowed it with very strong muscles, to enable it to force its contents in a less digested form into the intestines; for, on examining the duodenum, the food will be found to have undergone very little alteration in its appearance, from which it is probable that the stomach of the horse contributes little more towards digestion than combining the gastric juice with its contents, and immediately forcing them into the intestines, which, in this animal are excecdingly large, particularly the cœecum, the strong muscular bands of which render it, probably, an additional seat of digestion.

The cœcum, or blind gut, occupies the lower part of the abdomen, and terminates in a 
point called its appendix. This terminating point is sometimes filled with stones of an extraordinary magnitude. Specimens of this kind have been found of eight inches diameter. They are, probably, concretions of the earthy particles received with the food, which, by their gravity, precipitate during digestion, and take up their abode in the most depending part of the intestines. Whilst they remain stationary, they occasion but little inconvenience to the animal; but if they happen to be shifted towards the mouth of the gut, the consequences are generally fatal.

From the size and direction of the muscles of the stomach of the horse, some anatomists have been induced to attribute to it the action of trituration; but this opinion is easily controverted by taking it in a mechanical point of view, for to be capable of triturating its contents, it appears necessary that it should possess the faculty of re-action, either in a lateral or a rotatory 
tory direction, and both of these are completely prevented by the pressure of the abdominal muscles and other surrounding parts, so that the only action which it possesses, is simply that of compression.

The fibres of the muscles which perform this action, are wrapped round the cardiac or receiving orifice of the stomach in a transverse direction, by which means they act as a sphincter, and effectually close it, so as to prevent regurgitation, or the return of its contents. Vide plate 10, fig. 1---fig. 2 shews the circular muscles of the œsophagus or gullet.

ThIs prevention from vomiting appears to be a necessary ordination; for if the horse regurgitated, the food which returned must pass outwards through his nostrils, as the peculiar formation of the posterior part of his mouth would not permit it to go through that channel. 
ThE horse has no gall bladder*; but to counterbalance this privation, the gall duct is proportionably larger. As the horse has not always the opportunity of eating at his pleasure, like those animals which graze in a state of nature, it frequently occurs, that, after a long fasting he eats so voraciously as to overload his stomach. On this account, it is necessary to regulate the quantity of food to be given to him at one time. But, in stables, where horses stand together without any partition between them, this rule cannot be attended to, for the most greedy horse generally eats his own share and part of his neighbour's, and as greater expedition is required to do this, he of course swallows it without sufficient mastication, in which case it cannot be so easy of digestion. When the stomach is thus praternaturally distended, its functions are greatly impeded, if not totally sus-

* A celebrated Treatise upon Farriery by Mir. Taplin, has passed through eleven editions, with a chapter on the diseases of the gall bladder!!!

pended, 
pended, and from the great sympathy between the stomach and the brain, a degree of apoplexy is produced, terminating in delirium and death. In the language of farriery, this disease is denominated the staggers, and the foregoing is most probably its true source. At the same time a jaundice, or a circulation of the bile through the blood vessels, takes place, and it is possible that this arises also from the pressure of the stomach against the hepatic vessels preventing the bile from flowing into the duodenum. Thus it will be found that the jaundice almost always accompanies the staggers.

WAGGoN, stage, and post-horses are most subject to the staggers, and, on this account, the disease is supposed to be infectious, as it frequently carries off several in the same stable. But as horses of the above description stand together without any partition, it will not be irrational to conclude that the disease arises from the cause before-mentioned. For in every case

where 
where I have had opportunities of examining horses which have died of the staggers, I have uniformly found the stomach distended with a large quantity of dry undigested food. But as it may appear extraordinary that this should occur to many horses in the same stable, it will be necessary to assign some additional data to strengthen this theory. The following are the most prominent: If a carricr, or a proprietor of post-horses, loses a horse in this way, it must follow, that if he is not immediately replaced by another horse, the rest must have their labour proportionably increased. Hence debility follows increased fatigue, the digestion becomes weakened, and the remainder may die successively in the same manner, without any infection whatever. It also frequently happens, that if one horse in a stable dies of the staggers, the same disease is attributed to all the rest which die at the same time, although their deaths might have been occasioned by a very different disorder. Therefore proprietors of waggrons 
gons and stage coaches generally experience the greatest losses when the roads are bad, and the labour much increased.

As the foregoing evils are in a great measure the result of a want of regulation in the diet of the animal, it remains to point out the plan necessary to be pursued in this respect. The common practice is to feed all horses in the same proportion, without regard either to the labour they perform, or to their ages and constitutions. The impropriety of this practice must be sufficiently erident, and it is, without doubt, the basis of many diseases. In regulating the proportions to be given to different horses, much judgment is not required. The following hints may probably suffice. For a saddle or coachhorse, which, on the average, goes about ten miles daily (and there are some thousands which do not perform even so much) half a peck of sound oats, with eighteen pounds of good hay, will be quite sufficient. If the hay is not good, another 
another quarter of a peck of oats may be added. Upon this ratio, therefore, horses which work very hard should have a larger allowance, viz. from one peck to three half pecks of oats, and twenty pounds of hay daily.

The consumption of grain by horses in this kingdom is astonishing, œconomy in this department, therefore, becomes an object of national importance.

They who keep idle horses in a pampered state, would do well to consider how much, in this instance, they sacrifice the comforts of the poor, to the vanity and prejudices of worthless grooms.

THE food most generally made use of consists of hay, clover, oats, beans, and wheaten bran.

BARLEY 
BARLEY and buck-wheat are sometimes given. Barley is undoubtedly a wholesome food for horses, but it is seldom employed as such, except it has been damaged by the weather, and rendered unfit for malting. In this state, its wholesomeness becomes very questionable. Grain of every description may be much easier and more perfectly digested by being first bruised in a mill. Cut straw helps to fill the stomach; much nutriment, however, is not to be expected from it; but it has the good effect of obliging the horse to chew his corn better before he can swallow it. In the spring of the year, vetches and young clover are given to horses whose employments prevent them from being turned to grass; but these should be used very moderately, as fatal consequences sometimes arise from their fermentation in the stomach, and the rarefaction of the air contained in them. Carrots constitute a very grateful and nutritious diet, and are particularly beneficial to thick-winded horses. 
WITH regard to water, horses generally pre. fer that which is soft, and even thick and muddy. Soti water should therefore always be given to them, if possible. The quantity should be proportioned to the labour which the animal undergoes, for if he sweats much, he will consequently require more to repair the consumption of the fluids of his body. It is customary in hunting stables to warm the water before the horse drinks it; this is a very bad practice, as it renders him liable to be griped whenever he drinks it in any other state. It certainly is not prudent to give much cold water to a horse when he is heated by exercise, but other periods may be found when he may drink it with safety. Grooms have a foolish habit of galloping horses immediately after drinking, with the intention of warming the water in their stomachs. By these unnecessary precautions, it would appear that cold water was both umnatural and prejudicial to the animal; but it can only become so from his being rendered irritable and 
tender by the absurd modes with which he is treated in his domesticated state. In addition to these remarks, it will not be irrelevant to say something on the manner in which hunters and racers are generally trained for their respective employments. This is termed getting them into condition.

THE means resorted to for this purpose are purging and exercise, both of which, when regulated with judgment, are certainly proper preparatives; but as horses differ much in their constitutions, it must be obvious that the same mode of treatment cannot be adapted for all indiscriminately; and a want of attention to this circumstance is the cause why it does not always succeed.

WhENEVER the validity of long established. maxims is questioned, the supporters of those maxims constantly urge their experience in their 
defence of them; but men who have pursued but one path, cannot be said to possess an extensive experience. Their knowledge of a subject will be confined in proportion with the narrow scale of their experiments. Hence many fallacious processes are persisted in, merely because the partics have neither the inclination to change them, nor the perseverance to give new ones a fair trial.

THE object in training hunters and racers, appears to consist in an attempt to increase their powers of respiration, and to enable them to support violent exertion for a long duration. The first proceeding, therefore, is to divest them of all superfluous animal matter. This might be accomplished by exercise only; but as a more expeditious mode is sometimes required, purges are administered, which increase the absorption of the fluids, and carry them off by the intestines. 
WHEN the horse has been thoroughly purged, and recovered fiom the debility which generally ensues (for the doses are so strong, that it is no uncommon event for a horse to die under their operation) his exercise commences, or, in the language of the turf, he takes his sweats.

By this means his respiration is improved, and his muscular powers are increased. But the exercise which he receives out of doors is not deemed sufficient for this purpose, he is therefore cloathed from head to foot with a hood and two or three cloths, and the stable, at the same time, is kept as hot as possible by every attempt to exclude the external air. Notwithstanding this process reduces the weight of the horse, yet the debility which it must inevitably create, counterbalances, in a great meature, the advantages which are supposed to be derived from it. When the sweating which is excited by galloping is carried to an extreme, 
the muscles are so much exliausted of their interstitial fat and fluids, as to become extremely rigid, and, in some measure, inelastic, in which state the animal does not acquire a perfect use of them until the circulation of the blood has been increased by motion. This, therefore, shews that a horse may be galloped oft his speed, or, in other words, become slower in his pace the longer he is trained. It is usual to put race-horses on the muzzle for several hours before they run a race, to prerent them from filling their stomachs. It would certainly be improper to start a horse with a full belly; but, on the other hand, great debility must be produced from obliging him to fast for an unreasonable length of time. The same plan is pursued with hunters on the hunting days, particularly with regard to the allowance of water. But when it is recollected that a hunter sets out in the morning with nearly an empty stomach, and is frequently ridden for seven or eight hours without baiting, it cannot be rational to 
suppose that he can be so capable of going through excessive fatigue, as if he had previously received a quantity of food sufficient for the demands of nature,

Whatever food and water a hunter might take on the hunting morning (provided he was fed early) would undergo the digestive process, and be so disposed of by the time he reached the cover, as to occasion no inconvenience whatever. Thus, when the animal has been obliged to fast for an unreasonable length of time, and has also undergone excessive fatigue, the stomach loses its tone, and the appetite does not return until the following morning. As a remedy for this inconvenience, grooms give cordial balls, so that in process of time, the horse experiences the same effects which take place in mankind when accustomed to drink drams, and becomes, in a great measure, unserviceable, if he does not receive this artificial stimulus. 
NEXT to proper feeding, good cleaning is of the utmost importance. The method of performing this part of the duties of the stable is so familiar to every one, that it will not be necessary to describe it.

Ir should, however, be remembered, that as the horse sheds his coat in the spring and autumn, it is not proper to use a curry-comb at those periods, for fear of forcing off the hair too rapidly, and exposing him to catch cold. Hand-rubbing the legs is a very beneficial practice. Horses, after hard riding, are apt to break out again into a sweat in the stable, after they have been thoroughly cleaned and dried. This happens principally in hot stables, for the vessels of the skin having been greatly distended and relaxed in the act of throwing out the per- spirable matter, do not again readily recover their tone and contractile power, on this account the heat of the stable is alone sufficient to bring on a fresh perspiration. Horses, therefore, after 
hard exercise, should be cleaned and dressed in a moderately cool situation. Cleanliness in the litter and pavement of the stall, is also conducive to the health of the animal. The dung, if suffered to remain in one spot for any length of time, generates rolatile alkali in such a degree as to produce great irritation both on the eyes and lungs. Neither hay nor corn should be kept in the stable, nor in any situation within reach of its effluvia. The racks and mangers should be frequently scraped and washed.

Tre padding of the saddles should be exposed to the sun, or the heat of the fire, after being used. Bits should be kept clean, and wiped well before they are put into the horse's mouth, as he has a natural aversion to any thing greasy.

INNKEEPERS and coach-masters wou!d find it their interest to prevent the abominable custom of washing horses over their whole bodies with M 4 cold 
cold water immediately after having gone a stage. That they survive it, is no proof of its utility, but only serves to show the power which nature has of resisting the effects of any treatment which is hostile to her œconomy. If the animal was put into motion immediately after this operation, it might be less prejudicial; but when he is tied up in a stable in that state for two or three hours, and left to dry by evaporation only, it cannot be difficult to perceive the impropriety and danger of such a practice. The legs of horses of all descriptions should never be washed without being afterwards rubbed dry. The feet should be picked very clean after exercise, and, if hard and dry, should be stopped with clay, or any other substance which will retain moisture. During the day time, if the horse does not work hard, the litter should be removed entirely from under him, so that he may stand on the bare parement, which method is very beneficial to his legs and feet. It is common to lay a little straw in the stall, under 
the horse's belly, upon entering the stable, to induce him to stale; but this is not a good practice, for the animal functions become so much controlled by this association of two different actions, as to be incapable of performing their office without such an artificial stimulus. Whistling alone is sufficient for this purpose.

In this place it will not be improper to point out the bad consequences of forcing a horse to travel, for a great length of time, without permitting him to void his urine, for by being thus obliged to retain it, the sphincter of the neck of the bladder acquires the habit of contracting so strongly, as to become insensible to the natural stimulus of the accumulation of the fluid contained within it. From this cause, there are but few old horses which are not afflicted, more or less, with strangury. 



\section{CHAPTER IX.}

On the AGE of the HORSE.

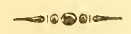

QUADRUPEDS generally furnish some visible mark, whereby their age may be ascertained with tolerable certainty. Thus, the ox acquires aunually an additional ring on his horns; the buck, an additional branch to the palm.

In the horse it is manifested by an alteration in the appearance of the teeth, and certain parts of the mouth. The horse possesses forty teeth, viz. twelve front teeth, or incisores, or nippers, twenty-four molares or grinders, and four canine teeth, which are called tushes; these last are wanting in the mare, except in some very few instances. Until five years old, the age of the horse is ascertained by the successive shedding 
shedding of the twelve front teeth or incisores, which process begins at two years and a half old, and is carried on in the following order, namely, from two years and a half until three, he sheds the two middle teeth of the lower jaw, and also of the upper jaw*. Vide pl.12, fig. B. From three years and a half until four, he sheds the two next in both jaws. Vide fig. C. From four and a half until five, he sheds the two corner teeth of both jaws; and, at the same time, the canine teeth or tushes make their appearance. Vide fig. D. He is then no longer called a colt. At the upper surface or top of every tooth, there is a small black cavity resembling the eye of a bean. This cavity in the teeth of the lower jaw furnishes the age from five years until seven; after which period it is usual to pronounce the horse to be aged, and

* As the colt cannot bite the grass perfectly when he has shed the two middle teeth, it will be beneficial to feed him with mashes of bran, and hay, until the new teeth are of a sufficient size. 
deprived of any signs whereby his age can be ascertained. Nevertheless, the age may be calculated until twelve years by the same marks in the upper jaw, which remain after those in the lower jaw are worn out. This will be explained in its proper place. At five years old, the black marks or cavities in the two middle teeth of the lower jaw are filled up, and nearly disappear; for as they are shed the first, so do they lose their marks before any of the rest. Vide fig. E. At six years old, the black marks of the two second teeth are filled up in the same manner as the foregoing. Vide fig. F. At seven years old until eight, the marks of the corner teeth of the lower jaw fill up and disappear. At the same time the tushes, which antecedently to this period were concave in the surface next to the tongue, alter their shape, and become round or convex. The marks of the lower teeth being all obliterated at eight years old, it will be necessary to have recourse to the upper teeth, which undergo the same process 
process as the lower teeth, except with this difference, namely, that they do not begin to fill up until all the lower teeth are deprived of their marks, and that there is an interval of two years between every tooth in the upper jaw, whereas in the lower jaw the interval is only one year. Thus, at eight the cavities of the two middle teeth of the upper jaw begin to fill up. Vide fig. G. At ten, the cavities of the two next. Fig. H. And at twelve, the cavities of the corner teeth are totally effaced. Fig. I. This rule, however, is subject to some variation in different horses, in proportion with the different qualities of their teeth, or on account of the habit of crib-biting, which wears away the teeth much faster than in their natural course. In addition to these appearances of the teeth, other signs of advanced age nuay be discovered, among which the following are the most remarkable: The roof of the mouth or palate is constructed with transverse ridges from one side to the other. Vide fig. G, H, I. These ridges 
are distant from each other about three quarters of an inch; their edges incline upwards, by which means they serve as points of contact for the food, and prevent it from falling out of the mouth during mastication.

IN the ox these ridges are papillous, the points taking a direction upwards, in which manner they correspond with the direction of those in the tongue.

THE insides of the checks of the ox are also furnished with papillæe of a pyramidal form, pointing upwards towards the throat, the office of which is probably to hold the cud in its proper situation while the animal chews it.

These ridges are large and distinct in a young horse, but become flatter and more level as the animal advances in years, and in very old horses they are nearly absorbed. The front teeth or incisores of both jaws, in a young horse, 
meet exactly in a line, and perpendicularly to each other. Vide fig. $\mathrm{K}$. As the horse grows older, these teeth take a more horizontal direction, nearly in a line with the jaws, the upper teeth projecting very considerably over the lower teeth; at the same time the upper corner tooth forms a curve over the lower corner tooth. Vide fig. L. Furrows appear on their front surfaces, and their colour becomes yellow and opaque. Other characteristics of age may be seen externally, for instance, the eyes sink in their orbits, the eye-lids become lean and wrinkled, and the cavity above the eye* appears more hollow. Grey hairs shoot out upon the forehead and the lower part of the mouth, the middle of the nose becomes indented by the long-continued pressure of the nose-band of the head-collar, and the lips exhibit a lean and shrivelled appearance, the lower lip hanging considerably below the upper

* This cavity, howerer, is sometimes deep in a young horse. 
lip. The ears also drop more or less in a lateral direction. These external marks of old age, together with those of the teeth, the dealer in horses excrts his ingenuity to counteract.

He therefore commences his operations by making an opening between the skin and cellular membrane, at a small distance above the eye, into which he introduces a quill, and by blowing into it, fills up the cavity and gives it a plump appcarance. He proceeds next to furnish the corner teeth with the same marks which they possessed at seven years old. For this purpose he forms an artificial cavity in the head of the tooth with an engraving tool, and gives it a black colour by burning it with a hot iron. This process in the stable vocabulary, is called Bishopping. By such practices as these, an inexperienced person may be deceived; but by attending to the following observations, the imposition may be easily detected; for although the dealer has it in his power to make marks or 
cavities in the corner teeth, yet he cannot alter their horizontal direction, nor restore them to the perpendicular approximation which is the attendant of youth. Vide $f_{g}$. K. Neither can he re-produce the prominence of the ridges of the roof of the mouth, nor furnish the tushes with their original concave surfaces. As it suits the purpose of the dealer to make an old horse appear younger, so does he sometimes find it convenient to make a young horse appear older. A horse is more saleable at fire years old than at four, on which account the dealer attempts to produce an additional year, by drawing the corner teeth before the natural period of their dropping out. The bars of the mouth are also cut to let the tushes protrude prematurely. But although the corner teeth are removed, and the protrusion of the new tecth is thereby somewhat accelerated, yet it is an unerring rule, that the animal has not attained his fifth year until the comer tecth, both of the upper and lower jaw, are complete in their size and appearance, and the 
the marks of the middle teeth begin to fill up. The tushes also should rise considerably above the jaw.

IT is difficult to discover with accuracy the age of crib-biters and horses whose teeth are extremely hard; the former lose the marks of their teeth before their usual period, the latter retain them long after the age of seven years. In examining a horse's mouth, it is necessary to look at both sides of it, as a considerable difference in the appearance frequently occurs from the mastication of the food being performed on one side of the mouth only, in which case the teeth on that side of the jaw which has most friction, will be most forward in their alteration. 



\section{CHAPTER $X$.}

On the EDUCATION of the HORSE.

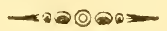

$V_{1 R}$

IRGIL, in his Georgics, thus poetically gives his advice upon this subject:

" Tu quos ad studium atque usum formabis agrestem, " Jam vitulos hortare, viamque insiste domandi :

" Dum faciles animi juvenum, dum mobilis ætas."

But previous to laying down any rules upon this head, it will be necessary to enquire into the degree of understanding possessed by the horse, which, with that of other brutes, has generally been called instinct. Natural historians have attempted to explain this faculty; but many of them (particularly the French) have indulged in such reveries, as to render their works unworthy of attention or belief.

N 3

REASON 
182 ON THE EDUCATION OF THE HORSE.

REASON may be said to consist in the faculty of associating ideas, and forming conclusions, independently of corporeal action, relative situation, or the presence of the objects reasoned upon. But instinct seems to be confined to the faculty of discriminating between noxious and innoxious food, the aroiding danger cither by flight or resistance, and to the performing certain necessary functions, which, it is supposed, the animal has not been taught by others. Instinct may be improved by age and experience; but it will never render a brute capable of thinking abstractedly, or without the concurrence of certain signals or appearances which he has been accustomed to associate with particular actions*.

* The most extraordinary faculty in brutes, is that of finding their way back again, when they hare been remored to a considerable distance from their homes.

This lias been attempted to be explained by the supposition of their recollecting the appearance of objects on the road, or the different scent of the earths orcr which they have passed. But as bot'l of these must present themselves in an inverted order of succession on their return, it is difficult to conceive that their understanding can be equal to the task of such a counter-arrangement.

Thus 
ON THE EDUCATION OF THE HORSE. 183

Thus we find in most animals, even of the ferocious tribe, an apparent attachment to their feeders; but it is probable that this attachment is less the effect of gratitude, than the result of simple recollection of the source from whence they satisfy one of the most urgent calls of nature. Hence the horse can distinguish the voice of the person who feeds him from any other, and will express his satisfaction by neighing; but may not this testimony of joy arise solely from the expectation of receiving his accustomed allowance of corn ? For by constantly feeding him immediately after performing certain actions, he will acquire the habit of repeating those actions when demanded of him at other periods. This practice ought to constitute the basis of horse-breaking; but how seldom it is adopted, may be daily scen throughout the country. The parties who pursue this branch of business, are too often of a ferocious disposition; added to which, an habitual state of intoxication tends not a little to heighten their

$$
\text { N4. }
$$
natural. 
181 ON THE EDUCATION OF THE HORSE.

natural cruelty. The horse is, by nature, neither vicious nor untractable; the chief source of his opposition arises from fcar. On this account, it is not surprising that he should resist, at first, the attempts made to subjugate him. But if, by gentle usage, he is convinced that no injury is intended hin, he submits, still preserving his natural vivacity, and bccomes the pleasant instrument of most of our comforts and luxuries. Unfortunately, however, violence and privation of rest and food, are generally substituted for the means here recommended. The colt which is naturally dull and sluggish endures this treatment, and surrenders himself to the will of his merciless rider; but the colt of mettle and spirit defends himself with all his powers, and worked up to desperation, is transformed from a generous to a mischievous and dangerous animal.

As a proof of the force of habit on the horse, we may select the custom of whistling 
ON THE EDUCATION OF THE HORSE. 185 to him while he is staling, or evacuating his urine. The sound of whistling possesses in itself originally no particular stimulus on the urinary passages; but by whistling to a colt when staling, and repeating it constantly upon that occasion, such an associated action will in time be produced on those parts, as to bring on the propensity to discharge his urine whenever he hears the whistle. If so great a controul on a function naturally spontaneous can be obtained by habit, it is evident that the same principle will apply to the animal in the more essential parts of his education. Thus, by firing a pistol in the stable, and fecding the horse instantly afterwards, and repeating this practice for a short time, that which was originally the cause of terror, will ultimately become the signal of gratification.

ANAlogous to this is the method by which they are taught to perform certain tricks with great dexterity. Admitting this plan of in- 
186 ON THE EDUCATION OF THE HORSE.

struction to be the best, it is obvious that it cannot be commenced at too early an age. Hence it is adviseable to accustom colts to the halter at thrce months old, to handle and caress them, to lift up their legs with the hand, to strike the feet gently with a hammer, and to place bags stuffed with straw across their backs. By pursuing this method, a colt may be broken in, at a proper age, with very little trouble or danger.

IN bringing young horses into service, it is necessary to consider their age, size, and constitution. Small horses are generally fit for labour at an earlier age than large ones, because they sooner acquire the extent of their natural growth, and have their corporeal powers more concentrated. A large raw-boned colt, with his legs badly formed, can never support much fatigue, because he has not only the mechanical - disadvantage of the malposition of his legs operating against him, but also the bulk of lis body being 
ON THE EDUCATION OE THE HORSE. 187 being disproportioned to his muscular strength, must render his exertions more feeble, and less capable of long duration; an irritable habit of body will also prove a great impediment. Colts of the blood kind acquire strength comparatively at a much earlier age, since it is customáry to begin to race them at two years old; but their future growth is considerably impeded by the violent treatment which they undergo in training. On this account they seldom arrive to a large size. But this circumstance should be no cause of discouraging the breed of blood horses, for in their natural properties they are much superior to all others. This superiority is not confined to internal or invisible causes only; much of it arises from the external conformation of the body. The mechanical advantages which they derive from this source, consist in the great length of their quarters, and the depth and capacity of their chests; for in their relative proportion with 
183 ON THE EDUCATION OF THE HORSE.

horses of an ordinary species, they are mucl stronger, and possessed of greater speed.

THE most ostensible characteristic of the blood horse is compactness of fibre. This may be traced in every part, namely, skin, muscle, tendon, ligament, bone, and hoof. It is this property which increases his strength without adding to his bulk. Other parts, such as the brain, heart*, and blood vessels, are remarkable. The texture of his skin is finer, the hair softer, and the legs smooth and not tufted.

THE capacity of the cranium or skull, which contains the brain, is proportionably larger than that of the cart horse; even the features of the face, viz, ears, eyes, and nostrils, are on a bolder scale. Vide plate 11, fig. 2.

* The heart of Eclipse weighed fourteen pounds. 
ON THE EDUCATION OF THE HORSE. 189

His principal excellence, however, arises from his powers of continuance, or of supporting fatiguc.

These powers in the horses of Arabia (if we may give credit to the assertions of travellers) are wonderful, and the more so when we reflect on the great heat of that climate. The true Arabian horse of the first race, may be considered as the most perfect model of the species.

THE blood horses of Great Britain are originally descendants from this stock, but not from the most noble sort. The natives of the eastern countries are very tenacious of their best breeds, and the Arabian horses which have been imported into England, have been generally purchased by seafaring men, who were probably no great connoisseurs in horse-flesh, and whom the natives would consequently endeavour 
190 ON THE EDUCATION OF THE HORSE.

to impose upon by selling to them those of an ordinary kind. In the genealogies of their horses they are even more particular than we are in this country, and it is remarkable that they never suffer a mare to be exported.

As the present is the age for improvements in the breed of cattle, it may be an object worthy of consideration to improve also the breed of horses, by sending a person properly qualified to the East to purchase horses for that purpose; this might be done either by a society of gentlemen, or at the expence of government*.

* In regard to breeding from the natural stock of this country (Great Britain) it is a question worthy of the attention of the physiologist, whether we should not sometimes have a better produce from the promiscuous intercourse of animals, than from the studied selections of breeders, especially when it may be supposed that, among the great proportion of castrated males, some might, if they had been left perfect, be in every respect better adapted to breed from, than those which are appropriated, from necessity, to that purpose? The method which is generally adopted to improve the breed of any particular species, is by crossing them with those of a better kind; 
ON THE EDUCATION OF THE HORSE. 191 but if the ratio of improvement can be reduced to mathematical calculation, it is evident that the offspring from such an union, although it may be superior to the worst of the two parents, yet it will be inferior to the best, if, as we are taught to believe, it partakes of the qualities of them both.

Thus the produce from a blood horse and a cart mare, will be a heterogeneous monster, inferior to either of its progenitors; and the same result will ensue from all crosses which are very remote from each other in their individual properties. It would seem therefore that the best way of improving the breed, would be to select the likeliest individuals of the same blood, and to propagate from them only. 



\section{CHAPTER XI.}

On PROGRESSION.

THE successive alternation of the limbs in the motion of quadrupeds is so transitory, as to render it very difficult to discern, at the same view, their action separately and collectively. The horse may be considered as a machine supported by four perpendicular columns, each of which has its own center of gravity; but during progression, each of these columns must shift its center, and obtain a new basis successively. In order to effect this, the alternate actions of flexion and extension of the limbs are carried on by means of joints acted upon by muscles in different directions. 
Trus the paces of the animal consist of at repetition of compound circular movements of the legs upon transferable centers. The horse naturally employs three paces, namely, the walk, the trot, and the gallop. All other paces are generally artificial, and forced upon him by education.

\section{THE WALK.}

BORELLI, in his ingenious treatise "de motu animalium," says that the horse commences this pace with one of his hind legs first ; "incipit gressus pede postico;" and he attempts to prove the necessity of this law, by observing that the body would lose its stability, if the hind leg was not advanced under it, in order to acquire a new center of gravity previous to its progressive motion. This rule, however, is by no means constant, as appcars by ocular demonstration, 
THE walk consists of four motions, which may be particularized as follows, by the legs $\mathbf{A}$, B, C, D. Vide pl. 13, fig. 1, 2.

In fig. 1, the horse has advanced the near* fore leg (A) and placed it again on the ground; this action being completed, the off hind leg (C) is elevated and advanced under the body, but before it reaches the ground, the off fore $\operatorname{leg}(B)$ is raised and advanced, in order to make room for it, as is particularly the case when the horse oversteps the print of the fore foot with his hind foot. When the off hind leg (C) has reached the ground (vide fig. 2) the horse stands upon three legs, forming a triangle $(\mathrm{A}, \mathrm{C}, \mathrm{D})$. When the off fore leg (B) alights on the ground, the near hind leg (D) commences its action, and is advanced in the same manner as before,

* The near legs are those on the same side on which the rider mounts. 
and the horse is again supported by three legs $(A, B, C)$.

Thus the animal, during the walk, is always supported by a triangular position of three legs, namely, two fore legs and one hind leg, or one fore leg and two hind legs, alternately.

THE walk is, of all paces, the easiest to the rider, provided he sits on the center of the horse's back, as it consists of an alternate depression of the fore and hind quarters; for instance, when either of the fore legs is advanced, the fore quarters must sink; but when the leg, by the advancement of the body, reassumes its perpendicular position, the fore quarters will recover their former altitude. The same action takes place in the hinder quarters. This motion may be compared to the ribration of the beam of a pair of scales. The walk should be light, firm, and quick. The knee should be bent moderately, 
derately, and the leg appear to be suspended in the air for an instant*; the foot also should alight perfectly flat on the ground. But to be capable of a free unembarrassed walk, it is necessary that the horse should be well shaped in his fore quarters and legs; for a quadruped that is not firm on his center of gravity when he is standing still, can never be firm during progression. It will therefore be expedient to recapitulate some remarks on the external conformation contained in the former part of this work, viz. that the shoulder should be oblique, and the fore legs stand perfectly straight from the chest to the ground. If the fore legs are short in comparison with the hind legs, or if they incline too much under the body, the horse will step short, and on his toe. If the chest is narrow, and the toes turn outwards, the

* This temporary suspension of the ley in the air during the walk is a tolerably certain sign that the horse is sound; for an unsound horse is unabe to sustain his weight on one leg only, long enough to sccomplish it.

$$
\text { O \& }
$$


legs will strike each other during their motion, particularly when going upon rough uneren surfaces. If the toe turns inwards, and the chest is too wide, the horse will tread principally on the outward quarter of the foot, and consequently will be more unsteady than if he pressed equally upon every part. The neck should be handsomely united with the shoulders, and the head should be carried with a light and elevated air.

IN conjunction with this disposition of the fore quarters, it is necessary that the hind quarters should be well constructed, and in a proper position, namely, that the leg from the hough to the ground should be straight, and in a perpendicular line under the articulation of the thigh bone with the pelvis, commonly called the round bone. If the hind legs are placed too far behind the croupe, they cannot advance sufficiently under the body when in action, whence three fourths of the weight of the body 
will be thrown on the fore legs, by which their action must incvitably be impeded. If a horse walks well, he generally excels in every other pace*.

IT is difficult, however, to confine young: mettlesome horses to a walk, and it requires great temper and perseverance, together with a light firm hand, to accomplish it. Whenever thie horse changes to a trot, he should be stopped immediately for a moment or two, and then suffered to proceed again.

But this should not be done by roughly. checking him with the bridle, or chastising him either with whip or spur, as such practices only render him more impatient and unsteady. If the horse naturally carries his head well, it is best to ride him with a moderately loose rein,

* The word excels, is not meant to signify superior speed; it is intended to be applied only to the property of a true and harmonious manner of going.
O 4
raising 
raising the hand when he feels likely to change into a trot. A tight rein should always be avoided, for if he carries his head low, it tends to deaden his mouth, and to teach him a bad habit of depending on the bridle for support, in which case he always gocs heavily and on his shoulders. It is probably of some advantage to use the words walk, trot, gallop, when you wish your horse to enter upon any one of these paces.

\section{THE TROT.}

IN the walk, the horse moves all his legs separately and in regular succession; but when he is excited to accelerate his pace, he moves two at once, viz. a fore and a hind leg diagonally, by which means he passes over as much ground with two motions in the trot, as he does in the walk with four. 
But as in the trot he is supported by two legs only, he is more liable to fall in that pace than in either the walk or the canter, in both of which he has always three legs on the ground at the same period. The trot, particularly in the circle, is well adapted to give freedom and elasticity of motion to a young horse, and to confirm him in his center of gravity. In performing this lesson, the outside legs work on a larger circle than those on the inside; he is consequently obliged to advance the outside shoulder as much as possible, to keep pace with the inside shoulder, which moves on a smaller extent of ground. The same thing takes place also in the outward hind leg, for the same reason. In working a horse in the circle, it is customary to rein him up tight, so as to restrain his head to one particular position; but this practice tends very much to confine him in his shoulders, and thereby to defeat the intention of the lesson.

THE. 
THE horse should have his head at liberty, which will permit him to advance his shoulders, and to move with greater elasticity. When a horse is forced in the trot beyond his powers, or does not carry himself well on his center, he is apt to confuse it with a canter, viz. to trot with his fore legs, and canter with his hind legs, and vice versa. Whenever this confusion occurs, he should be checked instantly, for this compound motion both reduces his speed and renders him more unsafe in his going. If, from an upright shoulder or bad position of the fore leg, the horse goes heavily before, he will be liable to strike his fore feet with the toes of his hind fect, and produce a disagreeable noise, called Forging. This fault may be corrected by throwing him more on his haunches, and by attending to a proper mode of shocing. As the fault arises, in a great measure, from the fore foot not being quick cnough in its motion to get out of the way of the hind foot, it is evident that this may be remedied by accelerating that motion, 
motion, and this may be effected by keeping the fore foot as low at the heel as possible, by which means the extension of the flexor muscles of the leg being increased, they will be stimulated to act sooner than they otherwise would do, and the gaining but a moment of time in their action is sufficient for the purpose. At the same time the toes of the hind feet should be shortened as much as possible, and the hoof should project, in a small degree, beyond the shoe, which will prevent the iron from striking the fore foot. Horsemen generally rise in the saddle during the trot, by which method they avoid the concussion they would otherwise experience. But by this custom they certainly interrupt the harmony of the horse's motion, by obliging him to dwell longer on one leg than the other, in doing which he accommodates himself to the motion of his rider. Besides this interruption, it greatly incommodes the animal, if it is not performed very steadily, and perfectly on the center of gravity; and nothing 
can beso ungraceful in appearance, as the figure of a rider swinging his arms and legs backwards and forwards as if they did not belong to his body.

Fig. 1, plate 1t, represents the horse in a moderate trot, in which pace he covers no more ground at each motion than extends from one hind leg to the other. Vide letters D, C.

But in fig. 2, where the trot is accelerated, he not only covers more ground by the greater extension of his leģ, but gains also an additional space by the momentum of his body during the period when all his legs are in the air. Thus the letter $\mathrm{C}$ marks the spot which the near hind foot occupied before it was raised in the air, and the letters $\mathbf{A}, \mathbf{B}$, describe the spots of ground to which the near fore foot and off hind foot will reach when they alight on the carth. This momentum is, in a great measure, lost, when the horse goes in harness, as the vis inertix 
inertix of the carriage is sufficient to counterbalance it.

When a horse, whose fore legs are much shorter than his lind legs, or whose shoulders are very upright, trots fast, he is obliged to go with his hind legs very wide, so that his hind feet may come on the outside of his fore feet. By this means he sinks his croupe, and brings it more on a level with his fore quarters, and at the same time he avoids striking his fore feet with his hind feet. Horses of this conformation sometimes go in the same form as dogs gencrally do, namely, with their fore and hind legs in two different lines of direction, by which one hind foot comes on the outside of the fore foot, and the other hind foot between the two fore feet, and this is done with the same intention as in the former instance. They are, however, very unsafe to ride, for the hind foot is always more or less in danger of catching the fore foot, in which case, except the shoe is torn off, they 
must inevitably fall with great violence. The elongated or darting trot, is computed not to be so speedy as the short quick trot; but it furnishes a proof of great strength and elasticity of muscle, and is more peculiar to blood horses than to those of any other description. The motion, however, is so different from the short contracted pace of common horses, that bad riders are frequently puzzled to accommodate their seats to it.

Horses have been said to possess the ability of trotting eighteen miles within the hour; such horses do not trot, but run, that is to say, move all their legs separately and successively as in the walk; whereas in the trot, a horse moves two at once, viz. a fore leg and a hind leg diagonally. Custom, however, has determined it to be a trot when the horse does not rise into a gallop. It is a law in the animal œeconomy, that parts which are most exercised become the strongest, and that animal bodies will perform particular 
particular motions to which they have been most accustomed with greater facility than others. Thus horses which have been kept solely to trotting, cannot gallop so fast as they can trot, nor for so long a continuance. But the same porvers which enable them to excel in the trot, would also have rendered them fast gallopers, if they had been employed in that action. Hence it is that particular stallions acquire the reputation of getting fast trotters, or high leapers; for as every person who breeds a colt from horses of this description concludes that these qualities must be specifically generated with him, he constantly exercises him in these pursuits, until the muscles which are principally employed acquire a superior strength to the rest of the body, and furnish the animal with the desired quality. 


\section{The CANTER and GALLOP.}

THE canter is not generally a natural pace. When the horse is excited to move his station from one place to another, he performs it with a velocity proportionate to the exciting cause. Thus he changes from the walk to the trot, and from the trot to the gallop, according to his inclination.

IN each of these changes he acquires an addition of speed; but as the trot is equal in speed to the canter, he seldom adopts the canter, but changes to the gallop, when he wishes to accelerate his motion. The horse is taught to perform the canter by shortening the gallop. To accomplish this he should be well formed in his hind quarters, and stand with his haunches well under him, as it is almost impossible to make a horse canter whose hind legs stand far behind 
him, and whose fore legs incline greatly under his body. The concussion is not so great in the canter as in the trot, because the action is divided into four motions. Thus, if the hore leads with the off fore leg B (vide pl. 15, fig. 1) the fect will come to the ground in the following succession, viz. the near hind leg $\mathrm{D}$, off hind leg $\mathrm{C}$, near fore $\operatorname{leg} \mathrm{A}$, and off fore $\operatorname{leg} \mathrm{B}$; but during this alternation, there is a period when three feet are on the ground at the same time, and in the same order as in the walk; for instance, the two hind feet and the near fore foot will be on the ground just prior to the moment when the off fore foot alights, which having taken place, the near hind foot rises from the ground, leaving the other three, viz. two fore feet and the off hind foot, stationary. This could not be represented in the plate, as it would have given the appearance of walking instead of cantering, but upon an attentive observation in the living subject, it will be found to be true. In the canter, the horse moves obliquely, by ad- 
vancing either his right or left shoulder in conformity with the leading leg. Thus, if he leads with the right fore leg, the right hind leg must follow, and be advanced more under the body than the left hind leg. By this position, the feet describe a rhomboidal quadrangle (A B C D) which gives greater stability to the body during progression, than if the animal moved with an equilateral projection of his limbs. If the horse leads with the right fore $\operatorname{leg} B$, and follows with the left hind $\operatorname{leg} \mathrm{D}$, he is said to canter false. This may be casily felt by the rider, as the body of the animal will move in a tortuous, unharmonious manner. Whenever this takes place, he should be stopped immediately, as he incurs the dainger of falling. It is easiest to the rider when the horse leads with the off or right fore leg, because the rider holding the reins in the left hand, generally turns his body somewhat to the same side, which inclination accords also with the oblique direction of the horse's body. To oblige the horse to 
lead with the off fore leg, it will be nccessary to shorten the near or left hand rein, and to press the horse's side with the left leg, and to apply the spur, if necessary. By shortening the left rein, his head and neck will be inclined to the left or near side, which will confine the motion of his near or left shoulder, and force him to advance the off shoulder, at the same time the pressure of the rider's left leg throws off the croupe to the right side, and gives the hind quarters the same direction as the fore quarters. If the horse is required to lead with his near or left leg, the right hand and heel must be employed for that purpose.

\section{THE GALLOP}

Is commonly divided into the hand gallop and the full gallop; but as this distinction applies more to the different degrees of velocity than to any peculiarity in the pace, it will be 
unnecessary to enter into a separate description. In the gallop, the horse leads with one fore leg somewhat adranced beyond the other, but not so much so as in the canter ( fig. 1) and when he is going at his utmost speed, the legs are nearly equal (fig. 2). The fleetest gallopers carry their bodies perfectly horizontal, or, in other words, bear the least rescmblance in their motion to that of a rocking-horse.

For, in the action of progression, it will be found that all bodies will be retarded in their progress in proportion as they depart from a right line, either horizontally or perpendicular* 1y. None but horses of grcat powers are able to gallop in this form, for to supply the want of undulation in the body, they must bend their limbs in a greater degree, and hence the necessity of their standing perfectly on the center of gravity. As the action of the gallop is more cxtended than the canter, it is necessary that the horse should have his head more at liberty, 
for a horse cannot gallop out with his head reined up. Thus, in the swift gallop, he carries his head and neck nearly horizontal. Grooms and jockies teach horses to pull against them in the gallop, and this practice helps to support them when they stand up in the stirrups; but this cannot counterbalance the bad effects of deadening the horse's mouth by the constant pressure of the bit; for when the horse thus bears on the hand, a considerable portion of the power which should be concentrated in his bo$\mathrm{dy}$, for the purpose of maintaining his equilibrium, is directed to his head, and hence he becomes much more liable to fall in case of meeting with any casual obstacle. In proportion with the want of sensibility in the horse's mouth, the rider will have less command of him; this accounts for their bolting out of the course so frequently during a race.

To ascertain the extent of ground which the horse passes over at each stroke, it will be P 3 necessary 
necessary to measure the distance between two succeeding impressions of the hind feet, viz. from $\mathrm{A}$ to $\mathrm{B}$, fig. 2 .

Horses sometimes change the leading leg during the gallop; if they change the hind leg at the same time in unison with the fore leg, it furnishes a proof of great strength and command of their limbs; but if they change the fore leg without the hind leg, they bccome disunited, and should be instantly stopped.

I $\mathrm{r}$ is a great advantage to a horse to be able to change his leading legs in this manner, as he thereby relieves either side of his body alternately. It will be found a good practice to teach him to perform this change by signal from the hand and heel of his rider. The best method to accomplish it, is to gallop him in a serpentine direction, obliging him to change to right or left, in conformity with the line of his direction. A horse should never be stopped suddenly 
suddenly in the gallop, as it endangers his loins and houghs, and often produces an irrecoverable injury. Instances have occurred of the legs being broken by the concussion, and the sudden and violent contraction of the muscles, which take place on such an occasion.

\section{THE PASSAGE.}

THE passage is a term in the manege properly signifying the contracted trot, in which the horse moves with his haunches far advanced under him, and his fore quarters and legs elevated as much as possible. This term is ge nerally and improperly made use of when the horse moves sideways either to the right or left, describing two parallel lines of direction with his fore and hind feet. This pace is more properly denominated, Head or tail to the roall. As the horse acquires the habit of preserving his center of gravity by moving in a right line

$$
\text { P } 4
$$


either forwards or backwards, so will he, by the above method, acquire the faculty of preserving his center when moving in a lateral direction.

THE advantages arising from this pace, consist in enabling the horse to change his line of direction, either to the right or left, with greater facility, whence he will avoid obstacles much more quickly, and will be less liable to fall in crossing ruts or other uneven surfaces, and he will also be more expert at cramp leaps and perplexing situations, in which a different horse would be unable to proceed.

CARRIAGE horses likewise will turn with less trouble and constraint when they have learned this pace. As this motion is perfectly novel and unnatural to a young horse, the gentlest means should be employed in teaching him. It is therefore best to begin it on foot, in the following manner, namely, one person should 
should place himself on the near side of the horse's head, and hold the near or left rein in his left hand, and the off or right rein passing over the neck to the near side in his right hand. Another person should stand opposite the hind quarters on the same side with a whip. The person holding the reins should then gently urge the horse to move, but should prevent him from advancing, by lightly checking him with the bridle, and inclining lis head rather towards the off side, at the same time the person holding the whip should touch him gently on the quarter, which will oblige him to more his hind legs in the same direction. It is necessary, however, to observe, that his shoulders should incline towards the side on which he is going rather more than the hind quarters, by which means he will move in an oblique manner. At first he should not be forced to continue this motion beyond three or four paces at a time, for fear of irritating him, as from not knowing what 
what is required of him, he feels in constant apprchension of falling.

As the horse recovers his center in a straight line of progression, by advancing one leg beyond the other, so will he recover his center in a lateral progression, by crossing one leg beyond the other. Thus, if the horse moves sideways to the right, he crosses over his left fore and hind legs beyond the right fore and hind legs at the same period, and thereby recovers his perpendicular position. In going tothe left he crosses with his right legs. But he would be unable to cross his legs if his body moved perfectly laterally, he is therefore obliged to advance one shoulder beyond the other by moving obliquely.

WHEN the horse has been accustomed to this pace for some time, it will be necessary that he should be taught to perform it with a rider on his back. For which purpose, if he is required 
quired to go to the right, the rider should gently shorten the right hand rein, and cross his lett hand with the left rein over the withers to the right side, at the same time gently pressing the horse's flank with his left lcg, he will oblige his croupe or hind quarters to move in a parallel direction with the fore quarters. The reverse of this is to be observed in going to the left. This pace forms the basis of all military movements in the cavalry, and must ever give a swordsman a most decided superiority over another whose horse possesses not the same qualifications, for, by the smallest signal from hand and heel, he can either approach or avoid his adversary, as occasion may require. 



\section{CONCLUSION.}

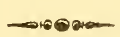

No amusement can be more instructive, of more acceptable to men of rank and fortune, than the cultivation of natural history; and no branch of it can be more interesting than that which relates to the horse.

How barren, indeed, of delight is the condition of him who passes through life an incurious spectator, ignorant of the common properties even of objects which are most familiar to him, and which are indispensably necessaryto his existence.

His mind, perpetually recurring on itself for support, tries in vain to shake off the burden 
of indolence, and too frequently sceks employment in pursuits of a degrading and unprofitable nature.

Is proportion with his want of knowledge, he will be the dupe of impostors and the prey of villains, and in no instance will he be more exposed to their artifices, than in that which is combined with the present subject.

Desirable must be an acquaintance with the constituent principles of the numerous productions with the munificent Creator has provided for the benefit of man; for it is not only satisfactory to comprehend the uses to which they may be applied, but it is also necessary to be capable of distinguishing that which is friendly or hostile to their œeconomy.

But natural historians appear to hare directed their researches principally among those animals which inhabit but a small part of the globe, 
while they have bestowed but little attention upon those which are most familiar and most serviceable.

HENCE we find the anatomy of the horse chiefly described by that of the human being, and consequently roid of accuracy and truth. The physiology of the horse is surely of as much importance as that of the butterfy, and the neglect it has hitherto experienced, can be attributed only to that propensity for the marvellous which most naturalists possess, and which has induced them to cxcrcise their labours upon animals that, by their scarcity, prevent, in most instances, the possibility of controversy or refutation. But they would have found in the structure and animal ceconomy of the horse, peculiarities sufficient to have enployed their ingenuity to its utmost extent.

THE retcrinary science is still in its infancy: and to the united exertions of the profession 
we can alone look for any considerable progress towards perfection. I shall therefore conclude with the words of Seneca, which, in the present case, are exceedingly applicable: “ Multum " restat operis, multumque restabit, nec ulli " nato post mille secula pracluactur occasio s aliquid adhuc adjiciendi." 

Plate 1.

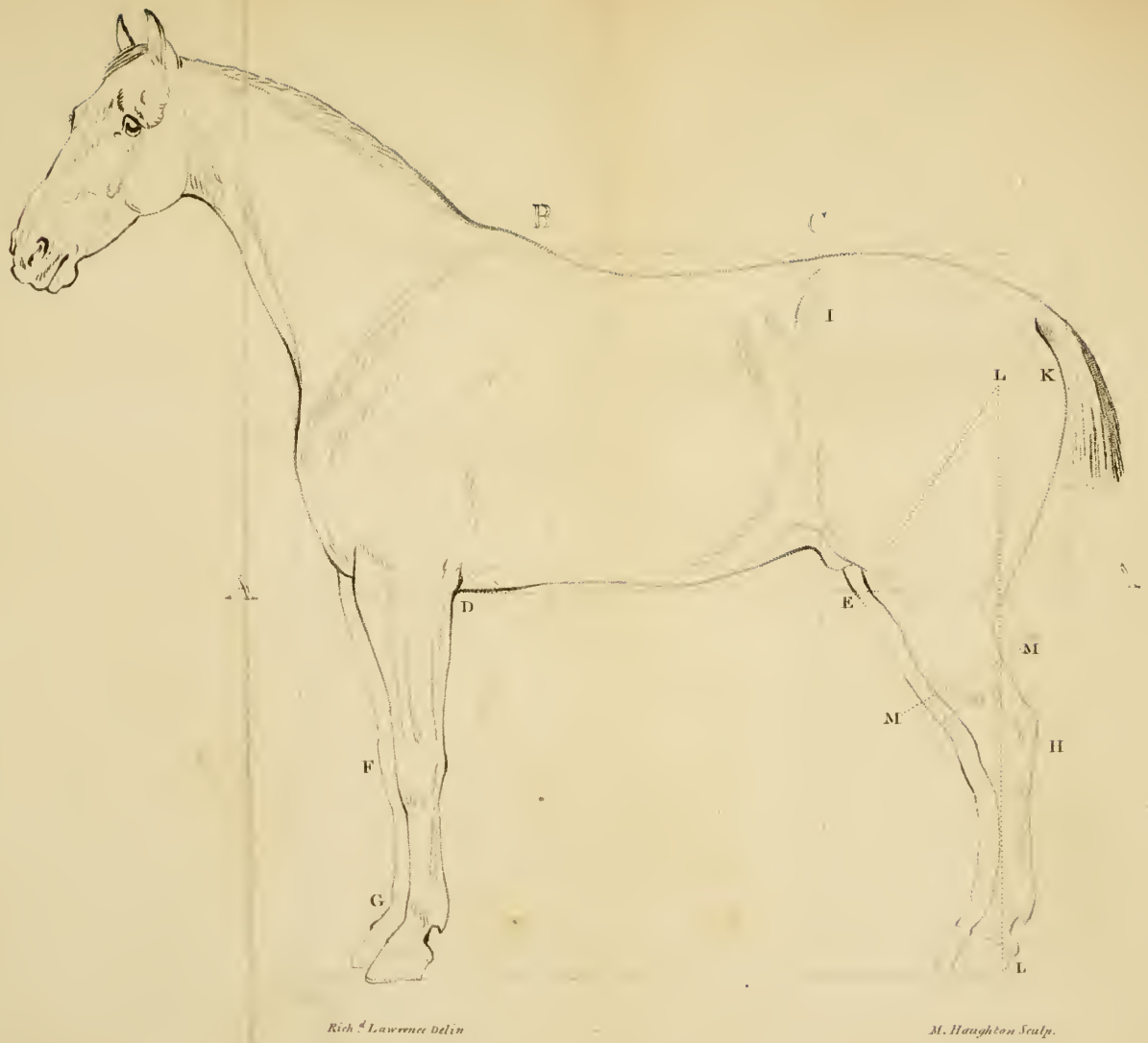




\section{EXPLAN NAIIONV.}

$\rightarrow 200-$

\section{PLATE I.}

AA. The line which divides the body from the legs, giving the proportion of both.

B. C. The lines which divide the body from the fore and hind quarters, giving their respective proportions.

D. The elbow.

E. The stifle.

F. The knee,

G. The fetlock.

H. The hough.

I. The hip.

K. The point of the buttock.

L. The hip joint, commonly called the whirl-bone ; the dotted line from $\mathrm{L}$ to $\mathrm{E}$, describes the position of the thigh bone.

MM. the thigh. 



\section{PLATE II.}

FIG. I represents the proper oblique position of the shoulder blade. $\mathrm{C}$ marks the center of its motion. $A$ and $\mathrm{B}$ give the extent of its motion; $\mathrm{E}$, the point of elevation of the lower part of the shoulder when it is advanced.

Fig. 2 represents a shoulder blade more perpendicular in its position ; $\Lambda$ and $\mathrm{B}$, the extent of its motion; $\mathrm{E}$, the point of eleration, which is not so high, nor so extensive, as in fig. 1 . 
Figl.

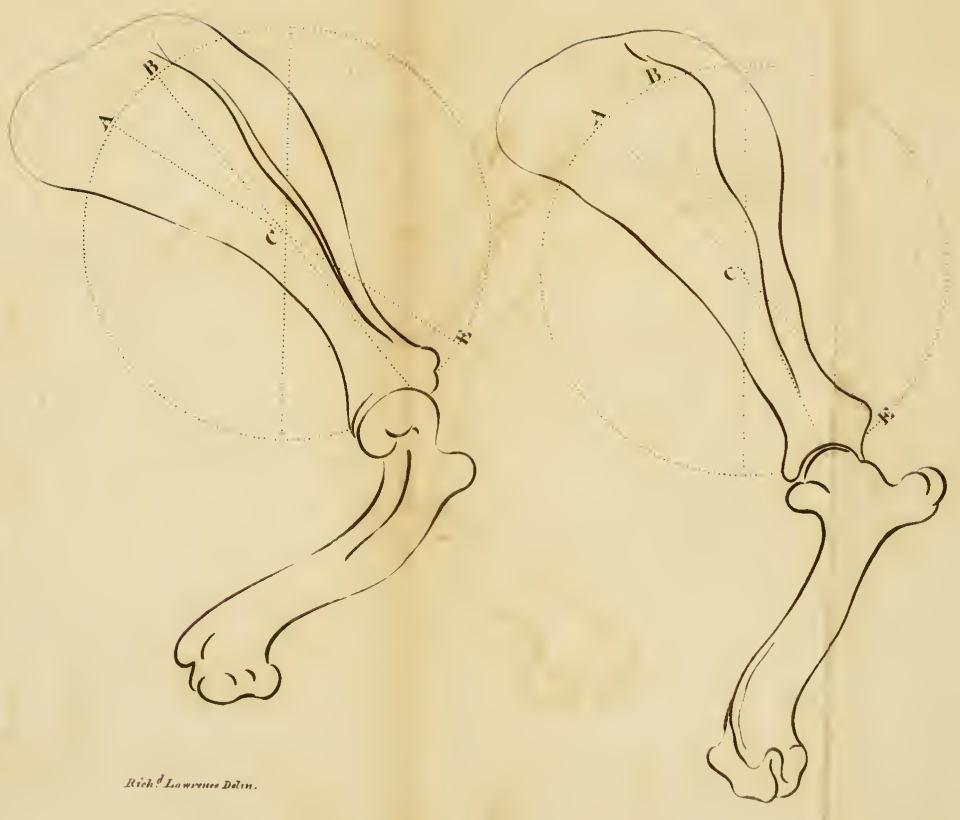





, 

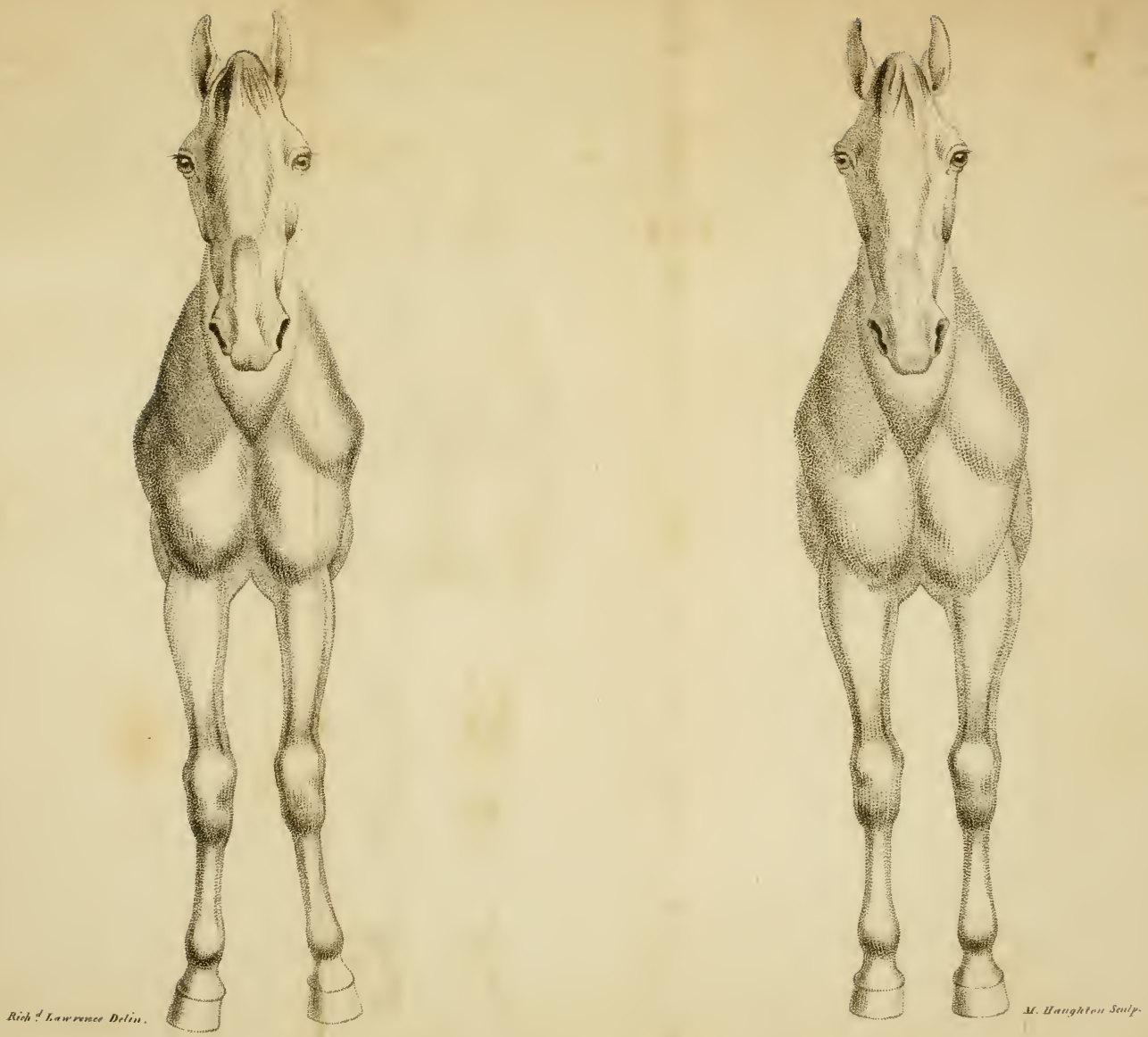


\section{PLATE III.}

FIG. 1 and 2 represent the front view of two horses.

Fig. I describes the malposition of the legs from the knee to the ground.

AA. shews the elbow inclined too much inwards towards the ribs.

Fig. 2 gives the proper position of the fore legs 


\section{PLATE IV.}

FIG. I represents a back view of the hind quarters of an ordinary bred horse, with a flat croupe and high hips.

AA. show that position of the houghs, commonly termed cow-houghed.

Fig. 2 represents a back view of the blood horse.

BB. show the croupe to be more circular, and the hips lower.

AA. show the stifle to be wider than the croupe.

CC. The proper straight po:ition of the hind legs. 



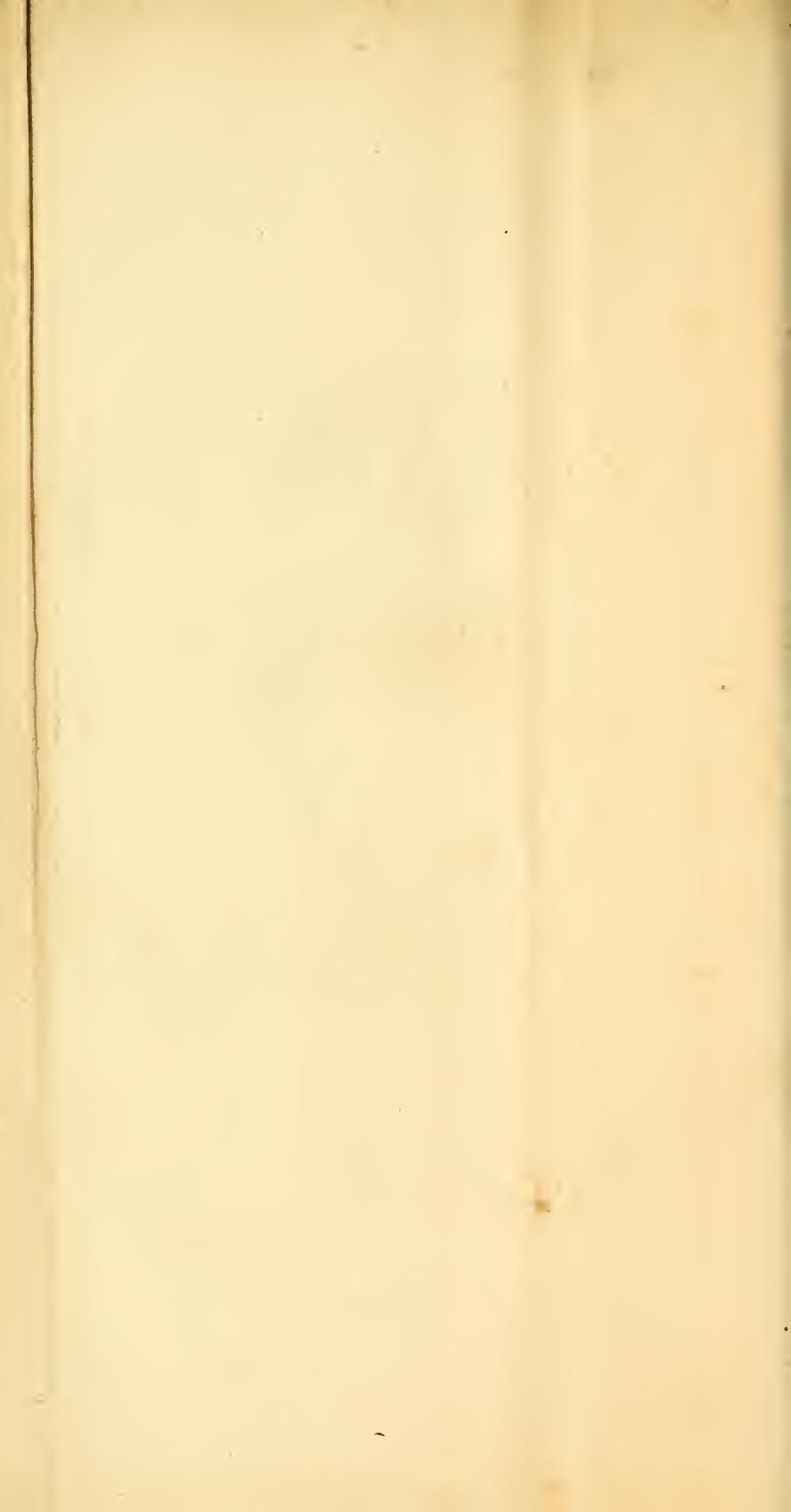



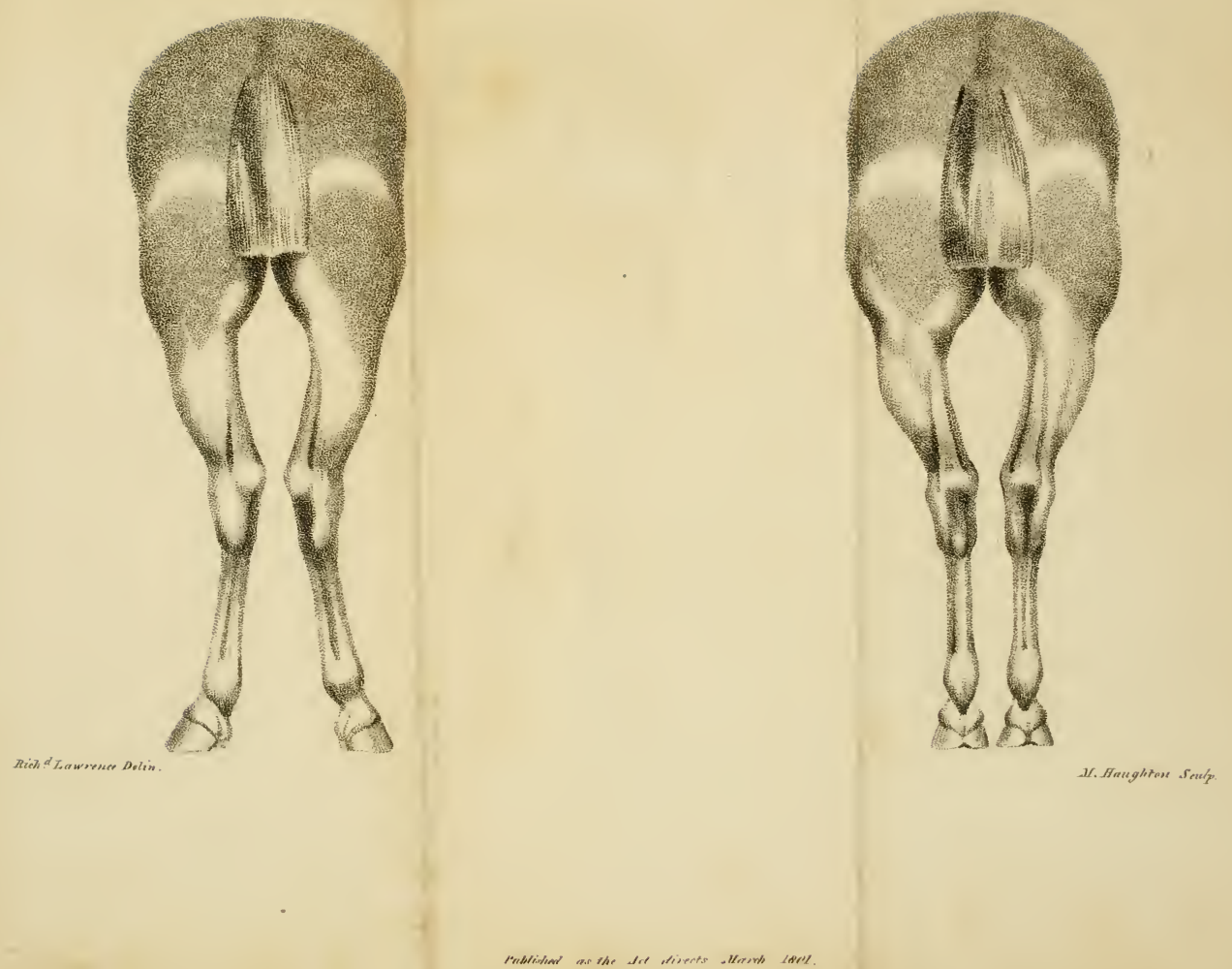


Plate 5.
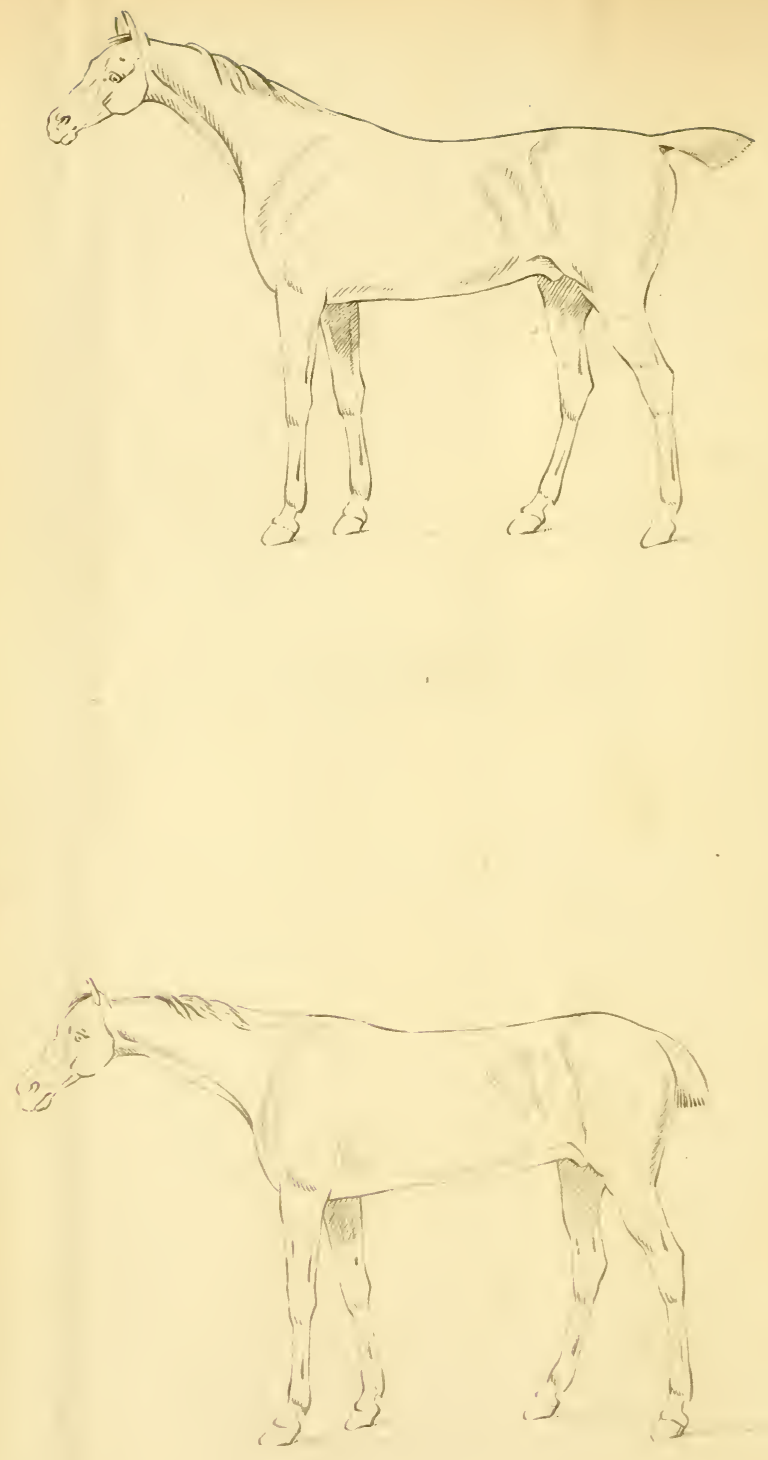


\section{PLATE V.}

FIGURES 1 and 2 represent two liorses of equal height and length. The points in which they differ consist in fig. 1 , being shorter in the back and longer in the quarters than fig. 2. 



\section{PLATE VI.}

FIG. 1 represents the hoof of a horse contracted in the heels by bad shaeing.

Fig. 2 represents the hoof of a colt, of which the quarters and heels are the widest parts.

Fig. 3 gives a view of the hoof when shod.

Fig. 4 gives a section of the hoof, describing the laminated fibres of its inwari surface, corresponding with those of the coffin bone. 

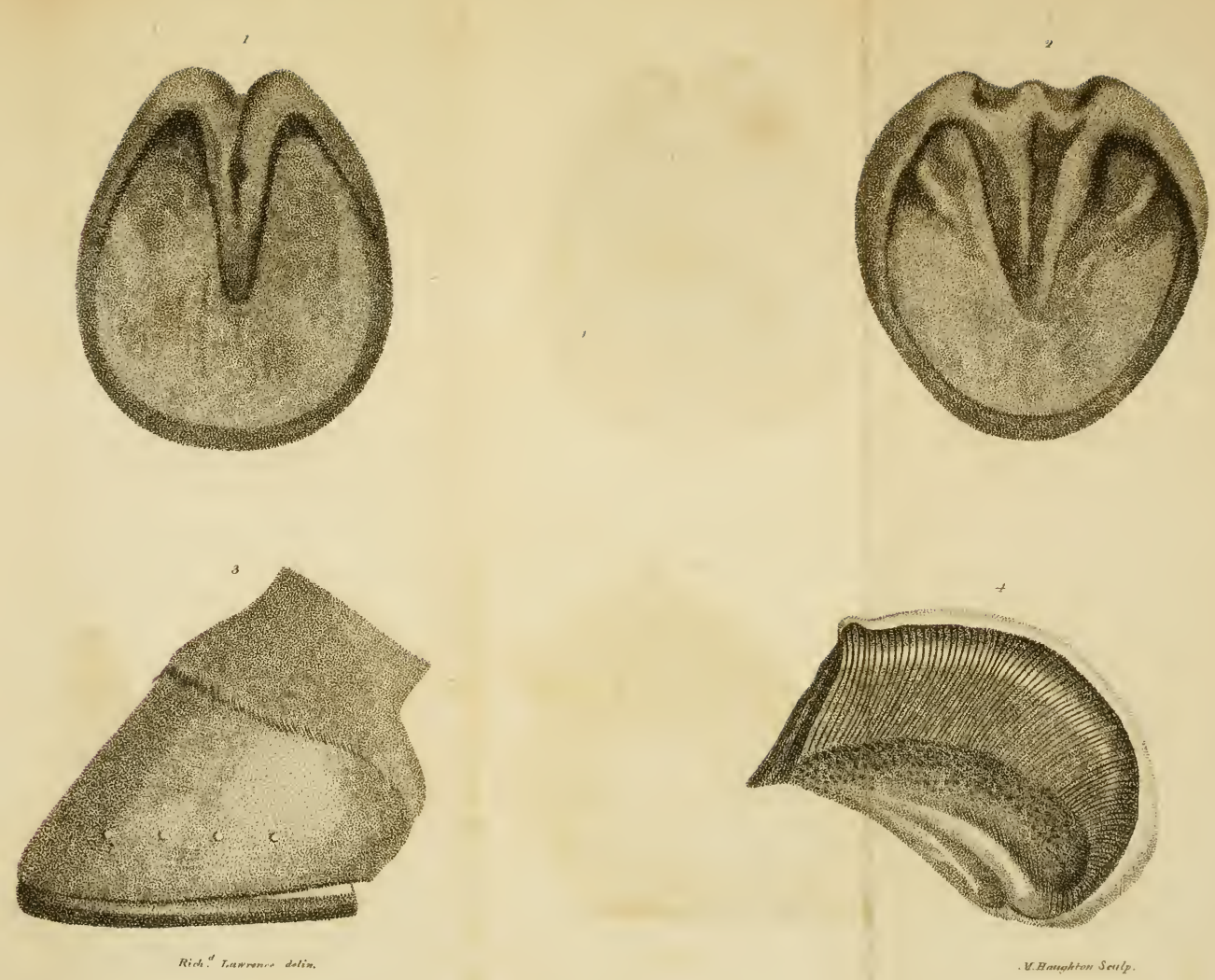

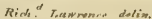

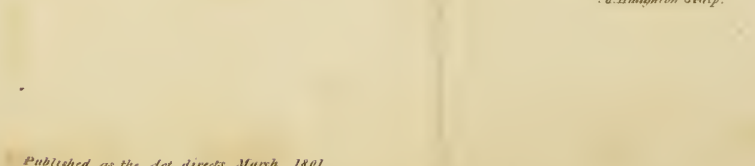


A
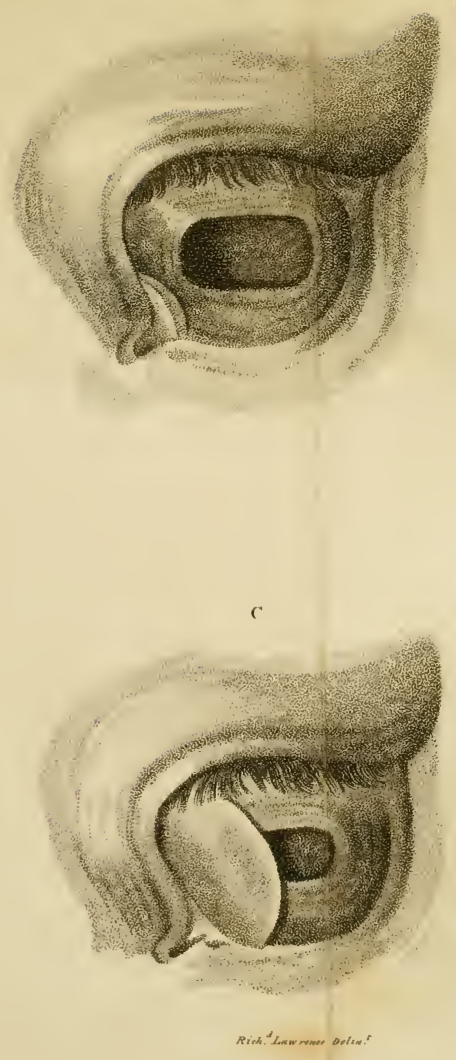

B

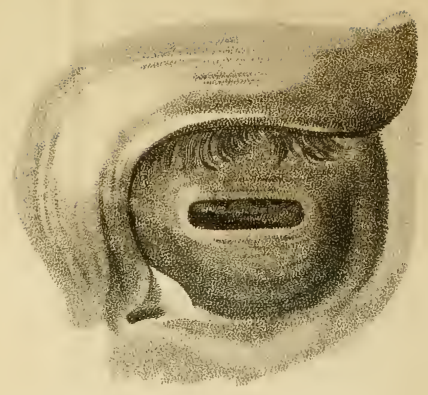

t

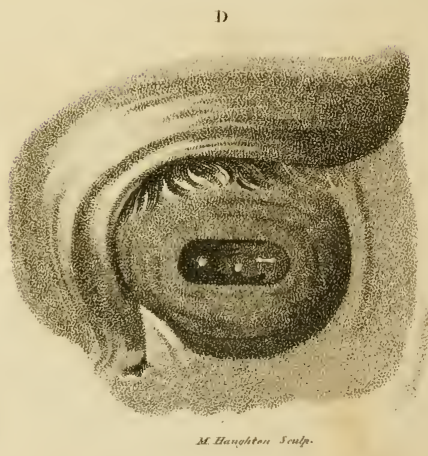




\section{PLATE VII.}

A. REPRESENTS the eye of the horse, in which the pupil is dilated, being in an obscure light.

B. represents the pupil contracted by the stimulus of a strong light.

C. shews the membrana nictitans, or haw, brought half way orer the eye.

D. shows the white specks in the pupil, occasioned by a partial opacity of the crystalline lens, or an incipient cataract. 




\section{PLATE VIII.}

FIG. 1 represents the outside profile view of the fure leg. Letter B describes a strain in the sheath of the tendons.

Fig. 2. The inside profile view of the fore leg. Letter $\Lambda$, a splent ; D, a windgall; $\mathrm{K}$, a sand-crack.

Fig. 3. Front view of the fore leg. Letter C, ringbone.

Fig. 4. Back view of the fore leg. Letter L, mallenders.

Fig. 5. Outside profile view of the hind leg. Letter 1, thorough-pin ; H, curb.

Fig. 6. Inside profile view of the hing leg. Letter G, blood-spavin ; F, bone-spavin.

Fig. 7. Back view of the hind leg. Letter M, rattails; $\mathrm{N}$, thie grease.

Fig. 8. Front view of the hind leg. Letter $\mathrm{O}$, sallenders. 



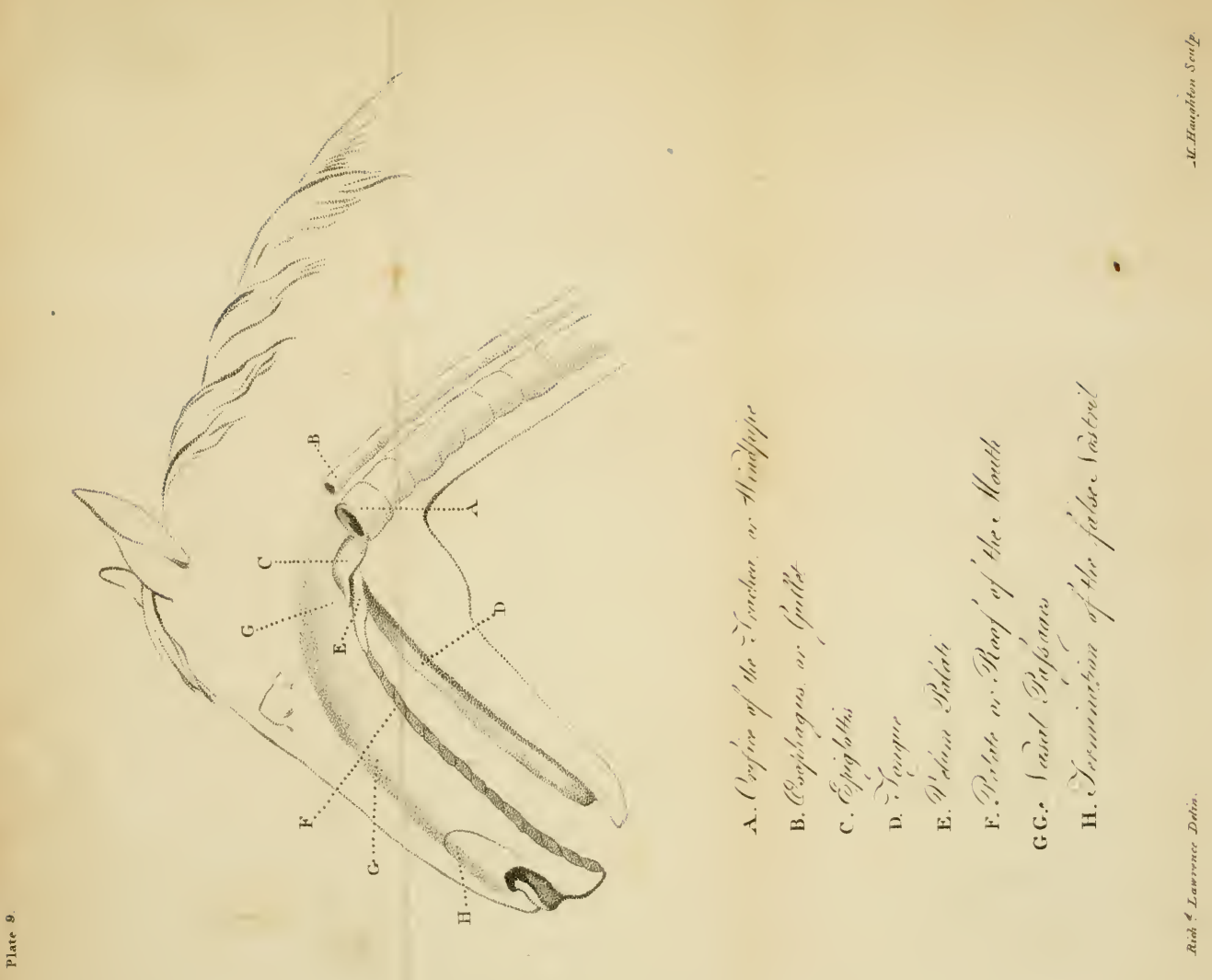




\section{PLATE IX.}

THIS plate is intended to describe, principally, the peculiar formation of the throat of the horse. With this view, the other parts of the head have been omitted, and some liberties have been taken with the perspective, in order to render those parts which are described more conspicuous. 


\section{PLATE X.}

FIG. I represents the view of the upper orifice of the stomach, with the fibres of the muscular coat crossing each other in their direction.

Fig. 2 shews a piece of the œsophagus or gullet, with the fibres of its muscles, imitating basket work, by taking their attachments beyond the origin of each other. 


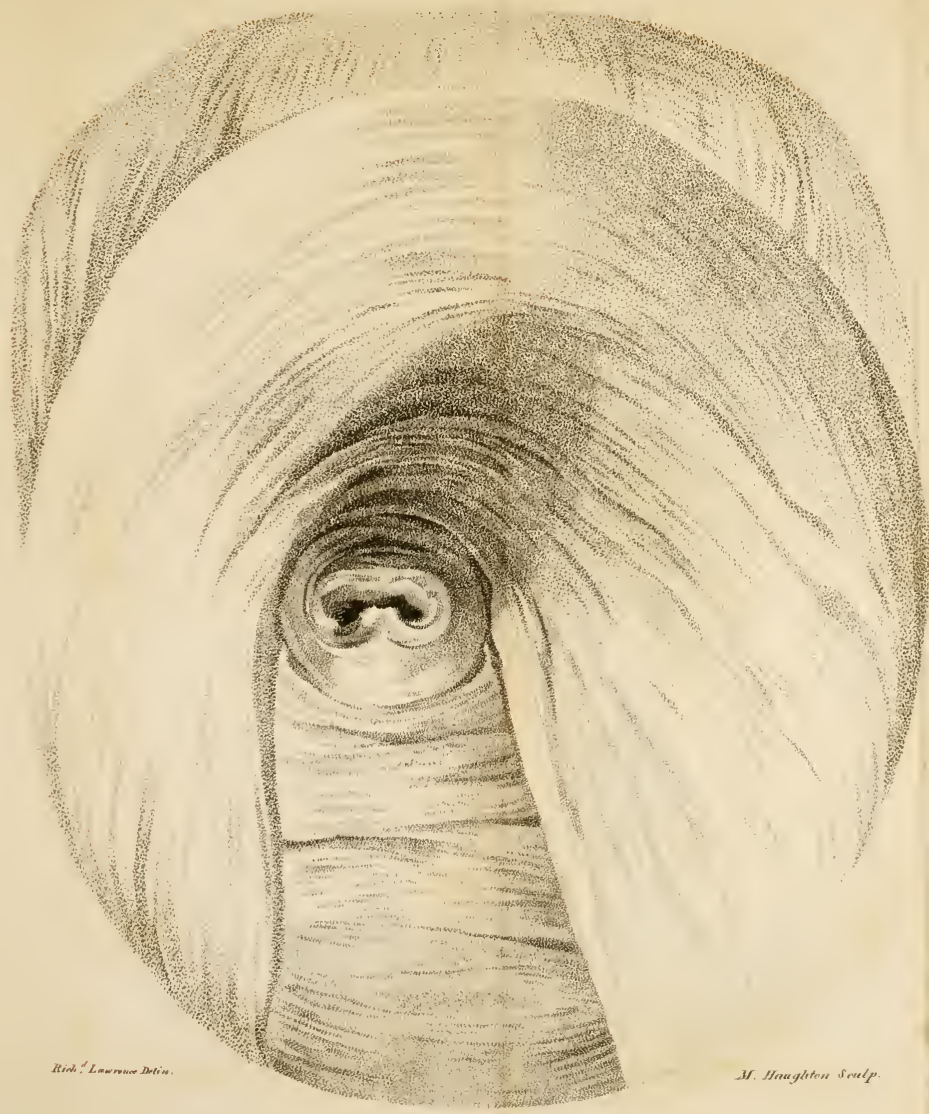





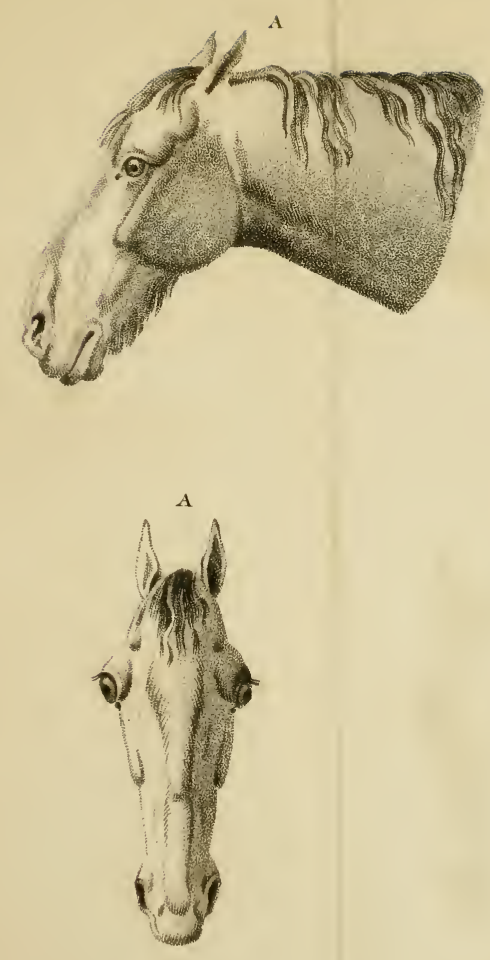

Rid. dow over Mrlin.
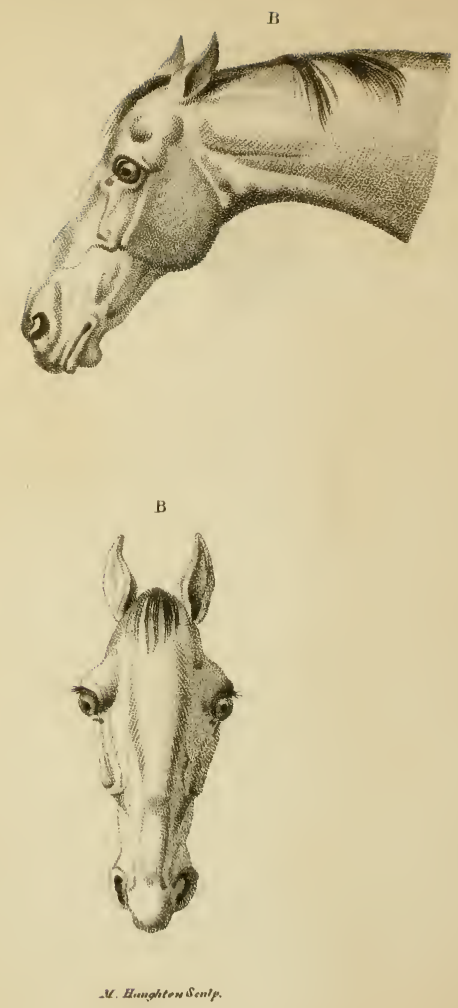


\section{PLATE XI.}

FIG A, represents the head of a cart horse, the features of which are small, and its union with the neck abrupt and void of grace.

Fig. B. represents the head of a blood horse. The features are larger in proportion, and more animated, and the neck proceeds from the head with a more easy and elegant line.

The lower B describes the front view of the head of the blood horse, which is shorter and broader in the forehead, proportionably, than the cart horse $A$. 




\section{PLATE XII.}

A. REPRESENTS the front teeth of the lower jaw of a colt until two years and a half old.

B. The lower jaw at two years and a half old, in which the two middle teeth have been shed.

C. Two new middle teeth, the two adjacent teeth shed.

D. Four new teeth, the two corner teeth shed.

E. The set of new teeth complete, the marks of the two middle teeth being filled up.

F. The marks of the four front teeth filled up.

G. The front teeth in the upper jaw, the two middle teeth having their cavities filled up.

H. Ditto, the marks of the four front teeth being filled up.

1. Ditto, the marks of all the teeth effaced.

K. Profile view of the mouth of a young horse.

L. Ditto of the mouth of an old horse. 

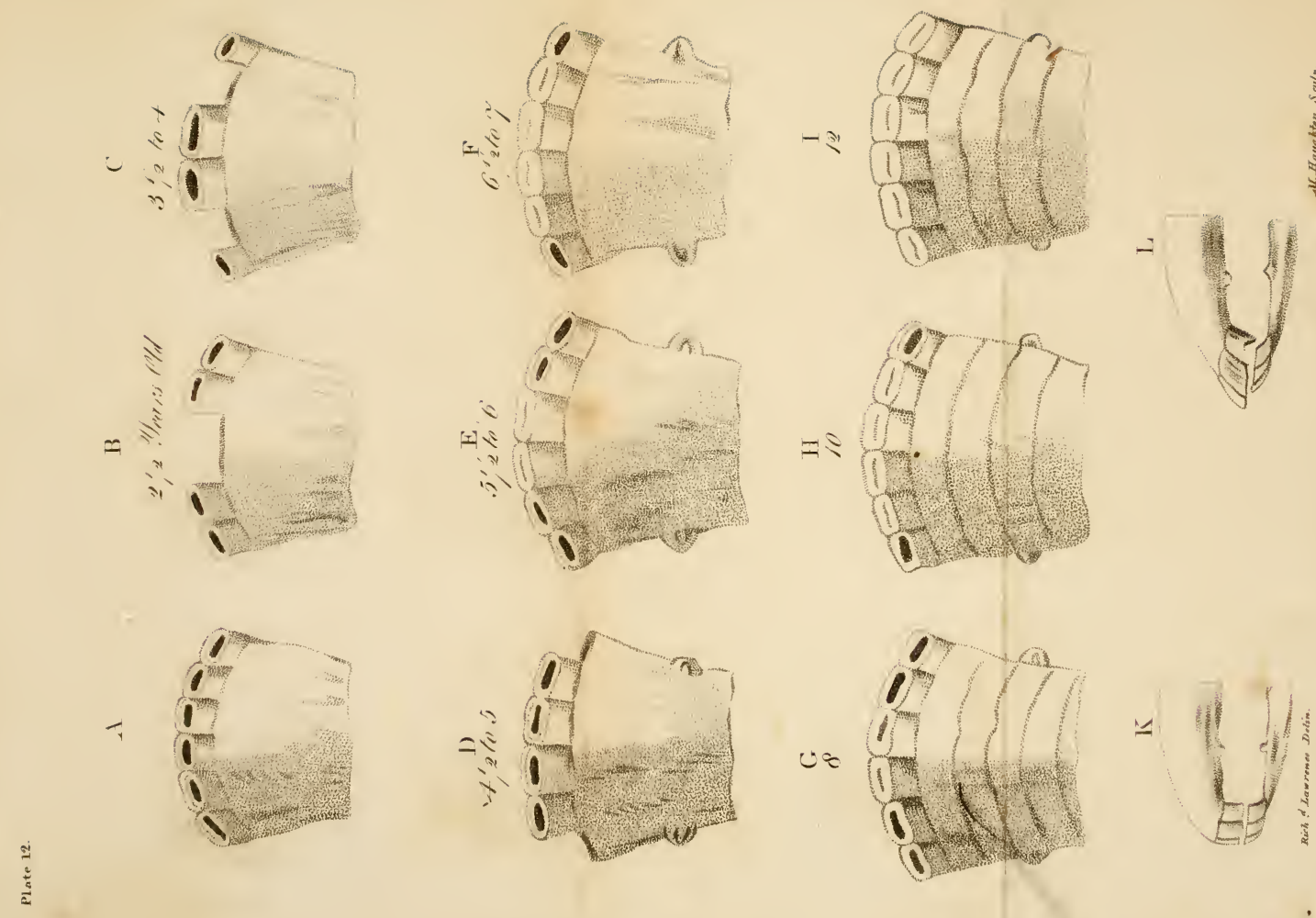


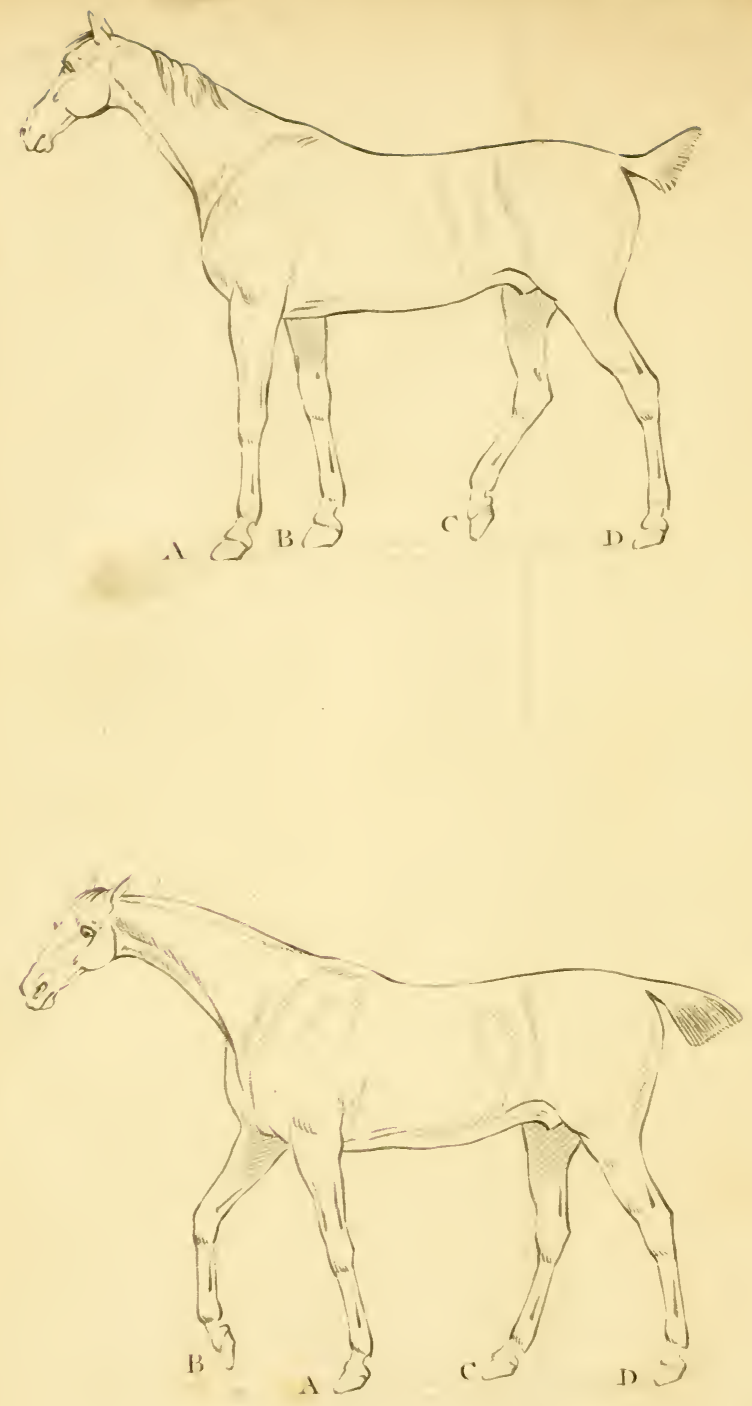


\section{PLATE XIII.}

FIG. I represents the horse in the walk, in which pace three legs are always on the ground at the same time. The off fore leg B having completed its action, is preparing to rise, at which moment the off hind leg $\mathbf{C}$ alights on the ground, and forms the triangle A, C, $\mathrm{D}$, as shown in fig. 2 . 
1x: $x$ 



\section{PLATE XIV.}

FIG. 1 represents the horse in a gentle trot. C and $\mathrm{D}$ mark the distance of ground passed orer at each motion.

Fig. 2 represents the darting or elongated trot, in which the horse gains an additional space by the momentum of his body during the period when all his legs are in the air. Thus the letter $C$ marks the ground which the near hind foot occupied before it was elevated; and the letters $A$ and $B$ mark the spots to which the near fore foot and the off hind foot will arrive when they have completed their action. 


\section{Platelt.}
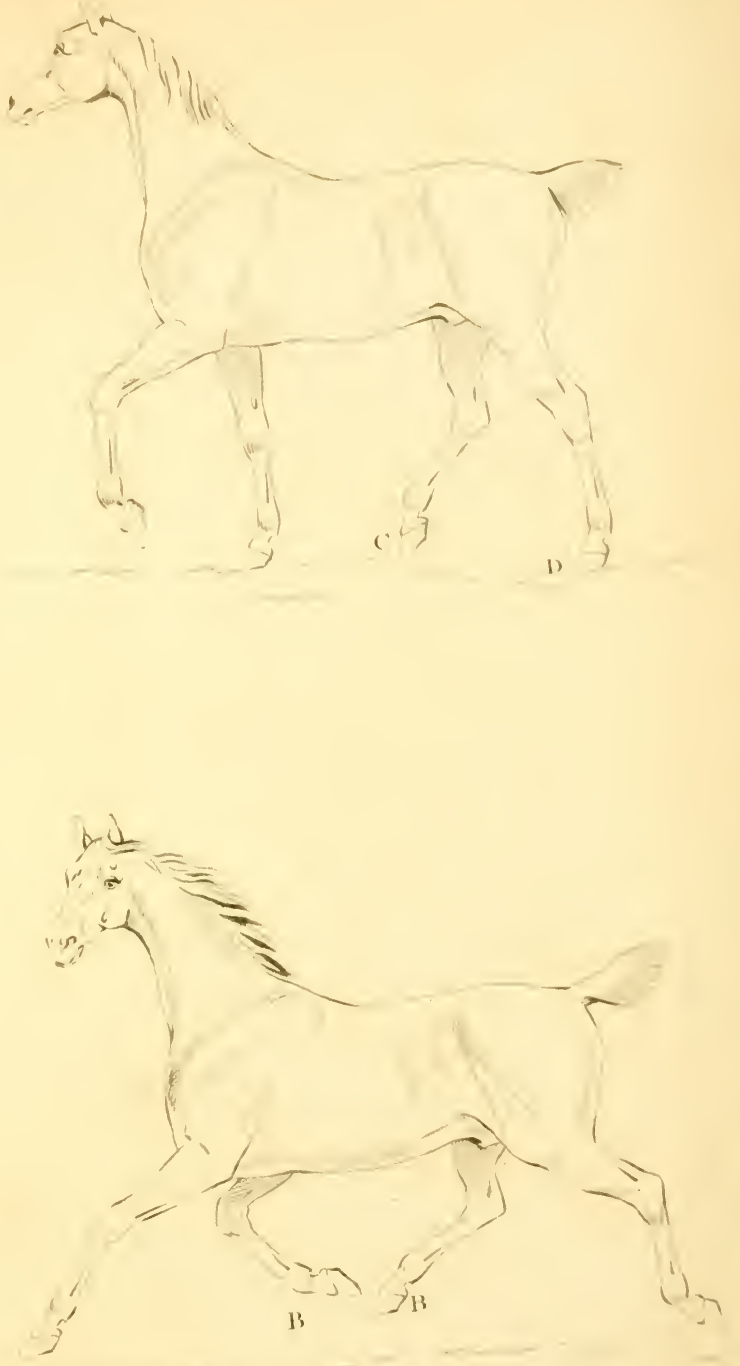

1 


Plate l.5.
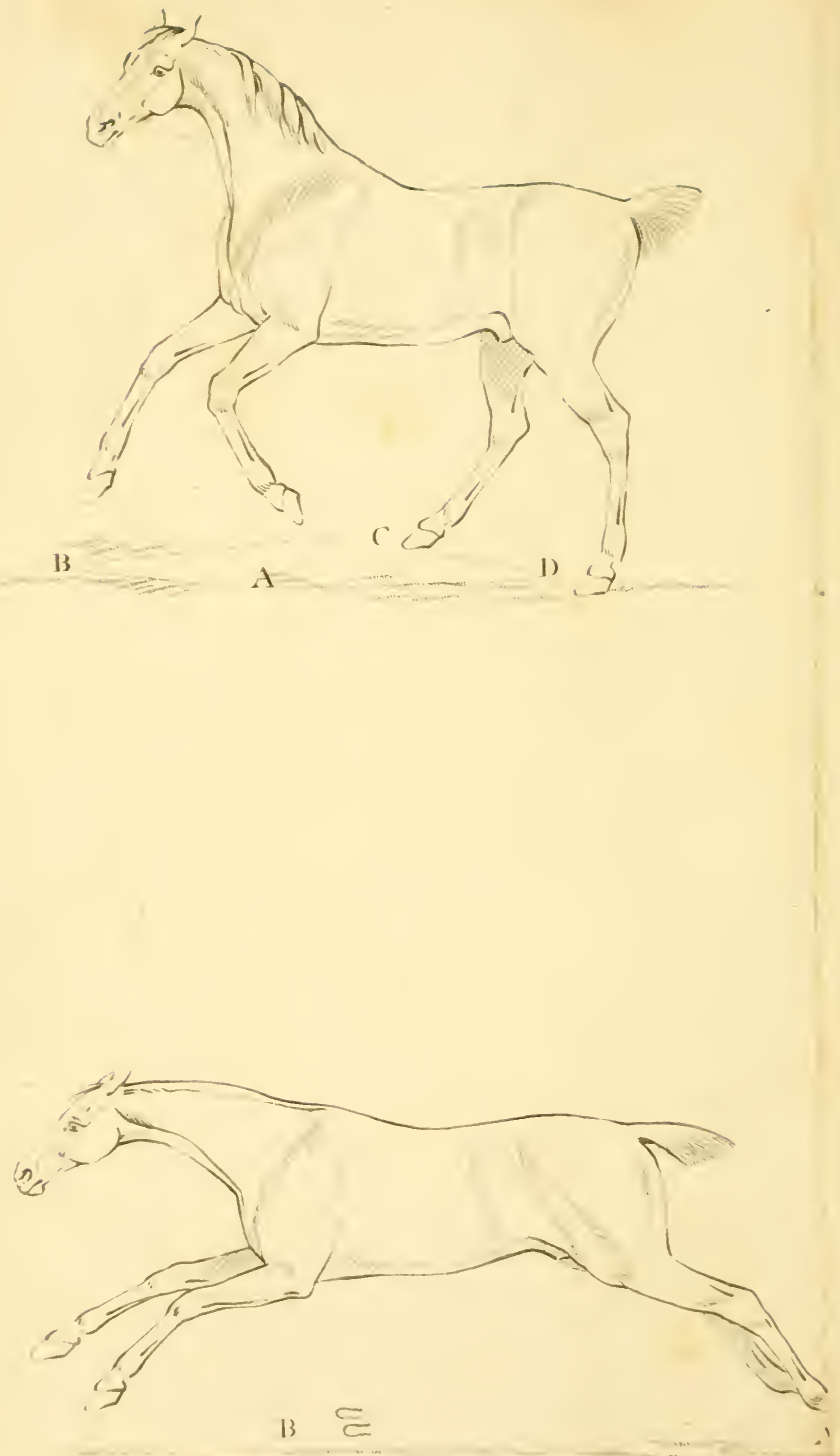


\section{PLATE XV.}

IIG. 1 represcnts the horse in the canter, in which pace his legs describe a rhomboidal qualdrangle, $\Lambda, \mathrm{B}, \mathrm{C}, \mathrm{D}$.

Fig. 2 represents the gallop. Letter $\Lambda$ marks the spots which the hind fect occupied before they quitted the ground. Letter B marks the spots upon which the hind feet will alight when they have completed their action; the distance between $A$ and $B$, therefore, gives the length of ground which is passed over at each stroke. 



